\title{
Tissue Factor, Blood Coagulation, and Beyond: An Overview
}

\author{
Arthur J. Chu \\ Division of Biological and Physical Sciences, Delta State University, Cleveland, MS 38733, USA \\ Correspondence should be addressed to Arthur J. Chu, ajchu91@hotmail.com
}

Received 18 May 2011; Revised 16 June 2011; Accepted 18 June 2011

Academic Editor: Juan Carlos Kaski

Copyright () 2011 Arthur J. Chu. This is an open access article distributed under the Creative Commons Attribution License, which permits unrestricted use, distribution, and reproduction in any medium, provided the original work is properly cited.

\begin{abstract}
Emerging evidence shows a broad spectrum of biological functions of tissue factor (TF). TF classical role in initiating the extrinsic blood coagulation and its direct thrombotic action in close relation to cardiovascular risks have long been established. TF overexpression/hypercoagulability often observed in many clinical conditions certainly expands its role in proinflammation, diabetes, obesity, cardiovascular diseases, angiogenesis, tumor metastasis, wound repairs, embryonic development, cell adhesion/migration, innate immunity, infection, pregnancy loss, and many others. This paper broadly covers seminal observations to discuss TF pathogenic roles in relation to diverse disease development or manifestation. Biochemically, extracellular TF signaling interfaced through protease-activated receptors (PARs) elicits cellular activation and inflammatory responses. TF diverse biological roles are associated with either coagulation-dependent or noncoagulation-mediated actions. Apparently, TF hypercoagulability refuels a coagulation-inflammation-thrombosis circuit in "autocrine" or "paracrine" fashions, which triggers a wide spectrum of pathophysiology. Accordingly, TF suppression, anticoagulation, PAR blockade, or general antiinflammation offers an array of therapeutical benefits for easing diverse pathological conditions.
\end{abstract}

\section{Introduction: Tissue Factor Biology}

Tissue factor (TF), also known as factor III, essentially provides additional protection to vital organs prone to mechanical injury; its strategic location is considered as a hemostatic envelope for arresting bleeding from vascular beds. High TF expression is found in highly vascularized organs (cells) such as the brain (e.g., astrocytes), placenta (e.g., trophoblasts), and the lungs (e.g., alveolar cells) followed by the heart (e.g., cardiac myocytes, pericytes, fibroblasts), kidney, intestine, testes, and uterus (e.g., epithelial cells surrounding the organs). The low expression is detected in the spleen, thymus, and liver [1]. Circulating (blood-borne) TF is mainly derived from its expression in blood cells (e.g., monocytes, macrophages, granulocytes, and platelets), platelet-free microparticles containing TF shed from cells, or even soluble TF protein; the serum level can be easily measured by TF antigen, ELISA, TF procoagulant activity (PCA), and so forth (for review, see [2]).

Full-length TF (Figure 1), a membrane integral glycoprotein $(46 \mathrm{kDa})$, is a 263 -amino acid single-chain polypeptide classified as CD142 (Type II cytokine receptor) with a 219amino-acid extracellular $N$-terminus and a 23 -amino-acid transmembrane domain followed by an intracellular 21amino-acid $C$-terminus $[3,4]$. The extracellular region contains FVII/VIIa binding domains. Extracellular soluble form (sTF) could be released from EC [5] in response to proinflammatory cytokines. The intracellular domain could undergo serine phosphorylation(s), which could modify its function [6-8]; for instance, the cytoplasmic domain negatively regulates TF expression, which is mediated by suppressed Erk1/2 phosphorylation.

TF initiates the extrinsic coagulation that plays an integral role in blood coagulation, thrombin (FIIa) generation, and thrombi formation in close relation to thrombosis and cardiovascular dysfunctions $[9,10]$. Such extracellular TF signaling proceeds with the sequential generation of coagulant mediators (FVIIa, FXa, and FIIa: active serine proteases) and fibrin production, all of which are proinflammatory [4]. TF extends its roles to diverse biological phenomena related to either ro both of these two major thrombotic and inflammatory events. Emerging evidence shows TF involvement in wound repairs, embryonic development, angiogenesis, tumor metastasis, cell adhesion/migration, innate immunity, and many pathological conditions. 
Chu AJ: Tissue factor, blood coagulation, and beyond: an overview

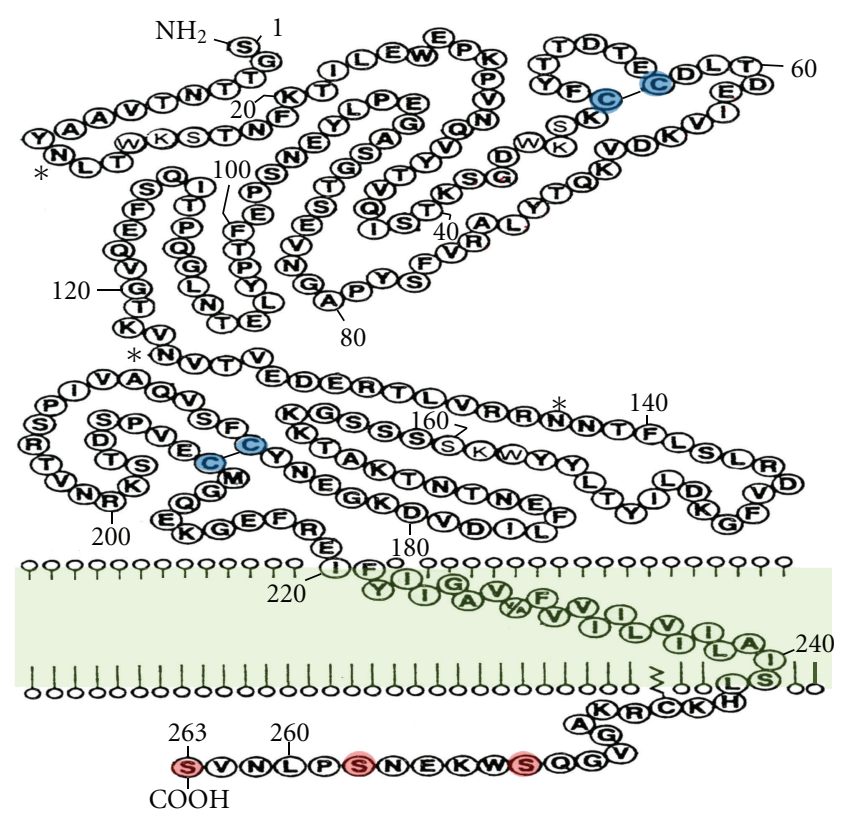

Figure 1: TF structure. The $46-\mathrm{kDa}$ membrane-bound single polypeptide chain consists of extracellular, transmembrane, and cytoplasmic domains. There are 2 intrachain disulfide bridges (Cys49-Cys57 and Cys186-Cys209, shown in blue) in the extracellular domain where it also contains FVII/FVIIa binding domain (see text) initiating signaling cascade for the extrinsic blood coagulation (Figure 2, left panel). There are three serine residues (shown in red) in the cytoplasmic domain for undergoing phosphorylation. *Denotes 3 proposed glycosylation sites at Asn11, 124, and 137. Adopted and modified from [3].

\section{Regulation of Tissue Factor Expression}

TF usually in its latent (cryptic) form is often upregulated (decrypted) upon vascular injury (by protein disulfide isomerase with phosphatidylserine (PS) exposure) [10-12], inflammation (e.g., LPS, ILs, TNF- $\alpha$, C-reactive protein (CRP), C. pneumoniae), IFN, MCP-1, ICAM, P-selectin, CD40/40L, PDGF, OxLDL, Lp(a), angiotensin II, plasmin, complement anaphylatoxin C5a, antiphospholipid antibody (aPL), advanced glycation endproducts (AGEs), hypoxia, and so forth (for review, see [4]) in cultures. Enhanced TF expression has also been reported due to SirT1 inhibition [13], homocysteine [14], oral contraceptives [15], shear stress [16], amyloid protein A [17], histamine [18], smoking [19], nicotine [20], estrogen [21], asbestos [22], serotonin [23], dexamethasone [24], arachidonic acid (AA) [25], bFGF [26], VEGF [27], EGF [28], aggregated LDL [29], leptin [30], urokinase [31], shingosine-1-phosphate [32], or many others. In general, TF expression is mediated by activations of intracellular signaling kinases (e.g., PKC, MAPK (Erk, p38)) and other signaling components such as transcription factors (e.g., AP-1, NFkB, Erg-1) (for review, see [4]). Exposure to calcium ionophores such as A23187 drastically sustains cellular TF PCA without increased TF expression in cultures, which could either have or not have any pathological implications, and the mechanism of action remains unclear [4].

In contrast, its downregulation has been reported including by HMG-CoA reductase inhibitors [33, 34], cyclooxygenase (COX) inhibitors [35-37], paclitaxel [38], lysophosphatidylcholine [39], insulin [40], nicotinamide [41], nitric oxide (NO)/or soluble guanylate cyclase activator [42], hydroxyurea [43], ethyl pyruvate [44], dimethyl sulfoxide (DMSO) [45], angiotensin converting enzyme (ACE) inhibitors [46], adiponectin [47], retinoic acid [48], all-trans retinoic acid [49], vitamin D3 [50], PGJ2 [51], PPAR $\alpha$ agonists (fenofibric acid, WY14643, and GW2331) [52]/activators (WY14643 and eicosatetraenoic acid) [53], liver X receptor agonists [54], pentroxifylline [55], phenolics/resveratrol derivatives [56], indobufen [57], amiodarone [58], metformin [59], elevated intracellular cAMP [4], and PI3K/ Akt/PKB signaling [60]. On the molecular biology front, miR-19 [61], short hairpin RNA [62], hairpin ribozyme [63], or antisense ODN [64-66] readily downregulates TF mRNA translation and expression.

\section{TF-Initiated Extrinsic Coagulation}

In a classical view, TF initiates the extrinsic blood coagulation, which proceeds as $\mathrm{Ca}+2$-dependent extracellular signaling to sequentially activate zymogens: FVII, factor $\mathrm{X}$ (FX), and prothrombin (FII) for the generation of coagulant mediators (active serine proteases): FVIIa, FXa, and thrombin (FIIa), respectively. As a result, FIIa cleaves off fibrinogen (FBG) into fibrin monomers that cross-link to produce insoluble blood clots. The extrinsic pathway plays an integral role in blood coagulation complemented by the intrinsic pathway that ensures FIIa regeneration and clot production (Figure 2, left panel) (for review, see [3, 4, $10,67])$. The intrinsic pathway merging with TF-initiated extrinsic coagulation at FX activation is beyond the focus of this paper.

3.1. FVII Activation. FVII readily undergoes proteolytic activation of peptide bond cleavage between Arg 152 and Ilu 153 by either TF dependence or other serine proteases (e.g., FXa, FIXa, FXIa, FXIIa, FIIa, or plasmin), resulting in two smaller chains of FVIIa. The $\mathrm{N}$-terminus-derived light chain $(\sim 20 \mathrm{KDa})$ contains the membrane-binding Gla domain, while the $C$-terminus-derived heavy chain $(\sim 30 \mathrm{KDa})$ contains the catalytic domain.

3.2. TF-Dependent FVII Activation. The ability of FVII to bind its cofactor (TF) has been reported with a-1:2 stoichiometric ratio. It has long been established that $\mathrm{Ca}+2$ and membrane anionic phospholipids are required for TFdependent FVII activation. Gla, EGF-1, EGF-2, and protease domain (PD) in FVII make essential contributions to the optimal interaction/binding with its counterpart: extracellular sTF1-219. It is said that zymogen FVII affinity for sTF causes secondary conformational changes of the PD, dictating the protease activity. EPR study shows multiple 
Chu AJ: Tissue factor, blood coagulation, and beyond: an overview

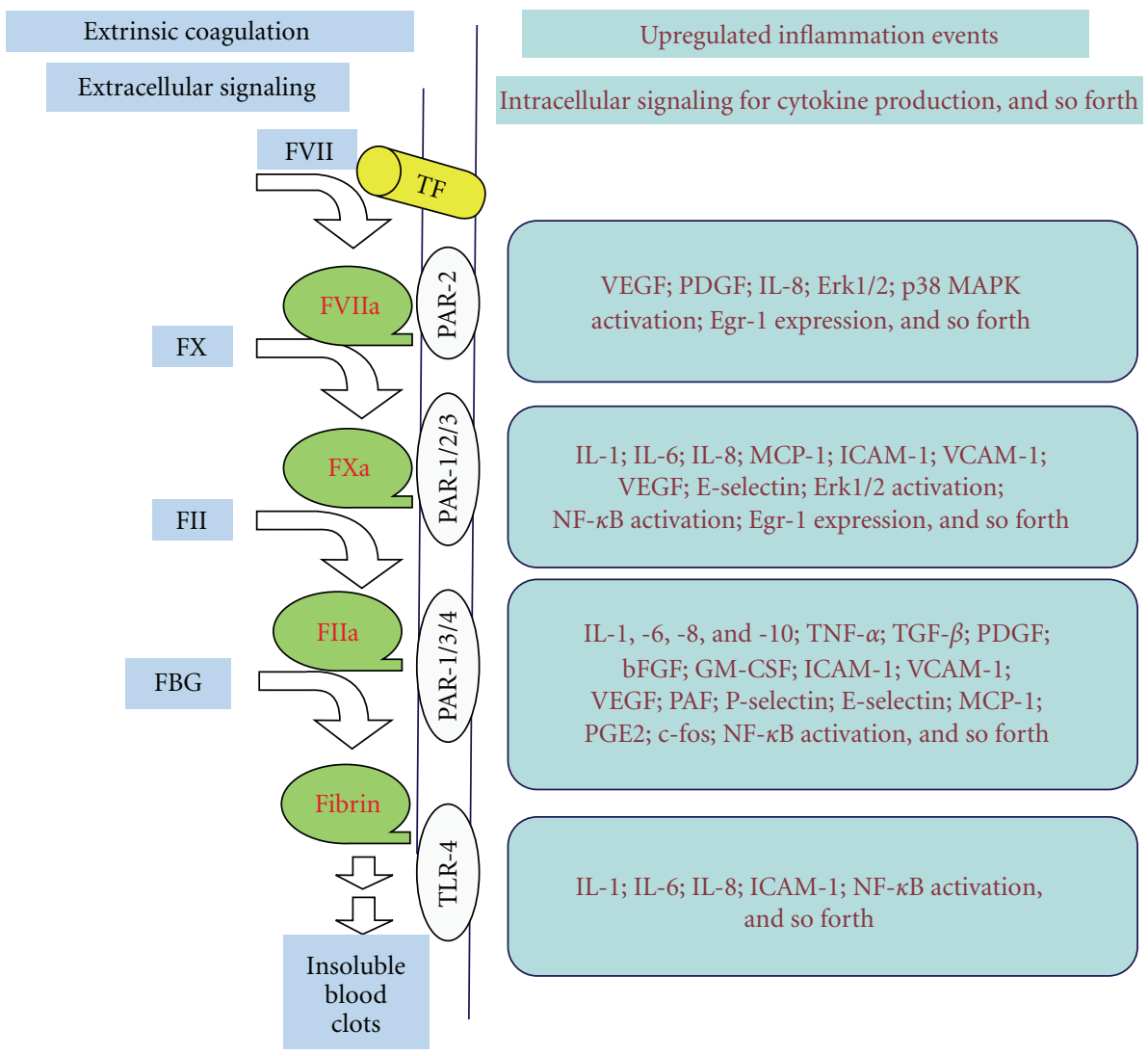

FIGURE 2: TF hypercoagulability and inflammation. TF-initiated extrinsic coagulation (left panel) essentially proceeds as extracellular signaling and results in the generation of active serine protease (coagulant mediators: FVIIa, FXa, and FIIa) derived from their corresponding zymogen activations. FBG is cleaved by FIIa to produce fibrin that is polymerized and cross-linked to yield insoluble blood clots. Such TF extracellular signaling activates cells for proinflammation. Through cell receptors on plasma membrane, signals from the coagulant mediators (FVIIa, FXa, and FIIa) as well as fibrin mediate diverse intracellular activation and the production of proinflammatory mediators (right panel) including cytokines, adhesion molecules, and growth factors, PAR: protease activated receptor; TLR: Toll-like receptor; IL: interleukin; NFkB: nuclear factor kappa B.

contacts between two proteins; the Gla binds sTF158 and 207, the EGF-1 binds sTF22 and 140, and the PD binds sTF45 and 94. In contrast, Gla-domainless-FVII shows a rapid loss in FVII binding affinity for TF. FVII affinity is also altered upon modification/conformational changes involving the EGF-1 region. Accordingly, any FVII global conformational misfolding/unfolding disrupting the binding sites could result in impaired FVII activation.

Furthermore, there are high-affinity $\mathrm{Ca}+2$ binding sites in Gla, EGF-1, and PD. It has been reported that one $\mathrm{Ca}+2$ molecule binds to $\mathrm{PD}$, another $\mathrm{Ca}+2$ binds to the EGF1 domain at a high-affinity site, and seven more $\mathrm{Ca}+2$ molecules bind with variable affinity for the Gla domain. Thus, it seems likely that $\mathrm{Ca}+2$ could play a critical role in FVII binding to TF. In addition to PS being essential for TF-dependent FVII activation, cholesterol enrichment of primary human monocyte-derived macrophages also drastically increases TF PCA [68].

3.3. Downstream Sequential Activations. The catalytic function of the binary complex TF/FVIIa relying in mutual binding conformation is believed to be directly responsible for FX and FIX activation. FXa acts as a molecular switch not only receiving the upstream (extrinsic and intrinsic) signals but also dictating the downstream coagulation. Strategically, FXa is an active enzyme component coupled with FVa in prothrombinase complex located at the center of the blood coagulation cascade, which converges the clotting signals derived from both the extrinsic (FVII activation) and intrinsic (FIX activation) pathways. FXa also undertakes a feedback activation of FVII. Finally, FIIa derived from FII cleavage by FXa assumes the main coagulant function at the termination stage; it directly catalyzes FBG cleavage releasing fibrinopeptides for fibrin clot production upon cross-linking. In addition, FIIa activates FXIII, FXI, FVIII, or $\mathrm{FV}$, assuring the propagation of blood coagulation.

\section{TF Hypercoagulability Leading to Thrombosis}

As a consequence of TF hypercoagulation, thrombosis featuring fibrin overproduction is a direct outcome 
Chu AJ: Tissue factor, blood coagulation, and beyond: an overview

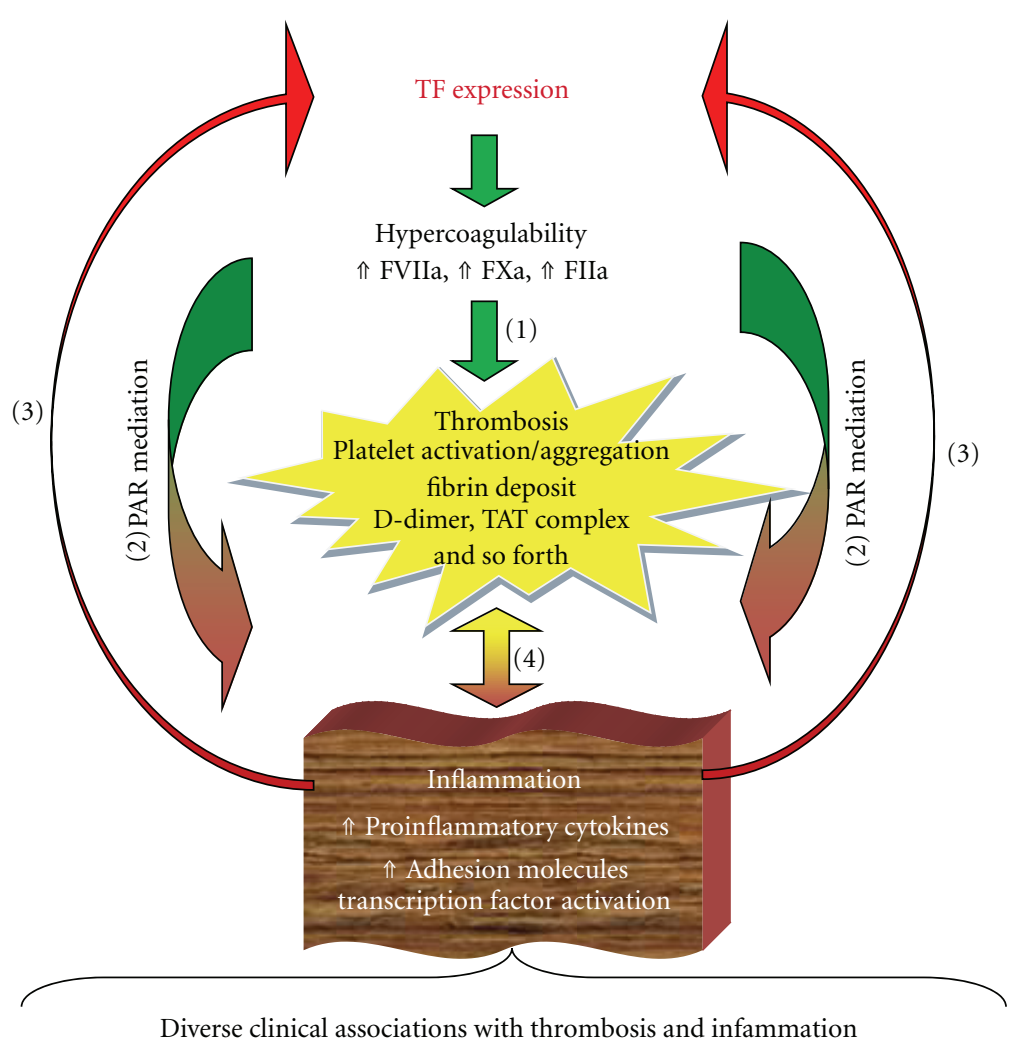

(cancers, diabetes, obesity, sepsis, DIC, miscarriage, atherosclerosis, APS, etc.)

FIgURE 3: Coagulation-inflammation-thrombosis circuit. TF hypercoagulability results in direct thrombotic actions (1). TF also plays converging and diverging roles in driving the coagulation-inflammation cycle ((2) coagulation-dependent inflammation and (3) inflammation-dependent coagulation). Namely, TF hypercoagulability could result in enormous inflammation as the result of continuously refueling the cycle in which coagulation and inflammation promote each other upon the cycle gaining its initial momentum. Thrombosisinflammation connection (4) is incorporated into the coagulation-inflammation cycle to form a complete coagulation-inflammationthrombosis circuit, which manifests diverse pathological conditions in relation to inflammation and thrombosis, including cancers, APS, cardiovascular dysfunctions, diabetes, obesity, and DIC.

(Figure 3(1)) in addition to proinflammatory environment for thrombogenesis (i.e., inflammation-dependent thrombosis discussed in Section 7.1). Moreover, elevated FIIa generation upon hypercoagulation impacts thrombogenesis by severalfold relevance to platelet activation/aggregation, clot stabilization, and antifibrinolysis (for review, see [69, 70]).

FIIa activates platelets mainly through protease-activated receptor (PAR) and glycoproteins (GPs) IIb/IIIa, and GPIb. PAR-1 is a primary receptor for FIIa by which platelets are activated to aggregate [71]. Platelet aggregation constitutes thrombus formation involving cross-linking of adjacent platelets mediated by the interaction of activated GP IIb/IIIa with distinct amino acid sequences, LGGAKQAGDV, and/or RGD, at each end of dimeric FBG molecules [72]. Alternatively, FIIa-induced platelet activation could result from polymerizing fibrin, which involves the recognition sites in the cross-linking of polymerizing fibrin and surface integrins via GP Ib. In fact, GP Ib acts as an FIIa-binding site and promotes platelet activation by low FIIa concentrations [73].
In addition, FIIa activates FXIII, and FXIIIa facilitates the stabilization and cross-linking of fibrin clots.

Concerning hemostatic imbalance with suppressed fibrinolysis, FIIa activates plasma carboxypeptidases recognized as thrombin activatable fibrinolytic inhibitor (TAFI) that attenuates fibrinolysis [74] thereby in favor of fibrin deposition/accumulation. Subsequently, TAFI inhibits various forms of plasminogen activator- (PA-) mediated fibrinolysis [75]. Upregulated plasminogen activator inhibitor-1 (PAI1) expression by FIIa via a PKC-dependent mechanism [76] could further contribute to antifibrinolytic process and fibrin accumulation.

\section{Coagulation-Dependent Inflammation}

Several lines of evidence reveal in vivo coagulationdependent inflammation. PARs generally mediate inflammation derived from coagulant mediators (e.g., FVIIa, FXa, and FIIa) and fibrin (Figure 2; right panel). Moreover, deficiencies in natural anticoagulants (e.g., tissue factor 
pathway inhibitor (TFPI), antithrombin (AT III), and activated protein C (APC)) are often susceptible to sepsis [77], disseminated intravascular coagulation (DIC) consequences [78], and inflammation [79]. Consistent with such notion of coagulation-dependent inflammation, anticoagulation readily results in anti-inflammatory effects in vivo and in vitro (discussed in Section 10).

\subsection{Coagulant Mediators Are Proinflammatory}

5.1.1. TF in Inflammation. sTF1-219 induces inflammatory arthritis [80], which is characterized by elevated plasma IL-6 and paw swelling accompanied by fibrin overproduction and platelet aggregation. TF mediates IL- $1 \beta$-induced vascular permeability, an inflammatory index [81]. Conversely, TF deficiency reduces inflammation [82]. The ability of antiTF Ab to prevent septic shock [83] and depress macrophage expression of adhesion molecule CD18 [84] is consistent with the proinflammatory function of TF.

5.1.2. FVIIa in Inflammation. Elevated plasma level of FVIIa shows significant correlations to CRP and IL-6 expression [85], while FVII deficiency protects from acute inflammation [86]. Administration with recombinant FVIIa enhances IL-6 and -8 productions in healthy human subjects [87].

5.1.3. FXa in Inflammation. FXa/PL infusion increases IL-6 and CRP in baboons [88]. FXa induces IL-6 [89], IL-8, MCP1, ICAM/VCAM, and E-selectin expressions [90]. Consistent with the notion of proinflammatory FXa, ZK-807834, an FXa inhibitor, blocks IL-6 elicitation [89].

5.1.4. FIIa in Inflammation. FIIa with fibrin (ogen) dependency induces macrophage adhesion and the production of IL-6 and MCP-1 [91]. FIIa signaling elicits IL-6 [92], IL-8 [93], MCP-1 [93], VEGF [94, 95], and ICAM/VCAM expression [96]. FIIa activates platelets releasing proinflammatory serotonin, histamine, and eicosanoid precursors as well as adhesion molecules [97].

5.1.5. Fibrin in Inflammation. Fibrin clot per se is proinflammatory. Fibrin enhances not only IL- $1 \beta$ production [98], but also NF- $\kappa$ B activation (a hallmark of inflammation) to induce the expression of ICAM-1 and IL-8 [99], which has been proposed to be mediated by Toll-like receptor- 4 . Ddimers elicit the synthesis [100] and release $[100,101]$ of IL- $1 \beta$ and IL-6, while fragment D or E [101] stimulates IL- $1 \beta$ secretion. FBG degradation product $D$ elevates IL1 to upregulate IL-6 production [102]. Fibrin fragment E enhances IL-6 production [103].

5.2. Protease-Activated Receptor (PAR) Mediates Inflammation. PARs functioning as molecular switches dictate crosstalks of hypercoagulable states with inflammatory outcomes (Figure 2). PAR expressed ubiquitously in different cell types belongs to the superfamily of GPCR; there are four major isoforms of which the expression is not affected by exogenous LPS, TNF- $\alpha$, IL- $1 \beta$, or IFN- $\gamma$. PAR activation by their corresponding activating peptides triggers inflammation [4, 104-106]. For instance, PAR-1 [107]/-2 [107-109]/-4 [107] activations lead to enhanced production of IL-6/8 and IL$1 \beta$ [110]. PAR-2 agonists induce TNF $\alpha$ [111] and IL-8 [112] secretion, while PAR-1 deficiency reduces inflammation [82].

The receptor activation involves a proteolytic cleavage of the extracellular domain, resulting in the formation of a new $N$ terminus that in turn acts as a tethered ligand to interact with exoloop $2 \mathrm{Glu}^{260}$ and then activate heterotrimeric $\mathrm{G}$ proteins, triggering an array of intracellular signaling cascade. For instance, the involved sequences of PAR1 (TLDP $R^{41} S^{42}$ FLLRNP) and PAR-2 (SSKGR $R^{36} S^{37}$ LIGKY) are cleaved between $\mathrm{R}$ and $\mathrm{S}$ by serine proteases such as FIIa that also cleaves PAR-3 (TLPIKTFRGAP) and PAR-4 (LPAPRGYPGQV) at $K / T$ and $R / G$, respectively [113].

The ability of PAR per se to mediate inflammatory responses $[4,104-106]$ is readily in line with coagulationdependent inflammation. It is now clear that PARs transmit clotting signals for proinflammation (Figures 2 and 3(2)). PAR-1, 3, or 4 is responsible for FIIa signaling. PAR-2 or 3 mediates FXa signaling, while PAR-2 enables FVIIa signaling (Figure 2, right panel). For instance, PAR-1 transmits FIIa signal enhancing the expression of IL-6, -8, TNF $\alpha$, MCP1, ICAM-1, PDGF (AB/BB), bFGF, TGF $\beta$, VEGF, $P$-selectin, and Erk/NF $\mathrm{B} / \mathrm{iNOS}$ activation, enhanced PI hydrolysis, COX-2 expression, upregulated $[\mathrm{Ca}+2] \mathrm{i}$ movement, platelet aggregation, and macrophage adhesion.Via PAR-2 signaling, FVIIa activates MAPK and promotes $[\mathrm{Ca}+2] \mathrm{i}$ movement, while FXa upregulates the expression of IL-6, -8, MCP-1, PDGF, VEGF, as well as NF $\kappa$ B and MAPK activation. PAR3 mediates FXa and FIIa proinflammation for enhanced cytokine production of IL-6/-8 and adhesion molecule (MCP-1), while PAR-4 transmits FIIa signaling in leukocyte rolling and adhesion (for review, see [4]).

Taken together, it is evident that coagulant mediator (e.g., FVIIa, FXa, and FIIa) generation and fibrin production in the extracellular compartment via PARs signal transduction and intracellular activations result in the productions of cytokines, adhesion molecules, growth factors, and other proinflammatory components.

\section{Inflammation Ensuring TF Hypercoagulation:Vicious Coagulation- Inflammation Cycle}

In addition to the above-mentioned TF divergent role in coagulation-dependent inflammation, TF converges various inflammatory signals in either local or systemic inflammation; not only "extrinsic", but also the resulting "intrinsic" ones reversely turn on and activate coagulation (Figure 3(3)). For instance, rIL-6/8 upregulate procoagulation [114]. The intramuscular injection of IL-6 results in FIIa generation in baboons [115]. TNF- $\alpha$ upregulates TF expression in ARDS [116]. CRP drastically activates TF expression [117]. Viral infection such as CpG ODN induces TF expression mediated by TLR-9/MyD88-Erk1/2 pathway with Egr-1 activation [118]. Long pentraxin-3, an acute inflammatory molecule, upregulates TF expression in lung injury [119]. Conversely, 
guggulsterone (an anti-inflammatory phytosterol) inhibits TF expression and arterial thrombosis [120], which is also in favor of such inflammation-triggered coagulation (Figure 3(3)).

Importantly, mounting evidence supports the existence of such a positive feedback/reversible loop (Figure 3(3)) in a complete coagulation-inflammation cycle [9]. For instance, FVIIa [121], FXa [121-124], FIIa [17, 31, 124], and PAR-1 [125] promote TF expression. PAR-2 agonists (e.g., trypsin [126], SLIGKV [126], and proteinase-3 [127]) induce TF mRNA. Conversely, TF expression is diminished by anticoagulants (e.g., TFPI [128-130], FVIIai [131], DX9065a [120], ZK 807834 [89], low-molecular-weight heparins (LMWHs) [132], heparin [133, 134], hirudin [135, 136], hirulog [137], AT III [138], APC [139]), which is consistent with the positive feedback loop of inflammation-dependent coagulation (Figure 3(2) and (3)) in completing the vicious cycle. In addition, Wakefield and his associates have demonstrated that selectin-deficient mice lacking the activation of the extrinsic pathway are defective in fibrin production [140].

Thus, it is clear that TF initiates cross-talks of hypercoagulable states with inflammatory outcomes (Figure 2). Furthermore, TF hypercoagulability results in enormous inflammation as the result of continuously refueling the coagulation-inflammation cycle ((Figure 3(2) and (3)) upon gaining its initial momentum such as local or systemic inflammatory/infectious conditions.

\section{The Paradigm: Coagulation-Inflammation- Thrombosis Circuit}

TF hypercoagulability drives "autocrine" and "paracrine" signaling, thereby amplifying, refueling, and ensuring the paradigm: coagulation-inflammation-thrombosis circuit where it includes the direct thrombotic actions (Figure 3(1)), coagulation-dependent inflammation (Figure 3(2)), a positive feedback loop of inflammation-triggered TF expression (Figure 3(3)), and thrombosis-inflammation connection (Figure 3(4)).

\subsection{Thrombosis-Inflammation Connection (Figure 3(4)) .} Thrombosis and inflammation are two major consequences of blood coagulation, both of which cross-talk and promote each other. Clinical association of thrombosis with inflammation has been reported in many cases [141]. Such inflammation-thrombosis connection (Figure 3(4)) provides an alternative pathway that blood coagulation via its inflammatory consequence indirectly contributes to thrombosis.

Several lines of evidence reveal thrombosis-dependent inflammation based on the ability of fibrin and its fragments to elicit IL-1 $\beta$, IL-6, and IL-8 expression [98-103]. Further, platelet activation/aggregation participates in complement activation resulting in inflammatory responses. $P$-selectin as a C3b-binding protein sufficiently leads to C3a generation and C5b-C9 formation, which supports a novel mechanism of local inflammation in vascular injury sites $[69,141]$.

Conversely, in vivo inflammation-dependent thrombogenesis also exists. IL-8 enhances fibrosis in rats [142]. In support of this notion, activation and antagonism of proinflammatory PARs, respectively, trigger and reduce thrombogenesis (for review, see [69]). For instance, PAR-4 activation [80] and PAR4-activating peptides [143] trigger platelet aggregation; consistently, PAR antagonism attenuates platelet activation/aggregation (for details, see Section 10.6) in line with such inflammation-dependent thrombogenesis. An earlier study has shown that $P$-selectin causes leukocyte accumulation to facilitate fibrin deposition [144], complementing thrombotic episodes. P/E/L-selectins, ICAM, and VCAM are responsible for leukocyte adhesion/rolling/recruitment interacting with platelets and VEC to enhance thrombus formation [145]. In parallel, selectin-deficient mice lacking the activation of the extrinsic pathway are defective in fibrin production [140]. Antibodies to cytokines and adhesion molecules attenuate venous thrombosis [146]. LYP20, an antibody against $P$-selectin, blocks leukocyte adhesion to EC and platelets [147] and modifies thrombosis [148], and $P$ selectin inhibition decreases vein wall fibrosis [149].

In addition, there is a general perception of inflammation-dependent thrombogenesis, which is supported by the observations that anti-inflammatory agents are of antithrombotic benefits. For instance, nonsteroid antiinflammatory drugs readily block thrombosis. COX-1 inhibitor such as low doses of aspirin suppresses platelet aggregation [150]. Similarly, COX-2 inhibition downregulates VEC/leukocyte activation [151].

7.2. The Circuit. Thrombosis-inflammation connection (Figure 3(4)) is integrated into the coagulation-inflammation vicious cycle (Figure 3(2) and (3)), thus rounting a complete circuit to link among coagulation, inflammation, and thrombosis. Concomitant with suppressed TF expression by COX inhibitors [35-37], the antiinflammatory and antithrombotic properties of COX-2 inhibitors $[150,151]$ seem likely to be in agreement with the involvement of TF hypercoagulability in driving the coagulation-inflammation-thrombosis circuit. Further, activated platelets stimulate TF expression [152], while antiplatelet agent (dilazep) inhibits TF expression [153]. Both observations are in favor of the thrombosisinflammation connection (Figure 3(4)) being part of the operative blood coagulation-inflammation-thrombosis circuit. The paradigm has also been observed in lung [154] and inflammatory bowel syndrome [155] while closely relating to cardiovascular risks $[9,69]$.

\section{Coagulation-Dependent Events: Thrombosis/Inflammation-Associated Conditions}

Mounting evidence reveals that TF hypercoagulability plays pathogenic roles closely relating to its not only inflammatory but also thrombotic actions. By driving the circuit (Figure 3), TF hypercoagulability is readily involved in an array of metabolic syndromes (e.g., atherosclerosis, hypertension, diabetes II, and obesity) and other clinical manifestations 
(e.g., cancers, antiphospholipid syndrome (APS), and fetal loss).

8.1. TF in Sepsis/DIC. Hypercoagulation is often observed in septic shock including endotoxemia or systemic inflammatory responses after trauma, which mainly results from TF overexpression [156-158]. The ability of TF blockade to ease septic shock [83] or organ injury [159] points to a fundamental pathogenic role of TF in sepsis. Extrinsic infection/inflammation upregulating TF expression mediates enormous local or systemic intrinsic inflammation as well as a thrombotic condition via the operational circuit (Figures 2 and 3). A common manifestation presents DIC, an acquired disorder with hemostatic imbalance; excessive FIIa formation leads to fibrin deposition in microcirculation and consequent ischemic organ damage. Thus, such autocrine or paracrine TF signaling could lead to substantial tissue damages or multiple organ failure.

8.2. TF in Cancers. TF overexpression has been reported in ovarian cancer [160], endometriosis [161], breast cancer [162], nonsmall cell lung carcinoma [163], prostate cancer [164], pancreatic cancer [165], melanoma [166], colorectal cancer [167], gastric cancer [168], esophageal cancer [169], hepatocellular carcinoma [170], brain tumor glioblastoma [171], leukemia [172], and lymphoma [173]. Accordingly, TF overexpression could be considered a biomarker for solid tumors [174].

The roles of TF in cancer have been demonstrated with severalfold relevance in relation to thrombotic condition, tumorigenesis per se and TF signaling (i.e., coagulationdependant inflammation). Cancer linked with hypercoagulability and thrombotic risk has long been recognized by Armand Trousseau since 1865. The American Society of Hematology calling for a special session on "cancer and thrombosis" addresses its complex clinical interface of prothrombotic association with malignancies and prophylactic approaches. Cancer certainly could be recognized as a prothrombotic risk factor, leading to, for instance, venous thromboembolism and its complication of pulmonary embolism and mortality. Namely, cancers readily induce thrombosis [175]. Enhanced TF expression typically accounts for the mode of mechanism of thrombosis accompanied by suppressed TFPI [176] and defective APC anticoagulation system. Not only tumor cellular membrane-bound TF, but also microparticle-associated TF [177] links cancer to thrombosis. In addition, the similar hypercoagulable state exists in cancer stem cells [178].

The critical role of TF in tumorigenesis is supported by the observations that inhibited TF expression blocks tumor growth, metastasis [179], angiogenesis [180], cell invasion [181], and many other cancer characteristics. TF per se plays important roles in cell proliferation, tumor development, and progression apart from the accompanying coagulationdependent inflammatory environment including MMP-9 [182], growth factors (VEGF, EGF, PDGF, etc.), and adhesion molecules certainly promoting "autocrine" tumorigenesis. Either VEGF or EGF in trun stimulates sustained TF expression [27, 28]. PTEN loss and tumor hypoxia readily induce TF expression [183], which could highlight TF as a major player in cancer progression.

Tumor-expressed TF promotes growth by increasing cell survival and/or angiogenesis. TF and VEGF expressions mutually enhance each other [184], where VEGF is a known main angiogenic factor of cancer characteristics. TF cytoplasmic domain has been shown to be critical for VEGF expression [185]; conversely, VEGF causes TF promoter activation and involves gene upregulation with transcription factor NFAT involvement [28]. It is of particular interest to note that the serine phosphorylated cytoplasmic domain inhibits cellular cytotoxicity [186], thereby leading to increased tumor survival and metastatic rate. In addition, increased TF cytoplasmic domain phosphorylation and PAR2 activation significantly correlate to cancer relapse [181]. Thus, a cooperation of the phosphorylated TF cytoplasmic domain with protease signaling could account for diverse contributions of TF to metastasis and angiogenesis $[81,187]$.

As the proceeding of TF-initiated extrinsic pathway, the resulting FIIa generation and fibrin production are of proangiogenesis. Furthermore, TF/FVIIa activates BcL2 [188], and FXa inactivates caspase-3 [189], both of which inhibit apoptosis. TF/FVIIa/FXa ternary complex possibly mediated by PAR-1/2 readily induces Erk $1 / 2$, Akt/PKB, and mTOR activation, all of which enhance the downstream signaling target phosphorylation for cancer cell undergoing antiapoptosis [190] and cell migration [191]. FIIa-PAR signaling in metastasis [192]/angiogenesis [94] and TF/FVIIa/PARs signaling in tumor growth [193] are also evident. FIIa could be recognized as a tumor growth factor [192, 194], which is accompanied by the enhanced tumor cell cycle mediated by downregulation of p27Kip1 and upregulation of Skp2 and MiR-222 [195]. FIIa is also able to upregulate cathepsin D which enhances angiogenesis, growth, and metastasis [196]. FIIa activates fibrinolysis inhibitors (e.g., TAFI [74] and PAI1 [76]), further promoting cancer progression [197].

8.3. TF in Obesity. TF gene overexpression in obese has been reported for more than a decade $[198,199]$ accompanied by upregulated PAI-1, angiogenesis, cell adhesion, and so forth, all of which could stem from TF hypercoagulability. Inflammation has been proposed to engage in obesity development [200], while less is clear about the precise role of thrombosis per se in obesity. With the functional coagulation-inflammation-thrombosis circuit (Figure 3), triggered inflammation constitutes the pathogenesis of obesity with manifestation including diabetes and cardiovascular risks (e.g., atherosclerosis, hypertension).

TF signaling (Figure 2) sets up inflammation, in part well accounting for elevated levels of IL-6 [200, 201], IL-8 [201], and TNF $\alpha$ [200] detected in obese subjects. Among which, either local or systemic inflammation ( TNF $\alpha$ ) significantly contributes to obesity [202]. Based upon high leptin and low adiponectin levels in obesity, the ability of leptin [30] or adiponectin [47], respectively, to augment or suppress TF synthesis could imply a mechanistic role of TF in developing inflammatory obesity. Furthermore, the involvement of 
PPAR $\alpha$ agonists [52]/activators [53] in downregulating TF expression also likely underlines a positive TF function in the process of inflammatory obesity.

8.4. TF in Diabetes. Diabetes including type I and II is a hypercoagulable state [203] with elevated plasma levels of clotting factors (FVII, FVIII, FX, FXI, FXII), D-dimers, and TAT accompanied by decreased AT III, heparin cofactor II, or APC, presenting a thrombotic condition.

Under hyperglycemia, excessive plasma glucose nonenzymatically conjugates with plasma proteins (e.g., hemoglobins) to form AGE. AGEs through their receptors exhibit biological damage in various tissues such as renal failure and vascular complications. For instance, hyperglycemia induces damage to vascular endothelial cells, which is mediated by the complex activation of MAPK, PKC, NF- $\kappa \mathrm{B}$, and ICAM-1, primarily causing hemostatic alterations [204].

Increased circulating AGEs enhance TF expression [205], making diabetes a hypercoagulable and thrombotic condition $[203,205,206]$. Platelet TF in diabetes II appreciably increases [207]; increased FIIa and FXa generations are also found in diabetic platelets, enhancing the thrombotic nature. TF overexpression essentially promotes diabetes progression as well as its manifestation. As a consequence of diabetic TF hypercoagulability, elevated inflammatory mediators elicit cardiovascular complications including atherosclerosis. It is estimated that $80 \%$ diabetic patients die from a thrombotic disease and $75 \%$ of which result from cardiovascular complications [208]. Diabetic complications are more threatening than hyperglycemia per se; accordingly, relief of hypercoagulability could become far more important than glycemic control. Population-based clinical trials (ACCORD [209], ADVANCE [210] as well as VADT [211]) have demonstrated no benefit to cardiovascular risk in diabetes II upon glycemic control with significant low AGE (e.g., glycated hemoglobin $<6 \%)$ for 2-3.5 years. Furthermore, rosiglitazone substantially lowering glycemia surprisingly increases the risk of myocardial infarction and death from cardiovascular causes [212]. For diabetic cardiovascular events, one could not expect that glycemic control per se significantly and promptly reverses the downstream damages done by AGEs. Apparently, nonglycemic factors (e.g., hypercoagulability, hypertension, and hyperlipidemia) play important roles in such complications.

Apart from thrombotic natures, TF could assume a pathogenic role in diabetic progression in a close relation to inflammatory process $[213,214]$. It is likely that $\mathrm{TF}$ signaling (Figure 2) through the coagulation-inflammationthrombosis circuit (Figure 3) operating in diabetes could well be responsible for insulin resistance. Proinflammatory mediator TNF $\alpha$ is known to promote insulin resistance in which serine phosphorylation of insulin receptor substrate (IRS) is encouraged. As a consequence of preventing insulin downstream IRS tyrosine phosphorylation, TNF $\alpha$ thereby blocks insulin signal transduction [215]. In sharp contrast to TNF $\alpha$ negative effects on insulin action, adiponectin positively enhances insulin sensitivity, and hypoadiponectinemia accordingly leads to insulin resistance [215]. Notably, anti-inflammatory adiponectin suppresses TF expression [47], which could be in support of the role of TF in diabetes pathology. From the viewpoint of PPAR $\alpha$ activation improving insulin sensitivity, the observations of PPAR $\alpha$ agonists [52]/activators [53] downregulating TF expression also likely point to positive TF function(s) in insulin resistance involving inflammatory diabetes development.

In summary, TF function has twofold significance in diabetes. TF not only dictates diabetic hypercoagulable nature and thrombotic outcomes [203], but also overlays its signaling in proinflammation (Figure 2) for insulin resistance. The ability of insulin [40] or an antidiabetic agent (metformin) [59] to attenuate TF expression seemingly reinforces a key pathogenic role of TF in diabetes.

8.5. TF in Cardiovascular Complications. Cardiovascular complications are a group of disorders closely associated with either inflammation or thrombosis or both. In these regards, it is not surprising that TF plays a major role in their pathogeneses [9]. TF overexpression, often correlated to gain-of-function of TF promoter polymorphism (A603G), promotes the development of cardiovascular diseases [216]. It has long been established that TF participates in the phase III of plaque rupture [217] during atherogenesis. TF expression is upregulated in atherosclerotic plaques of patients with unstable angina and myocardial infarction [218].

TF hypercoagulability driving the coagulationinflammation-thrombosis circuit (Figure 3 ) readily extends its diverse consequences to cardiovascular complications and vascular diseases [219] including arrhythmias [58], arterial hypertension [220], hypertrophy [221], ACS [222, 223], andatrial fibrillation (AF) [224], TF hypercoagulability with elevated proinflammatory cytokines (Figure 2) could in part well contribute to atherosclerosis known as chronic inflammatory disease [217]. In cultures, recombinant TF induces cellular apoptosis with increased caspase-3 activity and nuclear location of p53 while increasing cellular proliferation/hypertrophic growth [221]. As a consequence of accelerated cardiomyocyte turnover, TF could contribute to the induction and progression of cardiac hypertrophy. Angiotensin II stimulates TF synthesis [220], mediating hypertensive action. Histamine augments TF expression, accounting for its action in ACS [225]. In conjunction with its effects on endothelial damage/dysfunction and angiogenic actions [224], TF upregulation could well be involved in a thrombogenic state of AF [224].

In contrast, TF deficiency in mice shows cardiac fibrosis $[226,227]$ largely based upon TF functions in normal extracellular cardiac homeostasis, extracellular matrix regulation, and vascular maintenance [227]. Apparently, cardiac bleeding/hemorrhages in TF deficiency certainly encourages its fibrosis [226] where PA involvement could also be ensured by insufficient FIIa generation [74-76]. It awaits further confirmation in human conditions.

8.6. TF in Autoimmune Disorder: Antiphospholipid Syndrome (APS). Classically, APS is generally characterized by the 
presence of aPL including lupus anticoagulants, anticardiolipin antibodies, and anti- $\beta 2$-glycoprotein-1 ( $\beta 2 \mathrm{GPI})$ antibodies. It is proposed that TLR- 4 mediates anti- $\beta 2 \mathrm{GPI}-$ induced TF expression [228]. Alternatively, TF overexpression results from APS-associated complement activation. aPL activates complement via the classical pathway; activated complement (e.g., C5a) drastically stimulates TF synthesis. This autoimmune thrombophilic condition is largely due to enhanced coagulation (e.g., TF overexpression) accompanied by attenuated downregulation of blood coagulation (e.g., inhibited APC, TFPI, and AnxA5) and suppressed fibrinolysis. Increased microparticles and TF expression are found in APS with prothrombotic conditions of various manifestations, most commonly venous and arterial thromboembolism and recurrent pregnancy loss.

In addition, TF could play a pathological role in APS manifestation. It is not surprising if APS of TF overexpression also presents a hyperinflammatory condition in view of the paradigm of coagulation-inflammation-thrombosis circuit (Figure 3). Apart from that aPL-induced complement activation contributes to inflammation [229], TF signaling could well account for increased TNF $\alpha$ [230-232] production as major proinflammation reported in APS patients [233] in which $\mathrm{TNF} \alpha$ also seems to be responsible for its manifestation: fetal damage [232].

8.7. TF in Miscarriage. Miscarriage including fetal death, preeclampsia, and intrauterine growth restriction often closely links to APS involving complement and angiogenic actions. During trophoblast differentiation, aPL activates complement via the classical pathway. Complement activation ( $\mathrm{C} 3$ and $\mathrm{C} 5 \mathrm{a}$ ) directly mediates placental injury and causes fetal loss and growth restriction, resulting from an imbalance of angiogenic factors (e.g., VEGF and placental growth factor) as well as their corresponding receptors that are required for normal placental development [234].

Alternatively, TF overexpression is triggered by aPLinduced complement activation, and TF signaling fulfills such miscarriage/placenta damage/fetal injury. For instance, recent research demonstrates that neutrophil activation by TF/FVIIa/PAR-2 signaling [235] mediates aPL-induced pregnancy complication. In fact, TF on neutrophils and monocytes is a critical mediator in trophoblast injury and embryo damage in aPL-dependent or independent pregnancy loss [236]. Rapid increases in decidual and systemic TNF- $\alpha$ level are also responsible for fetal death/loss [232], which could be in line with TF signaling (Figure 2) playing a pathogenic role. Further, FIIa-induced platelet activation/aggregation activates complements, possibly conferring the direct fetal damage [234].

Anti-TF mAb prevents aPL-induced pregnancy loss [234], while statins $[237,238]$ may be a good treatment for women with recurrent miscarriages and intrauterine growth restriction. These clinical studies are consistent with a pathogenic role of TF in APS-induced fetal damage.

8.8. TF in Wound Healing. Wound, including diabetic foot, healing process generally consists of three phases (inflammatory, proliferative, and remodeling phases) that continuously overlap one another during the process. Hemostasis initiates angiogenesis-dependent wound healing. TF overexpression often occurring after wounding, trauma, or surgeries in part accounts for hypercoagulability encouraging wounding healing [239-241]. Given that inflammation involved in the initial phase, such "autocrine" or "paracrine" TF signaling essentially ensures fibrin matrix formation, angiogenesis, production of growth factors (VEGF, PDGF, bFGF, TGF $\alpha / \beta$, etc.), adhesion molecules, and so forth, (Figures 2 and 3 ), all of which significantly contribute to wound healing process.

8.9. TF in Development. Limited evidence reveals that TF extracellular domain is essential for embryogenesis [242244], which is believed to be mediated by TF-dependent FIIa generation and PAR-1 activation. Thus, TF serves as an important morphogenic factor during embryogenesis. Apparently, TF signaling with FVIIa, FXa, and FIIa generation for PAR activation/transduction triggers an array of biological events as a consequence of proinflammation (Figure 2, right panel), among which growth factors (EGF, VEGF, PDGF, bFGF, etc.) could play major roles in development [245]. Consistently, inactivation of TF gene results in embryonic lethality in a murine model [243]. It is said that TF expression coordinated with TFPI, ATIII, and FVII levels could be critical in embryonic development [246].

8.10. TF in Other Diseases. TF expression is often upregulated by an antibody to platelet factor 4 (PF4) upon a long exposure/treatment of heparin [247]. In heparin-induced thrombocytopenia, PF4 also impairs APC activity, making a pronounced hypercoagulable and prothrombotic condition. TF overexpression in adult onset asthma significantly correlates to the gain-of-function of TF promoter polymorphism (A603G) [216].

Concerning innate immunity and acute inflammation, complement activation is of TF relevance. Complement activation, especially $\mathrm{C} 5 \mathrm{a}$, upregulates TF expression, thereby extending to a broad spectrum of immune consequences [248]. TF overexpression exhibits "paracrine" signaling for fulfilling innate immunity regardless of TF expression by neutrophils remaining debatable. Similarly, TF overexpression is observed in bacterial (pneumonia [249], Helicobacter pylori [250]), viral (HIV) [251], or parasite (malaria) [252] infection.

In response to surgical procedures, enhanced TF synthesis is reported in major surgeries such as hip replacement, cardiopulmonary bypass (CPB) [253] or transplantation [254-256]. Upon tissue injury, exposure to protein disulfide isomerase and PS readily activates TF [10-12] and its signaling. It is plausible that TF hypercoagulability in part accounts for postsurgical inflammatory responses.

With regard to lifestyles, smoking upregulating TF expression apart from its apparent free radical inhalation elicits diverse health problems including cardiovascular and cancer risks. High-fat diets [257], oral contraceptives [15, $258]$, and estrogen replacement $[21,259]$ also promote TF expression, possibly driving the circuit (Figure 3 ) for diverse clinical manifestations in relation to inflammation or/and thrombosis. 
In addition, TF overexpression is associated with other pathological conditions such as liver cirrhosis [260], synovial inflammation [261], sickle cell anemia [262], or hepatic necrosis during cholestasis [263]. These pathological conditions likely result from the coagulation-inflammationthrombosis circuit (Figure 3); the precise mechanisms of action however remain to be defined.

\section{Noncoagulation-Mediated TF Roles}

The signaling function of TF cytoplasmic domain has been demonstrated although its biochemical mechanism remains unclear. For instance, cross-talk between intracellular TF domain with integin $\alpha 3 \beta 1$ promotes cell migration [264], while the cytoplasmic domain possibly upon phosphorylation of the three serine residues causes hyperchemotaxis [265]. The cytoplasmic domain contributes to renal albumin retention, and its renal expression protects against proteinuria. Consistently, the absence of the cytoplasmic domain is associated with increased albuminuria, increased spontaneous glomerular TNF $\alpha$ production, podocyte effacement/inflection, reduced podocyte numbers, resulting in albuminuria and proteinuria [266]. For cancer progression/relapse, increased cytoplasmic domain phosphorylation significantly correlates to metastasis and angiogenesis [267]. It is proposed that the cytoplasmic domain per se is critical for VEFG expression [185], an important angiogenic component in tumorigenesis.

\section{Antagonisms against TF Signaling-Evolving Thrombotic or Inflammatory Events}

In view of the paradigm of coagulation-inflammationthrombosis circuit (Figure 3), any interruption of the circuit is accordingly expected to exert broad antagonism against hypercoagulation, inflammation, thrombosis, and their complications. Table 1 lists some typical examples of targeting TF hypercoagulation for fighting diverse pathological conditions in cell cultures, ex vivo, animal studies, or clinical trials. Strategies targeting TF signaling include TF suppression, general anticoagulation, FVIIa inhibition, FXa inhibition, FIIa inhibition, PAR antagonism, and many others.

10.1. TF Suppression. Inhibited TF synthesis readily leads to many clinical applications for easing pathological conditions including inflammation, thrombosis, and cardiovascular dysfunctions. For instance, vitamin D3 deficiency often exists in APS; consistently, vitamin D3 inhibits transcription factors (e.g., $\mathrm{AP}-1$ and $\mathrm{NF} \kappa \mathrm{B}$ ) to reduce TF overexpression for easing APS-induced thrombosis [268]. 1, 25(OH $)_{2}$ D3 analogs are also used for immunomodulation and antineoplastic therapy of leukemia [50]. A novel NOreleasing statin derivative exerts antiplatelet/antithrombotic activity [269]. Indobufen, through a thromboxane-mediated mechanism, exhibits antagonisms against atherothrombosis [57]. Amiodarone inhibiting TF translation attenuates arterial thrombosis including coronary artery thrombosis as much as ventricular arrhythmias [58]. Nicotinamide inhibits coagulation and inflammation, resulting in antiinflammation with reduced IL- 6 and CD11a in sepsis or DIC [41]. ACE inhibitors offsetting ATII-induced TF overexpression reduce the risk of recurrent myocardial infarction in patients with left ventricular dysfunction [46]. Ethyl pyruvate inhibiting TF mRNA expression shows combined anti-inflammatory and anticoagulant effect [44]. DMSO inhibiting thrombus formation and vascular smooth muscle cell activation could improve acute coronary syndromes [45]. Liver X receptor agonists attenuate atherothrombosis [54]. A hairpin ribozyme inhibiting TF gene expression and TF mRNA shows antithrombotic action [63]. Hydroxyurea has antithrombotic activity [43], while pentoxifylline attenuates DIC [55]. Adiponectin could prevent endothelial dysfunction and atherogenesis in acute coronary syndrome [47]. PPAR $\alpha$ agonists [52]/activators [53] reduce the thrombogenicity of atherosclerotic plaques. TF suppression by adiponectin [47] or PPAR $\alpha$ activation [52, 53] could also constitute antagonism against diabesity. Metformin, an antidiabetic agent, suppresses the production of TNF $\alpha$ [59], a known factor for insulin resistance [213-215]. Antisense oligonucleotide blocking TF expression prevents leukocyte adhesion following renal ischemic reperfusion injury [66, 270]. COX inhibitors readily show anti-inflammation [152, 153] as well as antithrombosis. Red wine phenolics and quercetin improve cardiovascular health and prevent $\mathrm{CHD}$ [56]. Guggulsterone suppresses TF expression together with anti-inflammation and antagonism against arterial thrombosis [120]. HMG-CoA reductase inhibitors (e.g., pravastatin) prevents APS-mediated miscarriages and placental and fetal injury $[33,34,237,238]$, in addition to the general anti-inflammatory effects of statins on lowering CRP, IL-1 $\beta$, IL-6, and so forth. However, little is known and remains inconclusive about the antithrombotic/antiinflammatory relevance of targeting TF synthesis by various inhibitions of intracellular signaling kinases (e.g., MAPK, $\mathrm{PKC}$ ) or transcription factors (e.g., $\mathrm{NF} \kappa \mathrm{B}$ ); the signaling downregulation per se already shows anti-inflammation [4].

Interestingly, paclitaxel exhibits anticancer activity [38]. COX-2 inhibitors show the prevention of colorectal cancer [271], while all-trans retinoic acid inhibiting cancer procoagulation could of benefit to leukemia [49]. shTF RNA inhibits breast cancer growth/angiogenesis in vivo independent of VEGF regulation in mice [62], and TF RNAi antagonizes metastasis [272].

10.2. FVIIa Inhibition. FVIIa inhibition readily shows antagonism against inflammation. Recombinant nematode anticoagulant protein c2 (NAPc2), a novel inhibitor for TF/FVIIa complex, diminishes coagulation-dependent IL-6 and IL8 productions [87]. Active site-inhibited FVIIa depresses LPS-inducible plasma levels of TNF- $\alpha$ [273], IL-6 [273275], and IL-8 [274, 275]. FVIIai suppresses sTF-induced inflammation in an in vivo model [80]. A small molecule BCX-3607 (TF/FVIIa inhibitor) also decreases IL-6 level in an endotoxemia mouse model [276].

Hemextin AB complex, a snake venom protein complex, directly inhibits FVIIa catalytic activity for anticoagulation 
TABLE 1: Targeting TF-initiated coagulation and signaling consequence for easing clinical events.

\begin{tabular}{|c|c|}
\hline Strategy and agent & Antagonism against \\
\hline \multicolumn{2}{|l|}{ TF suppression } \\
\hline HMGCR inhibitors & Inflammation; thrombosis; miscarriage; APS; cancer growth \\
\hline COX inhibitors & Inflammation, APS; thrombosis; miscarriage; cancers \\
\hline Vitamin D3 & APS; thrombosis; cancer \\
\hline Amiodarone & AT; arrhythmia \\
\hline Ethyl pyruvate & Inflammation; coagulation \\
\hline $\mathrm{NO}$ & Platelet activation; thrombosis \\
\hline Indobufen & AT \\
\hline Hydroxyurea & Thrombosis \\
\hline RNAi & Metastasis \\
\hline DMSO & ACS \\
\hline Adiponectin & Atherogenesis; diabetes; ACS \\
\hline Hairpin ribozym & Thrombosis; I/R injury \\
\hline TF sh RNA & Breast cancer growth/angiogenesis \\
\hline Metformin & Diabetes II \\
\hline Liver $\mathrm{X}$ receptor agonists & AT \\
\hline Paclitoxel & Cancers \\
\hline Antisense TF ODN & I/R injury \\
\hline ACE inhibitors & MI \\
\hline Nicotinamide & Sepsis; DIC; coagulation; inflammation \\
\hline $\operatorname{PPAR} \alpha$ activation & Obesity; diabetes \\
\hline Guggulsterone & Inflammation; $\mathrm{AT}$ \\
\hline ATRA & Leukemia; CHD \\
\hline Phenolics/resveratrol & $\mathrm{CHD}$ \\
\hline \multicolumn{2}{|l|}{ FVIIa inhibition } \\
\hline BcX-3607 & Thrombosis; inflammation \\
\hline FVIIai & Colorectal metastasis; inflammation; thrombosis/MI \\
\hline rNAPc2 & Coagulation; inflammation; angiogenesis; tumor growth \\
\hline Hemextin $\mathrm{AB}$ & Coagulation \\
\hline BMS593214 & AT; VT \\
\hline PN7051 & Thrombosis \\
\hline PHA-798 & Thrombosis \\
\hline FFR-rFVIIa & Inflammation; thrombosis; metastasis \\
\hline \multicolumn{2}{|l|}{ FXa inhibition } \\
\hline Fondaparinux & DVT; VTE; PE \\
\hline Enoxaparin & Inflammation; AT; VT \\
\hline WX-FX4 & Metastasis/tumor growth/angiogenesis \\
\hline DX-9065a & Inflammation; platelet aggregation; DIC; tumor proliferation \\
\hline TAK-442 & Coagulation; VT \\
\hline ZK-807834 & Inflammation; AT; VT \\
\hline Oral rivaroxaban & AF; VTE \\
\hline Oral GW 813893 & Thrombosis \\
\hline Oral BMB344577 & Cancer proliferation \\
\hline Oral apixaban & Platelet aggregation \\
\hline LMWH AVE5026 & AT; VT; coagulation \\
\hline Oral DU176b & Thromboembolism; coagulation \\
\hline
\end{tabular}


Table 1: Continued.

\begin{tabular}{|c|c|}
\hline Strategy and agent & Antagonism against \\
\hline Oral sulfanilamide & Coagulation \\
\hline Oral DPC423 & Thrombosis \\
\hline Oral YM-75466 & Thrombosis \\
\hline MCM09 & Cancer metastasis \\
\hline Oral BAY597939 & Thromboembolism \\
\hline Ixolaris & Tumor growth; angiogenesis \\
\hline NAP5 & Coagulation \\
\hline Tinzaparin & Metastasis \\
\hline SamOrg123781A & AT \\
\hline rTAP (rAST) & Thrombosis; restenosis \\
\hline Rivaroxaban & Stroke; AF \\
\hline \multicolumn{2}{|l|}{ FIIa inhibition } \\
\hline FM-19 & Platelet activation; ACS; tumor growth \\
\hline Dabigatran etexilate & Breast cancer progression \\
\hline Argatroban & DVT; VTE; tumor migration/metastasis \\
\hline Heparin & Inflammation; DVT; VTE; pregnancy loss; metastasis \\
\hline Foypan & Metastasis \\
\hline Ximelagatran & DVT; VTE; AT \\
\hline Hirudins & Inflammation; DVT; VTE; AT \\
\hline Org 42675 & AT \\
\hline
\end{tabular}

\section{PAR blockade}

SCH 7979

RWJ 56110

RWJ 58259

PAR-1 antibody

PAR-2 mAb

ENMD-1068

P4pal

YD-3

SFLLR

FR 171113

TH146

FSLLRY-NH2

\section{Miscellaneous}

TFPI

APC

AT-III

Dilazep

CNTO 859

Anti-TF mAb

Oral warfarin

n-3 FA
Inflammation; platelet aggregation; I/R injury; cancer cell motility/metastasis/angiogenesis

Platelet aggregation; thrombosis

Platelet aggregation; vascular occlusion; neointimal thickness; restenosis; thrombosis

Platelet aggregation

Joint inflammation

Joint inflammation

DIC; thrombocytopenia; I/R injury

Platelet aggregation

Platelet aggregation

Platelet aggregation; AT

Platelet aggregation; thrombosis

Inflammation

Inflammation; pulmonary fibrosis; VT; pneumonia; RA; cancer; apoptosis

Inflammation; AT; VT; sepsis; metastasis; apoptosis

Inflammation; thrombosis; metastasis; angiogenesis

Platelet aggregation; APS

Tumor initiation/growth/angiogenesis

Septic shock; DVT; AT/VT; miscarriage

Inflammation; thrombosis; metastasis; tumor growth

Inflammation

APS: antiphospholipid syndrome; ACS: acute coronary syndromes; AF: atrial fibrillation; ATRA: all-trans retinoic acid; AT: arterial thrombosis; CHD: coronary heart disease; COX: cyclooxygynase; DIC: disseminated intravascular coagulation; DVT: deep vein thrombosis; HMGCR: HMGCoA reductase; MI: myocardial infarction; VT: venous thrombosis; VTE: venous thromboembolism; PE: pulmonary embolism; RA: rheumatoid arthritis; I/R injury, ischemia/reperfusion injury. 
[277]. Active site-blocked FVIIa [278] and BMS-593214 [279] provide cardioprotection and carotid arterial and venous thrombosis. Bolus of FFR-rFVIIa reduces thrombus and fibrin deposition in A-A shunt rat model [280]. FFRrFVIIa inhibits ex vivo fibrin deposition in patients undertaking percutaneous coronary intervention [281]. DEGR-rFVIIa prevents thrombus formation in whole blood [282]. Similarly, an active site-blocked FVIIai attenuates fibrin/platelet deposition [283]. By altering TF/FVIIa binding and inhibiting its activity, sTF mutant reduces arterial thrombosis in guinea pigs [284]. A cyclic dodecapeptide (PN7051) derived from the second EGF-like domain of FVII interferes with TF/FVII/FX complex to attenuate fibrin deposition, plateletfibrin adhesion and platelet-thrombus formation [285]. PHA-798 diminishes thrombus formation in primates [286]. It remains to be determined concerning the antithombotic application of rNAPc2.

Remarkably, it has also been documented that FVIIa inhibition exhibits anticancer actions. rNAPc2 $[287,288]$ or active site-blocked FVIIa [289] inhibits cancer metastasis, angiogenesis, and/or tumor growth.

10.3. FXa Inhibition. A growing list of oral FXa inhibitors is developed and available; animal or clinical studies show therapeutically anti-inflammatory applications: LMWH, enoxaparin, or DX9065a suppressing $P$-selectin, TNF$\alpha$, IL-6 [290], or MCP-1 [291] expression. ZK-807834 attenuates FXa-induced IL-6 production [89]. LMWH (AV 526 [292]) and direct FXa inhibitors (biarylmethoxy isonipecotanilides [293]) are antagonistic against AT/VT and coagulation. LMWHs including Fondaparinux [294], Enoxaparin [295], Bemiparin [296], Tinzaparin [297], Fraxiparine [298], Reviparin [299], and Dalteparin [300] exhibit clinical benefits for arterial/venous thrombosis, venous thromboembolism (VTE), and DVT; all LMWHs are able to markedly inhibit platelet aggregation in whole blood. SamOrg 123781A has recently been evaluated for its antithrombotic application with reduced platelet adhesion and thrombus formation in pigs [301]. Recombinant antistasin (rATS) or tick anticoagulant peptide (rTAP) reduces restenosis in balloon angioplasty rabbits [302], and rTAP reduces TF/FVIIa-dependent thrombus formation in vitro [303]. DX-9065a depresses platelet aggregation [304] and leukocyte adhesion to EC [305] while providing effective protection against tumor-induced DIC [306]. Newly developed TAK-442A shows antithrombotic and anticoagulant activities against venous thrombosis [307]. Orally active amidinoaryl propanoic acid reduces platelet deposition and fibrin accumulation in venous-type thrombus in baboons [308]. ZK-807834 inhibits arterial thrombosis [309] as well as venous thrombosis in vascular injury rabbits [310] and electrolytic injury canines [311]. SF 303 and 549 inhibit A-V shunt-induced thrombus formation in rabbits [312]. Orally active YM-75466 inhibits thrombosis in mice [313]. FXV673 inhibits thrombus formation in canines [314]. Orally active pyrazole DPC423 attenuates electrically induced carotid artery thrombosis in rabbits [315]. Isoxazolines and isoxazoles prevent A-V shunt thrombosis [316], while RPR120844 reduces venous thrombosis in rabbits [317]. Rivaroxaban prevents and treats venous thromboembolism and is used for stroke prevention in AF [318]. GW813893 is of antithrombotic therapeutic benefits [319]. Apixaban inhibits platelet aggregation [320]. DU-176b is considered a new anticoagulant for the prophylaxis and treatment of thromboembolic diseases [321]. Oral BAY 59-7939 is for the prevention of venous thromboembolism [322]. Many more direct FXa inhibitors await clinical studies for their anti-inflammatory and antithrombotic applications.

Anticancer activity through direct FXa inhibition is also reported. WX-FX4 effectively inhibits metastasis/tumor growth/angiogenesis and prolongs survival [323]. LMWH Tinzaparin shows antimetastatic effect [324]. Ixolaris is able to block primary tumor growth and angiogenesis [325]. DX9065a inhibits cell proliferation [326], and MCM09 shows anticancer action by significantly lowering lung metastasis [327].

10.4. FIIa Inhibition. Heparin shows a variety of antiinflammatory potentials (for review, see [328]). Heparinbonded circuit prevents the increases in IL- 6 and IL- 8 in CPB patients [329], while heparin bolus reduces neutrophil activation without affecting platelet aggregation [330]. Heparin is also considered a treatment for pregnancy loss [331].

Direct FIIa inhibitor (hirudin) binds to FIIa active site and prevents PAR-1 from cleavage [332], thereby diminishing FIIa signaling in ICAM/VCAM expression [96] and elicitation of VEGF [333, 334], IL-6 [139], IL-8 [93], or MCP-1 [93]. Hirudin suppresses sTF1-219-induced inflammation [80]. A hirudin analog (lepirudin) alleviates LPSinduced platelet activation [335]. Lepirudin, desirudin, and bivalirudin [336] exhibit antagonism to DVT, VTE, and arterial thrombosis in clinical studies.

FIIa active site inhibitor (melagatran) diminishes $P$ selectin expression [332], ximelagatran [337] shows various antithrombotic actions, and argatroban attenuates DVT and VTE [338]. Org 42675 is a direct anti-FIIa agent with antiFXa activity, seemingly being superior to argatroban and fondaparinux in animal models of thrombosis [339].

A new direct FIIa inhibitor (FM-19) shows platelet inhibition in vitro and in vivo with an application for fighting ACS [340]; this oral anticoagulant also inhibits prostate tumor growth in vivo [341]. Several other direct FIIa inhibitors (e.g., argatroban [342], foypan [343], and dabigatran etexilate [344]) show promising anticancer potentials by preventing and slowing down tumor cell migration, metastasis, and cancer progression. Heparin and dalteparin downregulate PAR-1 cleavage [332], blocking PAR-1-mediated VEGF release in response to FIIa [93]. Heparin also reduces lung metastasis [327].

10.5. By Natural Anticoagulants: TFPI, APC, or ATIII. TFPI, a multifunction anticoagulant with trivalent Kunitz-type domains, downregulates TF-dependent blood coagulation by inhibiting FXa and TF/FVIIa complex. The first domain is responsible for the inhibition of FVIIa in TF/FVIIa complex by a feedback inhibition through the inactive quaternary complex TF/FVIIa/TFPI/FXa, where FXa accelerates TFPI 
binding to FVIIa. The second domain directly binds and inhibits FXa. APC directly inactivates FVa and FVIIIa. $\mathrm{FVa}$ is an essential cofactor for FXa (prothrombinase) in prothrombin activation, while FVIIIa functions as a highaffinity receptor/cofactor for FIXa (intrinsic Xase) in FX activation. AT III virtually inhibits all clotting factors at a slow rate; it mainly targets FIIa, FXa and FIXa. In addition, AT III complex with FVIIa inactivates FVIIa activity; the inhibition is enhanced in the presence of TF or heparin.

10.5.1. Anti-Inflammatory Actions. TFPI plays a significant role in protecting against septic shock induced by $E$. coli in animal models [345], suppressing TNF- $\alpha$ expression and IL- 6 and -8 production. TFPI suppresses coagulationdependent IL-8 production [346] or VCAM-1 expression [347]. In cell cultures, TFPI reduces the autocrine release of PDGF-BB, MCP-1 and MMP-2 in response to FVIIa, and FXa [348]. Its coagulation-independent action includes the direct suppression in TNF- $\alpha$, IL- 6 , and IL- 8 production [349], reducing mortality from E. coli septic shock in baboons. TFPI also directly interferes with LPS reception [345]. TFPI in place of antibiotics could be a treatment for pneumonia [350]. Gene therapy with rTFPI could attenuate pulmonary fibrosis [351]. TFPI could also be used to relieve rheumatoid arthritis (RA) synovial inflammation [261].

It has long been established that APC protects from sepsis, DIC, and endotoxemia $[352,353]$; APC is recognized as one of the effective anti-inflammatory agents in clinical applications. APC inactivates the production of IL-1, -6, -8 or TNF- $\alpha$ [354]. APC consistently reduces septic mortality and blocks DIC upon E. coli. infection in either animal or human models [355, 356].

ATIII blocks FXa-induced IL-6, IL-8, MCP-1, ICAM/VCAM, and E-selectin expressions [90] in addition to arresting FIIa-induced (PAR-1-dependent) VEGF release [93] and MCP-1 expression [89]. ATIII inhibits LPSinduced IL-6 production [138]. Apart from inactivating $\mathrm{NF} \kappa \mathrm{B}$ [357], AT III direct anti-inflammatory action includes the suppression in INF- $\gamma$ and ILs (e.g., 1, 2, 4, 6, and 8 ) production, which is mediated by enhanced PGI production and diminished inducible NOS [358]. However, a discrepancy exists concerning improved survival rate in baboons [359] but not severe human sepsis treated with the high dose of ATIII [360]. Further research warrants verifying its anti-inflammatory action(s).

10.5.2. Antithrombotic Actions. rTFPI exhibits antithrombotic effect in a human ex vivo thrombotic model [361] without protection from dealth though, while a truncated TFPI 1-161 reduces thrombus formation [362].

APC antithrombotic potential is implied by increased APC resistance [363] and the deficiency [364] or low plasma level [365] of APC observed in thrombosis. APC profibrinolytic effects by inactivation of PAI-1 [366] and TAFI [367] synergistically diminish the direct thrombotic inputs from blood coagulation cascade. However, APC antithrombotic potential remains in the experimental stage of animal studies. For instance, a recombinant human APC
(LY203638) inhibits arterial thrombosis in a canine model [368]. A human APC product (CTC-111) reduces venous thrombosis in mice [369]. FLIN-Q3 diminishes A-V shuntinduced thrombosis in guinea pigs [370]. hAPC attenuates rat mesenteric occlusion [371], and rhAPC inhibits arterial thrombosis in baboons [372]. Infusion of bovine APC suppresses thrombus formation in rats [373] and rabbit microarterial thrombosis [374]. A rabbit APC-loaded stent reduces thrombus and platelet deposition in vitro and in vivo [375].

Little is known about the antithrombotic application of AT III; a bolus infusion with ATIII attenuates FIIa-induced leukocyte rolling/adhesion/recruitment in ischemia/reperfusion [376].

10.5.3. Anticancer Properties. The effects of TFPI, a "tumor suppressor-like molecule," include enhanced apoptosis [377] and blocked tumor growth and angiogenesis [288]. TFPI2 expression in tumor tissue could inhibit invasion, tumor growth, and metastasis [378]. ATIII demonstrates antimetastatic [379] and antiangiogenic potentials [380]. It remains unclear whether APC could exhibit consistent anticancer benefits [381] regardless of limited evidence showing inhibited tumor metastasis [382].

10.6. PAR Antagonism. PARs transmitting blood coagulation signals to cellular activation for proinflammation (Figure 2) are apparent therapeutical targets for interrupting the circuit (Figure 3). A growing list of PAR antagonists readily shows clinical applications concerning inflammation and thrombosis. For instance, RWJ 58259 [383] selectively blocks PAR-1, resulting in the attenuation in CD61 expression, platelet aggregation, thrombus formation, and restenosis. RWJ-56110 protects from FIIa-induced human platelet activation and platelet-mediated thrombosis [384]. Similarly, PAR-1 antagonists (SCH 79797 and 203099) depress $P$-selectin expression and platelet aggregation [385] and VEGF release [386]. SCH 79797 also limits myocardial ischemia/reperfusion injury in rat hearts [387] and offsets plasmin-induced IL-8 expression and PGE2 release [388]. Orally active himbacine-based SCH 530348 shows potent antiplatelet activity [389]. Refludan suppresses macrophage adhesion [390]. BMS 197525 [391] and 200261 [392] abolish platelet aggregation. Nonpeptide FR 171113 preferentially diminishes FIIa-induced thrombosis in guinea pig models [393]. TH146 and MAP4-TH146 readily inhibit FIIainduced human platelet aggregation and mouse thrombosis [394].

By blocking PAR-2 activation, peptide antagonists (FSLLRY-NH $\mathrm{N}_{2}$ and LSIGRL-NH ${ }_{2}$ ) suppress Serratia marcescens serralysin-induced IL-6/8 expression [109]. PAR2 mAb (SAM-11) and PAR2 antagonist (ENMD-1068) [110] significantly attenuate IL- $1 \beta$ production and joint inflammation. Anti-PAR-2 Abs and tryptase inhibitors (GW-45 and GW-61) cause significant decreases in IL-6 and IL-8 release from human peripheral blood eosinophils [108]. SR 48968 and 140333 reduce contractile [107]. FUT-175 consistent with PAR deficiency eases inflammatory bowel disease/symptom [395]. 
PAR4 antagonist (P4pal-10) is used for treatment of thrombocytopenia and DIC [396] protecting from systemic inflammation accompanied by stabilized liver, kidney, and lung function. A nonpeptide PAR-4 antagonist (YD-3) selectively depresses GYPGKF-induced platelet aggregation [397]. tc-Y-NH(2) and P4pal10 [398] provide protection against injury from myocardial reperfusion injury. P4pal-10 also protects from platelet-mediated thrombosis [399].

Similarly, general PAR downregulation could also achieve such anti-inflammatory and antithrombotic effects. For instance, IL-4 suppresses PAR-1, -2, and -3 mRNA expressions [400]. Cathepsin $\mathrm{G}$ and neutrophil elastase facilitate the internalization of PAR-1 [401]/-2 [402] to desensitize/disarm the reception function. The ubiquitination of PAR-2 by $\beta$-arrestin attenuates PAR-2 signaling induced by trypsins, tryptase, and coagulation mediators (FVIIa and FXa) [403]. By increasing GTPase activity of $\mathrm{G}_{\mathrm{q}}$, NO donors and cGMP [404] terminate PAR-1 signaling and exhibit vascular smooth muscle relaxation.

Concerning anticancer potentials, recent research advances reveal that PARs play roles in cancer metastasis [405] and angiogenesis [406]. Consistently, reduction of PAR-1 expression by siRNA or PAR-1 antagonism by SCH79797 significantly suppresses melanoma cell motility/invasion [406]. SCH79797 suppresses HIF and Twist expression attenuating cancer metastasis [407], while blocked VEGF release could be of antiangiogenesis [407].

10.7. Miscellaneous. Downregulation of TF function shows antithrombotic effects. An i.v. delivered antibody against rabbit TF (AP-1) inhibits intravascular thrombosis [408] and thrombus propagation without affecting bleeding time in rabbits [409]. Anti-TF mAb is of antisepsis [83] and prevents APS-mediated pregnancy loss [234]. TF blocking antibody (CNTO 859) readily reduces EGFR-mediated tumor initiation [178] and cancer initiation/angiogenesis [410]. TF blocking antibody also reduces allograft rejection [411]. Oral warfarin significantly reduces IL-6 at day 15 [412, 413]; this general anticoagulant also shows antagonisms against tumor growth/metastasis [414]. n-3 FA [25, 415], known as inflammation resolution, offsets AA stimulatory effect on TF expression [25] to ease inflammation and provide cardioprotection.

\section{Remarks}

Blood coagulation, a primitive biological phenomenon in the animal kingdom, has historically been recognized as a host defense to prevent one from bleeding to death. TF-initiated extrinsic pathway, known as being inducible compared to constitutive intrinsic pathway, plays an integral role in blood coagulation, FIIa generation, and thrombus formation (for review, see [3, 10, 67]). Accumulating evidence demonstrates TF diverse biological effects in local or systemic inflammation [4]. Not only does the extrinsic pathway but also intrinsic pathway results in inflammation [416]. Interestingly, TF hypercoagulability refuels a coagulation-inflammation-thrombosis circuit in "autocrine" or "paracrine" fashion (Figure 3), thereby manifesting many pathological conditions.

Such extracellular TF signaling activates cells, and its pronounced effects include proinflammatory cytokine production (Figure 2). It has been elucidated that inflammasomal activation [417] in response to innate pathogens [418], viral [419], fungus [420], influenza [421], microbes [422], and chemicals (e.g., cholesterol [423], uric acid [424], or aluminium hydroxide [417] crystals, asbestos [425], silica [425]) is essential for cytokine secretion (for review, see [426]). It, however, remains elusive if inflammasomal activation is involved in such inflammatory process triggered by TF signaling. Thus far, there is no indication whether coagulant mediators (e.g., FVIIa, FXa, FIIa) could activate procaspase1, facilitating proinflammatory cytokine secretion. Could PAR activation directly turn on inflammasomal activation, an interesting question seemingly further addressing the similar issues if inflammasomal activation is critical for coagulation-dependent inflammation?

Among diverse clinical conditions associated with TF overexpression and its signaling mentioned herein, the close link between TF hypercoagulability and neurological disorders is however seldom reported. Although high TF expression in the brain could in part account for thrombotic stroke consequences, it certainly warrants investigation to explore if TF and its signaling participate in other neuronal dysfunctions or CNS disorders. It would also be of particular interest to determine the biological events of coagulation concerning not only innate [248] but also adaptive immunity of B/T cell equipped and featured with such "autocrine" or "paracrine" TF signaling, if any.

In view of the paradigm of coagulation-inflammationthrombosis circuit eliciting diverse pathological events (Figure 3), targeting TF hypercoagulation is of therapeutical relevance. Apparently, the development of anticoagulants is of broad pharmaceutical interests; anticoagulation could turn into strategic approaches for intervention and cure not limiting to thromboprophylaxis. It is highly promising that anticoagulants available arresting different stages of blood coagulation cascade [427] exhibit benefits other than hemostasis. Approaches to direct FVIIa, FXa, or FIIa inhibition readily demonstrate broad clinical applications (Table 1). In these regards, TF posttranslational downregulation (including encryption) could deserve attention for interventional therapeutical relevance in prospective of such upstream downregulation of the extrinsic pathway (Figure 2, left panel) with broad suppression of downstream proinflammatory coagulant mediators (e.g., FVIIa, FXa, and FIIa) as well as fibrin production.

The observations of anticoagulation exhibiting anticancer properties clearly demonstrate the new frontiers of the emerging therapeutical era. Direct PAR blockade could be part of therapeutically targeting coagulation-dependent inflammation and the circuit (Figure 3). Further research is needed to study if PAR antagonisms could widely exhibit an array of clinical benefits to relieve diseases including cancer, obesity, diabetes, APS, and others in addition to inflammation and thrombotic related cardiovascular complications. 
Like any other therapies, anticoagulation bears certain limitations and cautions for its applications. For employing anticoagulants, bleeding or hemorrhage episodes become major concerns in relation to the safety and efficacy issues upon long-term uses or "over dosages." With cautions in mind, routine monitoring for hemostatic properties is highly recommended. Further investigations warrant addressing rationally designed anticoagulant approaches to achieving/maintaining/weighing in therapeutical benefits for diverse clinical applications.

\section{Abbreviations}

\begin{tabular}{|c|c|}
\hline AA: & Arachidonic acid \\
\hline ACS: & Acute coronary syndromes \\
\hline AF: & Atrial fibrillation \\
\hline AP-1: & Activator protein-1 \\
\hline APC: & Activated protein $\mathrm{C}$ \\
\hline aPL: & Antiphospholipid antibody \\
\hline APS: & Antiphospholipid syndrome \\
\hline AT: & Arterial thrombosis \\
\hline AT III: & Antithrombin III \\
\hline bFGF: & Basic fibroblast growth factor \\
\hline CHD: & Coronary heart disease \\
\hline COX: & Cyclo-oxgyenase \\
\hline CPB: & Cardiopulmonary bypass \\
\hline CRP: & C-reactive protein \\
\hline DIC: & Disseminated intravascular coagulation \\
\hline DVT: & Deep vein thrombosis \\
\hline EGF: & Epidermal growth factor \\
\hline Egr-1: & Early growth reponse-1 \\
\hline FBG: & Fibrinogen \\
\hline FIIa: & Thrombin \\
\hline FVIIa: & Activated factor VII \\
\hline FVIIai: & Active site inhibited FVIIa \\
\hline FXa: & Activated factor X \\
\hline HMGCR: & HMGCoA reductase \\
\hline ICAM: & Intracellular adhesion molecule \\
\hline IL: & Interleukin \\
\hline LDL: & Low-density lipoprotein \\
\hline LMWH: & Low-molecular-weight heparin \\
\hline $\operatorname{Lp}(\mathrm{a}):$ & Lipoprotein (a) \\
\hline LPS: & Lipopolysaccharide; bacterial endotoxin \\
\hline MAPK: & Mitogenic activating protein kinase \\
\hline MCP: & Monocyte chemotactic protein \\
\hline MI: & Myocardial infarction \\
\hline MMP: & Matrix metalloproteinase \\
\hline $\mathrm{NF}-\kappa \mathrm{B}:$ & Nuclear factor-kappa B \\
\hline $\mathrm{NO}(\mathrm{S}):$ & Nitric oxide (synthase) \\
\hline OxLDL: & Oxidized LDL \\
\hline PA: & Plasminogen activator \\
\hline PAF: & Platelet activating factor \\
\hline PAI-1: & Plasminogen activator inhibitor-1 \\
\hline PAR: & Protease activated receptor \\
\hline PC: & Protein C \\
\hline PCA: & Procoagulant activity \\
\hline PDGF: & Platelet derived growth factor \\
\hline PE: & Pulmonary embolism \\
\hline PG: & Glycoproteins \\
\hline
\end{tabular}

PGE2/J2: Prostagandin E2/J2

PKC: $\quad$ Protein kinase $\mathrm{C}$

PPAR: Peroxisomal proliferation activated receptor

PS: $\quad$ Phosphatidylserine

RA: Rheumatoid arthritis

TAP: $\quad$ Tick anticoagulant peptide

TAT: Thrombin-antithrombin complex

TF: $\quad$ Tissue factor

TFPI: TF pathway inhibitor

TGF: $\quad$ Transforming growth factor

TLR: Toll-like receptors

TNF- $\alpha$ : Tissue necrosis factor-alpha

VCAM: Vascular adhesion molecule

VEGF: Vascular endothelial growth factor

VT: $\quad$ Venous thrombosis

VTE: Venous thromboembolism.

\section{References}

[1] B. Østerud and E. Bjørklid, "Sources of tissue factor," Seminars in Thrombosis and Hemostasis, vol. 32, no. 1, pp. 11-23, 2006.

[2] N. S. Key and N. MacKman, "Tissue factor and its measurement in whole blood, plasma, and microparticles," Seminars in Thrombosis and Hemostasis, vol. 36, no. 8, pp. 865-875, 2010.

[3] L. C. Petersen, S. Valentin, and U. Hedner, "Regulation of the extrinsic pathway system in health and disease: the role of factor VIIa and tissue factor pathway inhibitor," Thrombosis Research, vol. 79, no. 1, pp. 1-47, 1995.

[4] A. J. Chu, "Tissue factor mediates inflammation," Archives of Biochemistry and Biophysics, vol. 440, no. 2, pp. 123-132, 2005.

[5] B. Szotowski, S. Antoniak, W. Poller, H. P. Schultheiss, and U. Rauch, "Procoagulant soluble tissue factor is released from endothelial cells in response to inflammatory cytokines," Circulation Research, vol. 96, no. 12, pp. 1233-1239, 2005.

[6] F. S. Kittur, C. Manithody, J. H. Morrissey, and A. R. Rezaie, "The cofactor function of the N-terminal domain of tissue factor," Journal of Biological Chemistry, vol. 279, no. 38, pp. 39745-39749, 2004.

[7] J. Ahamed, F. Niessen, T. Kurokawa et al., "Regulation of macrophage procoagulant responses by the tissue factor cytoplasmic domain in endotoxemia," Blood, vol. 109, no. 12, pp. 5251-5259, 2007.

[8] L. Sharma, E. Melis, M. J. Hickey et al., "The cytoplasmic domain of tissue factor contributes to leukocyte recruitment and death in endotoxemia," American Journal of Pathology, vol. 165, no. 1, pp. 331-340, 2004.

[9] A. J. Chu, "Tissue factor upregulation drives a thrombosisinflammation circuit in relation to cardiovascular complications," Cell Biochemistry and Function, vol. 24, no. 2, pp. 173192, 2006.

[10] B. Furie and B. C. Furie, "Mechanisms of thrombus formation," The New England Journal of Medicine, vol. 359, no. 9, pp. 938-949, 2008.

[11] J. Cho, B. C. Furie, S. R. Coughlin, and B. Furie, "A critical role for extracellular protein disulfide isomerase during thrombus formation in mice," Journal of Clinical Investigation, vol. 118, no. 3, pp. 1123-1131, 2008. 
[12] C. Reinhardt, M. L. von Brühl, D. Manukyan et al., "Protein disulfide isomerase acts as an injury response signal that enhances fibrin generation via tissue factor activation," Journal of Clinical Investigation, vol. 118, no. 3, pp. 1110 $1122,2008$.

[13] A. Breitenstein, S. Stein, E. W. Holy et al., "Sirt1 inhibition promotes in vivo arterial thrombosis and tissue factor expression in stimulated cells," Cardiovascular Research, vol. 89, no. 2, pp. 464-472, 2011.

[14] R. Dardik, D. Varon, I. Tamarin et al., "Homocysteine and oxidized low density lipoprotein enhance platelet adhesion to endothelial cells under flow conditions: distinct mechanisms of thrombogenic modulation," Journal of Thrombosis and Haemostasis, vol. 83, no. 2, pp. 338-344, 2000.

[15] H. Hölschermann, H. M. Terhalle, U. Zakel et al., "Monocyte tissue factor expression is enhanced in women who smoke and use oral contraceptives," Journal of Thrombosis and Haemostasis, vol. 82, no. 6, pp. 1614-1620, 1999.

[16] M. C. Lin, F. Almus-Jacobs, H. H. Chen et al., "Shear stress induction of the tissue factor gene," Journal of Clinical Investigation, vol. 99, no. 4, pp. 737-744, 1997.

[17] H. Cai, C. Song, I. Endoh et al., "Serum amyloid A induces monocyte tissue factor," Journal of Immunology, vol. 178, no. 3, pp. 1852-1860, 2007.

[18] J. Steffel, C. Arnet, A. Akhmedov, S. M. Iseli, T. F. Lüscher, and F. C. Tanner, "Histamine differentially interacts with tumor necrosis factor- $\alpha$ and thrombin in endothelial tissue factor induction: the role of c-Jun $\mathrm{NH}_{2}$-terminal kinase," Journal of Thrombosis and Haemostasis, vol. 4, no. 11, pp. 2452-2460, 2006.

[19] S. Matetzky, S. Tani, S. Kangavari et al., "Smoking increases tissue factor expression in atherosclerotic plaques: implications for plaque thrombogenicity," Circulation, vol. 102, no. 6, pp. 602-604, 2000.

[20] P. Cirillo, S. De Rosa, M. Pacileo et al., "Nicotine induces tissue factor expression in cultured endothelial and smooth muscle cells," Journal of journal of Journal of Thrombosis and Haemostasis, vol. 4, no. 2, pp. 453-458, 2006.

[21] K. P. Henrikson, J. A. Greenwood, B. T. Pentecost, E. E. Jazin, and H. W. Dickerman, "Estrogen control of uterine tissue factor messenger ribonucleic acid levels," Endocrinology, vol. 130, no. 5, pp. 2669-2674, 1992.

[22] A. Iakhiaev, U. Pendurthi, and S. Idell, "Asbestos induces tissue factor in Beas-2B human lung bronchial epithelial cells in vitro," Lung, vol. 182, no. 4, pp. 251-264, 2004.

[23] H. Kawano, H. Tsuji, H. Nishimura et al., "Serotonin induces the expression of tissue factor and plasminogen activator inhibitor-1 in cultured rat aortic endothelial cells," Blood, vol. 97, no. 6, pp. 1697-1702, 2001.

[24] K. V. Reddy, G. Bhattacharjee, G. Schabbauer et al., "Dexamethasone enhances LPS induction of tissue factor expression in human monocytic cells by increasing tissue factor mRNA stability," Journal of Leukocyte Biology, vol. 76, no. 1, pp. 145151, 2004.

[25] Y. Cadroy, D. Dupouy, and B. Boneu, "Arachidonic acid enhances the tissue factor expression of mononuclear cells by the cyclo-oxygenase-1 pathway: beneficial effect of n-3 fatty acids," Journal of Immunology, vol. 160, no. 12, pp. 61456150, 1998.

[26] D. Corseaux, T. Meurice, I. Six et al., "Basic fibroblast growth factor increases tissue factor expression in circulating monocytes and in vascular wall," Circulation, vol. 101, no. 16, pp. 2000-2006, 2000.
[27] A. L. Armesilla, E. Lorenzo, P. Gómez del Arco, S. MartínezMartínez, A. Alfranca, and J. M. Redondo, "Vascular endothelial growth factor activates nuclear factor of activated T cells in human endothelial cells: a role for tissue factor gene expression," Molecular and Cellular Biology, vol. 19, no. 3, pp. 2032-2043, 1999.

[28] S. Kato, M. Pinto, A. Carvajal et al., "Tissue factor is regulated by epidermal growth factor in normal and malignant human endometrial epithelial cells," Journal of Thrombosis and Haemostasis, vol. 94, no. 2, pp. 444-453, 2005.

[29] S. Camino-López, L. Badimon, A. González, D. Canals, E. Peña, and V. Llorente-Cortés, "Aggregated low density lipoprotein induces tissue factor by inhibiting sphingomyelinase activity in human vascular smooth muscle cells," Journal of Thrombosis and Haemostasis, vol. 7, no. 12, pp. 2137-2146, 2009.

[30] S. Rafail, K. Ritis, K. Schaefer et al., "Leptin induces the expression of functional tissue factor in human neutrophils and peripheral blood mononuclear cells through JAK2dependent mechanisms and TNF $\alpha$ involvement," Thrombosis Research, vol. 122, no. 3, pp. 366-375, 2008.

[31] S. Shetty, Y. P. Bhandary, S. K. Shetty et al., "Induction of tissue factor by urokinase in lung epithelial cells and in the lungs," American Journal of Respiratory and Critical Care Medicine, vol. 181, no. 12, pp. 1355-1366, 2010.

[32] H. Takeya, E. C. Gabazza, S. Aoki, H. Ueno, and K. Suzuki, "Synergistic effect of sphingosine 1-phosphate on thrombininduced tissue factor expression in endothelial cells," Blood, vol. 102, no. 5, pp. 1693-1700, 2003.

[33] J. L. Wei, H. M. Cui, and C. Y. Ma, "Simvastatin inhibits tissue factor and plasminogen activator inhibitor-1 secretion by peripheral blood mononuclear cells in patients with primary nephrotic syndrome," European Journal of Medical Research, vol. 12, no. 5, pp. 216-221, 2007.

[34] S. Steiner, W. S. Speidl, J. Pleiner et al., "Simvastatin blunts endotoxin-induced tissue factor in vivo," Circulation, vol. 111, no. 14, pp. 1841-1846, 2005.

[35] J. Steffel, M. Hermann, H. Greutert et al., "Celecoxib decreases endothelial tissue factor expression through inhibition of c-Jun terminal $\mathrm{NH}_{2}$ kinase phosphorylation," Circulation, vol. 111, no. 13, pp. 1685-1689, 2005.

[36] Y. Kunieda, K. Nakagawa, H. Nishimura et al., "HMG CoA reductase inhibitor suppresses the expression of tissue factor and plasminogen activator inhibitor-1 induced by angiotensin II in cultured rat aortic endothelial cells," Thrombosis Research, vol. 110, no. 4, pp. 277-234, 2003.

[37] H. Y. Wang, Y. M. Yang, Y. Zhuang, H. N. Chen, Y. L. Wan, and Y. T. Huang, "The effect of celecoxib on tissue factor expression in pancreatic cancer cells," Chinese Medical Journal, vol. 120, no. 20, pp. 1753-1756, 2007.

[38] E. Napoleone, F. Zurlo, M. C. Latella et al., "Paclitaxel downregulates tissue factor in cancer and host tumourassociated cells," European Journal of Cancer, vol. 45, no. 3, pp. 470-477, 2009.

[39] B. Engelmann, S. Zieseniss, K. Brand et al., "Tissue factor expression of human monocytes is suppressed by lysophosphatidylcholine," Arteriosclerosis, Thrombosis, and Vascular Biology, vol. 19, no. 1, pp. 47-53, 1999.

[40] A. J. Gerrits, C. A. Koekman, C. Yildirim, R. Nieuwland, and J. W. N. Akkerman, "Insulin inhibits tissue factor expression in monocytes," Journal of Thrombosis and Haemostasis, vol. 7, no. 1, pp. 198-205, 2009. 
[41] J. S. Ungerstedt, K. Heimersson, T. Söderström, and M. Hansson, "Nicotinamide inhibits endotoxin-induced monocyte tissue factor expression," Journal of Thrombosis and Haemostasis, vol. 1, no. 12, pp. 2554-2560, 2003.

[42] M. Gerlach, D. Keh, G. Bezold et al., "Nitric oxide inhibits tissue factor synthesis, expression and activity in human monocytes by prior formation of peroxynitrite," Intensive Care Medicine, vol. 24, no. 11, pp. 1199-1208, 1998.

[43] N. Maugeri, G. Giordano, M. P. Petrilli et al., "Inhibition of tissue factor expression by hydroxyurea in polymorphonuclear leukocytes from patients with myeloproliferative disorders: a new effect for an old drug?" Journal of Thrombosis and Haemostasis, vol. 4, no. 12, pp. 2593-2598, 2006.

[44] M. A. van Zoelen, K. Bakhtiari, M. C. Dessing et al., "Ethyl pyruvate exerts combined anti-inflammatory and anticoagulant effects on human monocytic cells," Journal of Thrombosis and Haemostasis, vol. 96, no. 6, pp. 789-793, 2006.

[45] G. G. Camici, J. Steffel, A. Akhmedov et al., "Dimethyl sulfoxide inhibits tissue factor expression, thrombus formation, and vascular smooth muscle cell activation: a potential treatment strategy for drug-eluting stents," Circulation, vol. 114, no. 14, pp. 1512-1521, 2006.

[46] E. Napoleone, A. Di Santo, M. Camera, E. Tremoli, and R. Lorenzet, "Angiotensin-converting enzyme inhibitors downregulate tissue factor synthesis in monocytes," Circulation Research, vol. 86, no. 2, pp. 139-143, 2000.

[47] Y. J. Chen, L. Q. Zhang, G. P. Wang et al., "Adiponectin inhibits tissue factor expression and enhances tissue factor pathway inhibitor expression in human endothelial cells," Journal of Thrombosis and Haemostasis, vol. 100, no. 2, pp. 291-300, 2008.

[48] T. Saito, T. Koyama, K. Nagata, R. Kamiyama, and S. Hirosawa, "Anticoagulant effects of retinoic acids on leukemia cells," Blood, vol. 87, no. 2, pp. 657-665, 1996.

[49] A. Falanga, M. Marchetti, S. Giovanelli, and T. Barbui, "Alltrans-retinoic acid counteracts endothelial cell procoagulant activity induced by a human promyelocytic leukemia-derived cell line (NB4)," Blood, vol. 87, no. 2, pp. 613-617, 1996.

[50] J. Chung, T. Koyama, M. Ohsawa, A. Shibamiya, A. Hoshi, and S. Hirosawa, " $1,25(\mathrm{OH})_{2} \mathrm{D}_{3}$ blocks TNF-induced monocytic tissue factor expression by inhibition of transcription factors AP-1 and NF- ${ }_{\kappa} \mathrm{B}$," Laboratory Investigation, vol. 87, no. 6, pp. 540-547, 2007.

[51] S. Eligini, C. Banfi, M. Brambilla et al., "15-Deoxy- $\Delta 12,14-$ Prostaglandin J2 inhibits tissue factor expression in human macrophages and endothelial cells: evidence for ERK1/2 signaling pathway blockade," Journal of Thrombosis and Haemostasis, vol. 88, no. 3, pp. 524-532, 2002.

[52] B. P. Neve, D. Corseaux, G. Chinetti et al., "PPAR $\alpha$ agonists inhibit tissue factor expression in human monocytes and macrophages," Circulation, vol. 103, no. 2, pp. 207-212, 2001.

[53] N. Marx, N. Mackman, U. Schönbeck et al., "PPAR $\alpha$ activators inhibit tissue factor expression and activity in human monocytes," Circulation, vol. 103, no. 2, pp. 213-219, 2001.

[54] N. Terasaka, A. Hiroshima, A. Ariga et al., "Liver X receptor agonists inhibit tissue factor expression in macrophages," The FEBS Journal, vol. 272, no. 6, pp. 1546-1556, 2005.

[55] V. Ollivier, C. Ternisien, T. Vu, J. Hakim, and D. de Prost, "Pentoxifylline inhibits the expression of tissue factor mRNA in endotoxin-activated human monocytes," FEBS Letters, vol. 322, no. 3, pp. 231-234, 1993.
[56] G. Kaur, M. Roberti, F. Raul, and U. R. Pendurthi, "Suppression of human monocyte tissue factor induction by red wine phenolics and synthetic derivatives of resveratrol," Thrombosis Research, vol. 119, no. 2, pp. 247-256, 2007.

[57] S. Eligini, F. Violi, C. Banfi et al., "Indobufen inhibits tissue factor in human monocytes through a thromboxanemediated mechanism," Cardiovascular Research, vol. 69, no. 1, pp. 218-226, 2006.

[58] A. Breitenstein, S. F. Stämpfli, G. G. Camici et al., "Amiodarone inhibits arterial thrombus formation and tissue factor translation," Arteriosclerosis, Thrombosis, and Vascular Biology, vol. 28, no. 12, pp. 2231-2238, 2008.

[59] M. Arai, M. Uchiba, H. Komura, Y. Mizuochi, N. Harada, and K. Okajima, "Metformin, an antidiabetic agent, suppresses the production of tumor necrosis factor and tissue factor by inhibiting early growth response factor-1 expression in human monocytes in vitro," Journal of Pharmacology and Experimental Therapeutics, vol. 334, no. 1, pp. 206-213, 2010.

[60] G. Schabbauer, M. Tencati, B. Pedersen, R. Pawlinski, and N. Mackman, "PI3K-Akt pathway suppresses coagulation and inflammation in endotoxemic mice," Arteriosclerosis, Thrombosis, and Vascular Biology, vol. 24, no. 10, pp. 1963-1969, 2004.

[61] X. Zhang, H. Yu, J. R. Lou et al., "MicroRNA-19 (miR- $\left.{ }_{19}\right)$ regulates tissue factor expression in breast cancer cells," Journal of Biological Chemistry, vol. 286, no. 2, pp. 1429-1435, 2011.

[62] J. E. Bluff, M. Amarzguioui, J. Slattery, M. W. Reed, N. J. Brown, and C. A. Staton, "Anti-tissue factor short hairpin RNA inhibits breast cancer growth in vivo," Breast Cancer Research and Treatment, vol. 128, no. 3, pp. 691-701, 2011.

[63] E. Cavusoglu, I. Chen, J. Rappaport, and J. D. Marmur, "Inhibition of tissue factor gene induction and activity using a hairpin ribozyme," Circulation, vol. 105, no. 19, pp. 2282-2287, 2002.

[64] Y. Förster and B. Schwenzer, "Inhibition of TF gene expression by antisense oligonucleotides in different cancer cell lines," Journal of Experimental Therapeutics and Oncology, vol. 4, no. 4, pp. 281-289, 2004.

[65] M. Pinotti, C. Bertolucci, E. Frigato et al., "Suppression of HUVEC tissue factor synthesis by antisense oligodeoxynucleotide," Thrombosis Research, vol. 122, no. 1, pp. 99-107, 2008.

[66] J. Yin, X. G. Luo, W. J. Yu, J. Y. Liao, Y. J. Shen, and Z. W. Zhang, "Antisense oligodeoxynucleotide against tissue factor inhibits human umbilical vein endothelial cells injury induced by anoxia-reoxygenation," Cellular Physiology and Biochemistry, vol. 25, no. 4-5, pp. 477-490, 2010.

[67] S. Butenas, T. Orfeo, and K. G. Mann, "Tissue factor activity and function in blood coagulation," Thrombosis Research, vol. 122, no. 1, pp. S42-S46, 2008.

[68] M. L. Liu, M. P. Reilly, P. Casasanto, S. E. McKenzie, and K. J. Williams, "Cholesterol enrichment of human monocyte/macrophages induces surface exposure of phosphatidylserine and the release of biologically-active tissue factor-positive microvesicles," Arteriosclerosis, Thrombosis, and Vascular Biology, vol. 27, no. 2, pp. 430-435, 2007.

[69] A. J. Chu, "Role of tissue factor in thrombosis. Coagulationinflammation-thrombosis circuit," Frontiers in Bioscience, vol. 11, no. 1, pp. 256-271, 2006.

[70] C. A. Kretz, N. Vaezzadeh, and P. L. Gross, "Tissue factor and thrombosis models," Arteriosclerosis, Thrombosis, and Vascular Biology, vol. 30, no. 5, pp. 900-908, 2010. 
[71] C. Tapparelli, R. Metternich, and N. S. Cook, "Structure and function of thrombin receptors," Trends in Pharmacological Sciences, vol. 14, no. 12, pp. 426-428, 1993.

[72] G. Soslau, R. Class, D. A. Morgan et al., "Unique pathway of thrombin-induced platelet aggregation mediated by glycoprotein Ib," Journal of Biological Chemistry, vol. 276, no. 24, pp. 21173-21183, 2001.

[73] F. Adam, M. C. Guillin, and M. Jandrot-Perrus, "Glycoprotein Ib-mediated platelet activation: a signalling pathway triggered by thrombin," European Journal of Biochemistry, vol. 270, no. 14, pp. 2959-2970, 2003.

[74] B. N. Bouma and J. C. Meijers, "New insights into factors affecting clot stability: a role for thrombin activatable fibrinolysis inhibitor (TAFI; plasma procarboxypeptidase B, plasma procarboxypeptidase U, procarboxypeptidase R)," Seminars in Hematology, vol. 41, no. 1, supplement 1, pp. 13-19, 2004.

[75] A. H.C. Guimarães and D. C. Rijken, "Thrombin activatable fibrinolysis inhibitor (TAFI) affects fibrinolysis in a plasminogen activator concentration-dependent manner. Study of seven plasminogen activators in an internal clot lysis model," Journal of Thrombosis and Haemostasis, vol. 91, no. 3, pp. 473-479, 2004.

[76] S. Mandl-Weber, B. Haslinger, and T. Sitter, "Thrombin upregulates production of plasminogen activator inhibitor type 1 in human peritoneal mesothelial cells," Peritoneal Dialysis International, vol. 19, no. 4, pp. 319-324, 1999.

[77] B. White and D. Perry, "Acquired antithrombin deficiency in sepsis," British Journal of Haematology, vol. 112, no. 1, pp. 26-31, 2001.

[78] N. Iversen, F. G. Strekerud, and U. Abildgaard, "Tissue factor pathway inhibitor (TFPI) in disseminated intravascular coagulation: low levels of the activated factor X-TFPI complex," Blood Coagulation and Fibrinolysis, vol. 11, no. 7, pp. 591-598, 2000.

[79] H. Asakura, Y. Ontachi, T. Mizutani et al., "Decreased plasma activity of antithrombin or protein $\mathrm{C}$ is not due to consumption coagulopathy in septic patients with disseminated intravascular coagulation," European Journal of Haematology, vol. 67, no. 3, pp. 170-175, 2001.

[80] N. Busso, V. Chobaz-Péclat, J. Hamilton, P. Spee, N. Wagtmann, and A. So, "Essential role of platelet activation via protease activated receptor 4 in tissue factor-initiated inflammation," Arthritis Research and Therapy, vol. 10, no. 2, article no. R42, 2008.

[81] M. Puhlmann, D. M. Weinreich, J. M. Farma, N. M. Carroll, E. M. Turner, and H. R. Alexander Jr., "Interleukin-1 $\beta$ induced vascular permeability is dependent on induction of endothelial tissue factor (TF) activity," Journal of Translational Medicine, vol. 3, article no. 37, 2005.

[82] J. P. Luyendyk, B. P. Sullivan, G. L. Guo, and R. Wang, "Tissue factor-deficiency and protease activated receptor1-deficiency reduce inflammation elicited by diet-induced steatohepatitis in mice," American Journal of Pathology, vol. 176, no. 1, pp. 177-186, 2010.

[83] F. B. Taylor Jr., A. Chang, W. Ruf et al., "Lethal E. coli septic shock is prevented by blocking tissue factor with monoclonal antibody," Circulatory Shock, vol. 33, no. 3, pp. 127-134, 1991.

[84] M. A. Cunningham, P. Romas, P. Hutchinson, S. R. Holdsworth, and P. G. Tipping, "Tissue factor and factor VIIa receptor/ligand interactions induce proinflammatory effects in macrophages," Blood, vol. 94, no. 10, pp. 3413-3420, 1999.
[85] E. Porreca, C. Di Febbo, A. di Castelnuovo et al., "Association of factor VII levels with inflammatory parameters in hypercholesterolemic patients," Atherosclerosis, vol. 165, no. 1, pp. 159-166, 2002.

[86] H. Xu, V. A. Ploplis, and F. J. Castellino, "A coagulation factor VII deficiency protects against acute inflammatory responses in mice," Journal of Pathology, vol. 210, no. 4, pp. 488-496, 2006.

[87] E. De Jonge, P. W. Friederich, G. P. Vlasuk et al., "Activation of coagulation by administration of recombinant factor VIIa elicits interleukin 6 (IL-6) and IL-8 release in healthy human subjects," Clinical and Diagnostic Laboratory Immunology, vol. 10, no. 3, pp. 495-497, 2003.

[88] E. K. Kruithof, D. Agay, J. C. Mestries, M. P. Gascon, and A. Ythier, "The effect of factor Xa/phospholipid infusion on the acute phase response in baboons," Journal of Thrombosis and Haemostasis, vol. 77, no. 2, pp. 308-311, 1997.

[89] K. McLean, S. Schirm, A. Johns, J. Morser, and D. R. Light, "FXa-induced responses in vascular wall cells are PAR-mediated and inhibited by ZK-807834," Thrombosis Research, vol. 103, no. 4, pp. 281-297, 2001.

[90] N. H. Senden, T. M. Jeunhomme, J. W. Heemskerk et al., "Factor Xa induces cytokine production and expression of adhesion molecules by human umbilical vein endothelial cells," Journal of Immunology, vol. 161, no. 8, pp. 4318-4324, 1998.

[91] F. M. Szaba and S. T. Smiley, "Roles for thrombin and fibrin(ogen) in cytokine/chemokine production and macrophage adhesion in vivo," Blood, vol. 99, no. 3, pp. 1053-1059, 2002.

[92] K. Johnson, Y. Choi, E. DeGroot, I. Samuels, A. Creasey, and L. Aarden, "Potential mechanisms for a proinflammatory vascular cytokine response to coagulation activation," Journal of Immunology, vol. 160, no. 10, pp. 5130-5135, 1998.

[93] Y. Hirota, Y. Osuga, O. Yoshino et al., "Possible roles of thrombin-induced activation of protease-activated receptor 1 in human luteinized granulosa cells," Journal of Clinical Endocrinology and Metabolism, vol. 88, no. 8, pp. 3952-3957, 2003.

[94] M. Caunt, Y. Q. Huang, P. C. Brooks, and S. Karpatkin, "Thrombin induces neoangiogenesis in the chick chorioallantoic membrane," Journal of Thrombosis and Haemostasis, vol. 1, no. 10, pp. 2097-2102, 2003.

[95] T. Arisato, K. P. Sarker, K. Kawahara et al., "The agonist of the protease-activated receptor-1 (PAR1) but not PAR3 mimics thrombin-induced vascular endothelial growth factor release in human vascular smooth muscle cells," Cellular and Molecular Life Sciences, vol. 60, no. 8, pp. 1716-1724, 2003.

[96] G. Kaplanski, V. Marin, M. Fabrigoule et al., “Thrombinactivated human endothelial cells support monocyte adhesion in vitro following expression of intercellular adhesion molecule-1 $\left(\mathrm{ICAM}_{-1} ; \mathrm{CD}_{54}\right)$ and vascular cell adhesion molecule-1 (VCAM $\left.-1 ; \mathrm{CD}_{106}\right)$," Blood, vol. 92, no. 4, pp. 1259-1267, 1998.

[97] A. R. Gear and D. Camerini, "Platelet chemokines and chemokine receptors: linking hemostasis, inflammation, and host defense," Microcirculation, vol. 10, no. 3-4, pp. 335-350, 2003.

[98] M. E. Lee, S. M. Kweon, and S. U. Nham, "Fibrin stimulates microfilament reorganization and IL- $1 \beta$ production in human monocytic THP-1 cells," Molecules and Cells, vol. 11, no. 1, pp. 13-20, 2001.

[99] X. Liu and T. H. Piela-Smith, "Fibrin(ogen)-induced expression of ICAM-1 and chemokines in human synovial 
fibroblasts," Journal of Immunology, vol. 165, no. 9, pp. 5255-5261, 2000.

[100] S. C. Robson, E. G. Shephard, and R. E. Kirsch, "Fibrin degradation product $\mathrm{D}$-dimer induces the synthesis and release of biologically active IL- $1 \beta$, IL- 6 and plasminogen activator inhibitors from monocytes in vitro," British Journal of Haematology, vol. 86, no. 2, pp. 322-326, 1994.

[101] M. Hamaguchi, Y. Morishita, I Takahashi, M. Ogura, J. Takamatsu, and H. Saito, "FDP D-dimer induces the secretion of interleukin-1, urokinase-type-plasminogen activator, and plasminiogen activator inhibitor-2 in a human promonocytic leukiemia cell line," Blood, vol. 77, no. 1, pp. 94-100, 1991.

[102] M. Csala, I. Léránt, G. Bánhegyi et al., "Prostaglandinindependent stimulation of interleukin-6 production by fibrinogen degradation product D in perfused murine liver," Scandinavian Journal of Immunology, vol. 48, no. 3, pp. 269-271, 1998.

[103] M. E. Lee, K. J. Rhee, and S. U. Nham, "Fragment E derived from both fibrin fibrinogen stimulates interleukin-6 production in rat peritoneal macrophages," Molecules and Cells, vol. 9, no. 1, pp. 7-13, 1999.

[104] R. C. Chambers and G. J. Laurent, "Coagulation cascade proteases and tissue fibrosis," Biochemical Society Transactions, vol. 30, no. 2, pp. 194-200, 2002.

[105] R. Ramachandran and M. D. Hollenberg, "Proteinases and signalling: pathophysiological and therapeutic implications via PARs and more," British Journal of Pharmacology, vol. 153, no. 1, pp. S263-S282, 2008.

[106] M. Riewald and W. Ruf, "Mechanistic coupling of protease signaling and initiation of coagulation by tissue factor," Proceedings of the National Academy of Sciences of the United States of America, vol. 98, no. 14, pp. 7742-7747, 2001.

[107] N. Asokananthan, P. T. Graham, J. Fink et al., "Activation of protease-activated receptor (PAR)-1, PAR-2, and PAR-4 stimulates IL-6, IL-8, and prostaglandin $\mathrm{E}_{2}$ release from human respiratory epithelial cells," Journal of Immunology, vol. 168, no. 7, pp. 3577-3585, 2002.

[108] V. Temkin, B. Kantor, V. Weg, M. L. Hartman, and F. LeviSchaffer, "Tryptase activates the mitogen-activated protein kinase/activator protein-1 pathway in human peripheral blood eosinophils, causing cytokine production and release," Journal of Immunology, vol. 169, no. 5, pp. 2662-2669, 2002.

[109] Y. Kida, H. Inoue, T. Shimizu, and K. Kuwano, "Serratia marcescens serralysin induces inflammatory responses through protease-activated receptor 2," Infection and Immunity, vol. 75, no. 1, pp. 164-174, 2007.

[110] E. B. Kelso, W. R. Ferrell, J. C. Lockhart et al., "Expression and proinflammatory role of proteinase-activated receptor 2 in rheumatoid synovium: ex vivo studies using a novel proteinase-activated receptor 2 antagonist," Arthritis and Rheumatism, vol. 56, no. 3, pp. 765-771, 2007.

[111] M. S. Kim, H. Jo, J. Y. Um et al., "Agonists of proteinaseactivated receptor 2 induce TNF- $\alpha$ secretion from astrocytoma cells," Cell Biochemistry and Function, vol. 20, no. 4, pp. 339-345, 2002.

[112] R. Ramachandran, A. H. Morice, and S. J. Compton, "Proteinase-activated receptor2 agonists upregulate granulocyte colony-stimulating factor, IL-8, and VCAM-1 expression in human bronchial fibroblasts," American Journal of Respiratory Cell and Molecular Biology, vol. 35, no. 1, pp. 133-141, 2006.

[113] E. J. Mackie, C. N. Pagel, R. Smith, M. R. de Niese, S. J. Song, and R. N. Pike, "Protease-activated receptors: a means of converting extracellular proteolysis into intracellular signals," IUBMB Life, vol. 53, no. 6, pp. 277-281, 2002.

[114] F.-J. Neumann, I. Ott, N. Marx et al., "Effect of human recombinant interleukin- 6 and interleukin- 8 on monocyte procoagulant activity," Arteriosclerosis, Thrombosis, and Vascular Biology, vol. 17, no. 12, pp. 3399-3405, 1997.

[115] E. K. Kruithof, J. C. Mestries, M.-P. Gascon, and A. Ythier, "The coagulation and fibrinolytic responses of baboons after in vivo thrombin generation-effect of interleukin 6," Journal of Thrombosis and Haemostasis, vol. 77, no. 5, pp. 905-910, 1997.

[116] K. Kambas, M. M. Markiewski, I. A. Pneumatikos et al., "C5a and TNF- $\alpha$ up-regulate the expression of tissue factor in intra-alveolar neutrophils of patients with the acute respiratory distress syndrome," Journal of Immunology, vol. 180, no. 11, pp. 7368-7375, 2008.

[117] J. Wu, M. J. Stevenson, J. M. Brown, E. A. Grunz, T. L. Strawn, and W. P. Fay, "C-reactive protein enhances tissue factor expression by vascular smooth muscle cells: mechanisms and in vivo significance," Arteriosclerosis, Thrombosis, and Vascular Biology, vol. 28, no. 4, pp. 698-704, 2008.

[118] J.-S. Kim, D.-W. Park, H.-K. Lee, J.-R. Kim, and S.-H. Baek, "Early growth response-1 is involved in foam cell formation and is upregulated by the TLR9-MyD88-ERK1/2 pathway," Biochemical and Biophysical Research Communications, vol. 390, no. 2, pp. 196-200, 2009.

[119] E. Napoleone, A. di Santo, G. Peri et al., "The long pentraxin $\mathrm{PTX}_{3}$ up-regulates tissue factor in activated monocytes: another link between inflammation and clotting activation," Journal of Leukocyte Biology, vol. 76, no. 1, pp. 203-209, 2004.

[120] C. Gebhard, S. F. Stämpfli, C. E. Gebhard et al., "Guggulsterone, an anti-inflammatory phytosterol, inhibits tissue factor and arterial thrombosis," Basic Research in Cardiology, vol. 104, no. 3, pp. 285-294, 2009.

[121] E. Camerer, J.-A. Røttingen, E. Gjernes et al., "Coagulation factors VIIa and Xa induce cell signaling leading to upregulation of the egr-1 gene," Journal of Biological Chemistry, vol. 274, no. 45, pp. 32225-32233, 1999.

[122] K. Akahane, K. Okamoto, M. Kikuchi et al., "Inhibition of factor Xa suppresses the expression of tissue factor in human monocytes and lipopolysaccharide-induced endotoxemia in rats," Surgery, vol. 130, no. 5, pp. 809-818, 2001.

[123] R. Jiang, N. P. Wang, K. A. Tanaka et al., "Factor Xa induces tissue factor expression in endothelial cells by $\mathrm{P} 44 / 42$ MAPK and NF- $\kappa$ B-dependent pathways," Journal of Surgical Research, vol. 169, no. 2, pp. 319-327, 2011.

[124] D. Chen, K. Riesbeck, J. H. McVey et al., "Human thrombin and FXa mediate porcine endothelial cell activation; modulation by expression of TFPI-CD4 and hirudin-CD4 fusion proteins," Xenotransplantation, vol. 8, no. 4, pp. 258-265, 2001

[125] C. Banfi, M. Brioschi, S. Barcella et al., "Tissue factor induction by protease-activated receptor 1 requires intact caveolin-enriched membrane microdomains in human endothelial cells," Journal of Thrombosis and Haemostasis, vol. 5, no. 12, pp. 2437-2444, 2007.

[126] F. Langer, C. Morys-Wortmann, B. Küsters, and J. Storck, "Endothelial protease-activated receptor-2 induces tissue factor expression and von Willebrand factor release," British Journal of Haematology, vol. 105, no. 2, pp. 542-550, 1999.

[127] M. Haubitz, M. Gerlach, H. J. Kruse, and R. Brunkhorst, "Endothelial tissue factor stimulation by proteinase 3 and elastase," Clinical and Experimental Immunology, vol. 126, no. 3, pp. 584-588, 2001. 
[128] N. M. Caplice, C. S. Mueske, L. S. Kleppe, and R. D. Simari, "Presence of tissue factor pathway inhibitor in human atherosclerotic plaques is associated with reduced tissue factor activity," Circulation, vol. 98, no. 11, pp. 1051-1057, 1998.

[129] A. Hamik, H. Setiadi, G. Bu, R. P. McEver, and J. H. Morrissey, "Down-regulation of monocyte tissue factor mediated by tissue factor pathway inhibitor and the low density lipoprotein receptor-related protein," Journal of Biological Chemistry, vol. 274, no. 8, pp. 4962-4969, 1999.

[130] I. Ott, Y. Miyagi, K. Miyazaki et al., "Reversible regulation of tissue factor-induced coagulation by glycosyl phosphatidylinositol-anchored tissue factor pathway inhibitor," Arteriosclerosis, Thrombosis, and Vascular Biology, vol. 20, no. 3, pp. 874-882, 2000.

[131] D. L. Miller, K. Welty-Wolf, M. S. Carraway et al., "Extrinsic coagulation blockade attenuates lung injury and proinflammatory cytokine release after intratracheal lipopolysaccharide," American Journal of Respiratory Cell and Molecular Biology, vol. 26, no. 6, pp. 650-658, 2002.

[132] E. Lindmark and A. Siegbahn, "Tissue factor regulation and cytokine expression in monocyte-endothelial cell co-cultures: effects of a statin, an ACE-inhibitor and a low-molecular-weight heparin," Thrombosis Research, vol. 108, no. 1, pp. 77-84, 2002.

[133] T. Pernerstorfer, U. Hollenstein, J. B. Hansen et al., "Heparin blunts endotoxin-induced coagulation activation," Circulation, vol. 100, no. 25, pp. 2485-2490, 1999.

[134] A. M. Gori, G. Pepe, M. Attanasio et al., "Tissue factor reduction and tissue factor pathway inhibitor release after heparin administration," Journal of Thrombosis and Haemostasis, vol. 81, no. 4, pp. 589-593, 1999.

[135] S. D. Gertz, J. T. Fallon, R. Gallo et al., "Hirudin reduces tissue factor expression in neointima after ballon injury in rabbit femoral and porcine coronary arteies," Circulation, vol. 98, pp. 580-587, 1998.

[136] H. Hölschermann, R. M. Bohle, H. Schmidt et al., "Hirudin reduces tissue factor expression and attenuates graft arteriosclerosis in rat cardiac allografts," Circulation, vol. 102, no. 3, pp. 357-363, 2000.

[137] X. Chen, S. Ren, M. G. Ma et al., "Hirulog-like peptide reduces restenosis and expression of tissue factor and transforming growth factor- $\beta$ in carotid artery of atherosclerotic rabbits," Atherosclerosis, vol. 169, no. 1, pp. 31-40, 2003.

[138] P. J. Souter, S. Thomas, A. R. Hubbard, S. Poole, J. Römisch, and E. Gray, "Antithrombin inhibits lipopolysaccharideinduced tissue factor and interleukin-6 production by mononuclear cells, human umbilical vein endothelial cells, and whole blood," Critical Care Medicine, vol. 29, no. 1, pp. 134-139, 2001.

[139] F. Shu, H. Kobayashi, K. Fukudome, N. Tsuneyoshi, M. Kimoto, and T. Terao, "Activated protein C suppresses tissue factor expression on U937 cells in the endothelial protein C receptor-dependent manner," FEBS Letters, vol. 477, no. 3, pp. 208-212, 2000.

[140] V. V. Sullivan, A. E. Hawley, D. M. Farris et al., "Decrease in fibrin content of venous thrombi in selectin-deficient mice," Journal of Surgical Research, vol. 109, no. 1, pp. 1-7, 2003.

[141] P. Libby and D. I. Simon, "Inflammation and thrombosis: the clot thickens," Circulation, vol. 103, no. 13, pp. 1718-1720, 2001.

[142] P. K. Henke, T. W. Wakefield, A. M. Kadell et al., "Interleukin8 administration enhances venous thrombosis resolution in a rat model," Journal of Surgical Research, vol. 99, no. 1, pp. 84-91, 2001.
[143] M. D. Hollenberg, M. Saifeddine, S. Sandhu, S. Houle, and N. Vergnolle, "Proteinase-activated receptor-4: evaluation of tethered ligand-derived peptides as probes for receptor function and as inflammatory agonists in vivo," British Journal of Pharmacology, vol. 143, no. 4, pp. 443-454, 2004.

[144] T. Palabrica, R. Lobb, B. C. Furie et al., "Leukocyte accumulation promoting fibrin deposition is mediated in vivo by P-selectin on adherent platelets," Nature, vol. 359, no. 6398, pp. 848-851, 1992.

[145] P. Tan, F. W. Luscinskas, and S. Homer-Vanniasinkam, "Cellular and molecular mechanisms of inflammation and thrombosis," European Journal of Vascular and Endovascular Surgery, vol. 17, no. 5, pp. 373-389, 1999.

[146] P. Thanaporn, D. D. Myers, S. K. Wrobleski et al., "P-selectin inhibition decreases post-thrombotic vein wall fibrosis in a rat model," Surgery, vol. 134, no. 2, pp. 365-371, 2003.

[147] J. F. Murphy and J. L. McGregor, "A peptide (P2) derived from the variable heavy chain of an anti-P-selectin monoclonal antibody (LYP20) inhibits leucocyte adhesion to thrombin-activated platelets and endothelial cells," British Journal of Haematology, vol. 120, no. 4, pp. 605-610, 2003.

[148] C. F. Toombs, G. L. Degraaf, J. P. Martin, J. G. Geng, D. C. Anderson, and R. J. Shebuski, "Pretreatment with a blocking monoclonal antibody to P-selectin accelerates pharmacological thrombolysis in a primate model of arterial thrombosis," Journal of Pharmacology and Experimental Therapeutics, vol. 275, no. 2, pp. 941-949, 1995.

[149] T. W. Wakefield, R. M. Strieter, C. A. Wilke et al., "Venous thrombosis-associated inflammation and attenuation with neutralizing antibodies to cytokines and adhesion molecules," Arteriosclerosis, Thrombosis, and Vascular Biology, vol. 15, no. 2, pp. 258-268, 1995.

[150] M. Hayden, M. Pignone, C. Phillips, and C. Mulrow, "Aspirin for the primary prevention of cardiovascular events: a summary of the evidence for the U.S. Preventive services task force," Annals of Internal Medicine, vol. 136, no. 2, pp. 161-172, 2002.

[151] B. Pitt, C. Penine, and J. T. Willerson, "Cyclooxygenase-2 inhibition and cardiovascular events," Circulation, vol. 106, no. 2, pp. 167-169, 2002.

[152] P. Cirillo, P. Golino, P. Calabrò et al., "Activated platelets stimulate tissue factor expression in smooth muscle cells," Thrombosis Research, vol. 112, no. 1-2, pp. 51-57, 2003.

[153] H. Deguchi, H. Takeya, H. Wada et al., "Dilazep, an antiplatelet agent, inhibits tissue factor expression in endothelial cells and monocytes," Blood, vol. 90, no. 6, pp. 2345-2356, 1997.

[154] M. A. Krupiczojc, C. J. Scotton, and R. C. Chambers, "Coagulation signalling following tissue injury: focus on the role of factor Xa," International Journal of Biochemistry and Cell Biology, vol. 40, no. 6-7, pp. 1228-1237, 2008.

[155] S. Danese, A. Papa, S. Saibeni, A. Repici, A. Malesci, and M. Vecchi, "Inflammation and coagulation in inflammatory bowel disease: the clot thickens," American Journal of Gastroenterology, vol. 102, no. 1, pp. 174-186, 2007.

[156] M. Levi, T. van der Poll, and H. Ten Cate, "Tissue factor in infection and severe inflammation," Seminars in Thrombosis and Hemostasis, vol. 32, no. 1, pp. 33-39, 2006.

[157] S. Gando, "Tissue factor in trauma and organ dysfunction," Seminars in Thrombosis and Hemostasis, vol. 32, no. 1, pp. 48-53, 2006.

[158] C. Lupu, A. D. Westmuckett, G. Peer et al., "Tissue factordependent coagulation is preferentially up-regulated within arterial branching areas in a baboon model of Escherichia 
coli sepsis," American Journal of Pathology, vol. 167, no. 4, pp. 1161-1172, 2005.

[159] M. S. Carraway, K. E. Welty-Wolf, D. L. Miller et al., "Blockade of tissue factor: treatment for organ injury in established sepsis," American Journal of Respiratory and Critical Care Medicine, vol. 167, no. 9, pp. 1200-1209, 2003.

[160] K. Uno, S. Homma, T. Satoh et al., "Tissue factor expression as a possible determinant of thromboembolism in ovarian cancer," British Journal of Cancer, vol. 96, no. 2, pp. 290-295, 2007.

[161] G. Krikun, F. Schatz, H. Taylor, and C. J. Lockwood, "Endometriosis and tissue factor," Annals of the New York Academy of Sciences, vol. 1127, pp. 101-105, 2008.

[162] T. Ueno, M. Toi, M. Koike, S. Nakamura, and T. Tominaga, "Tissue factor expression in breast cancer tissues: its correlation with prognosis and plasma concentration," British Journal of Cancer, vol. 83, no. 2, pp. 164-170, 2000.

[163] S. Regina, J. Rollin, C. Bléchet, S. Iochmann, P. Reverdiau, and Y. Gruel, "Tissue factor expression in non-small cell lung cancer: relationship with vascular endothelial growth factor expression, microvascular density, and K-ras mutation," Journal of Thoracic Oncology, vol. 3, no. 7, pp. 689-697, 2008.

[164] V. Kaushal, P. Mukunyadzi, E. R. Siegel, R. A. Dennis, D. E. Johnson, and M. Kohli, "Expression of tissue factor in prostate cancer correlates with malignant phenotype," Applied Immunohistochemistry and Molecular Morphology, vol. 16, no. 1, pp. 1-6, 2008.

[165] A. A. Khorana, S. A. Ahrendt, C. K. Ryan et al., "Tissue factor expression, angiogenesis, and thrombosis in pancreatic cancer," Clinical Cancer Research, vol. 13, no. 10, pp. 2870-2875, 2007.

[166] C. Kirszberg, L. G. Lima, A. Da Silva de Oliveira et al., "Simultaneous tissue factor expression and phosphatidylserine exposure account for the highly procoagulant pattern of melanoma cell lines," Melanoma Research, vol. 19, no. 5, pp. 301-308, 2009.

[167] C. Shigemori, H. Wada, K. Matsumoto, H. Shiku, S. Nakamura, and H. Suzuki, "Tissue factor expression and metastatic potential of colorectal cancer," Journal of Thrombosis and Haemostasis, vol. 80, no. 6, pp. 894-898, 1998.

[168] M. Z. Wojtukiewicz, E. Sierko, L. R. Zacharski, L. Zimnoch, B. Kudryk, and W. Kisiel, "Tissue factor-dependent coagulation activation and impaired fibrinolysis in situ in gastric cancer," Seminars in Thrombosis and Hemostasis, vol. 29, no. 3, pp. 291-299, 2003.

[169] F. S. Ribeiro, T. A. Simão, N. D. Amoêdo et al., "Evidence for increased expression of tissue factor and protease-activated receptor-1 in human esophageal cancer," Oncology Reports, vol. 21, no. 6, pp. 1599-1604, 2009.

[170] R. T. Poon, C. P. Lau, J. W. Ho, W. C. Yu, S. T. Fan, and J. Wong, "Tissue factor expression correlates with tumor angiogenesis and invasiveness in human hepatocellular carcinoma," Clinical Cancer Research, vol. 9, no. 14, pp. 5339-5345, 2003.

[171] S. Dützmann, F. Gessler, P. N. Harter et al., "The promigratory and pro-invasive role of the procoagulant tissue factor in malignant gliomas," Cell Adhesion and Migration, vol. 4, no. 4, pp. 515-522, 2010.

[172] G. A. Hair, S. Padula, R. Zeff et al., "Tissue factor expression in human leukemic cells," Leukemia Research, vol. 20, no. 1, pp. $1-11,1996$.

[173] H. Wada, T. Sase, and M. Yamaguchi, "Hypercoagulant states in malignant lymphoma," Experimental Oncology, vol. 27, no. 3, pp. 179-185, 2005.
[174] Y. Förster, A. Meye, S. Albrecht, and B. Schwenzer, "Tissue factor and tumor: clinical and laboratory aspects," Clinica Chimica Acta, vol. 364, no. 1-2, pp. 12-21, 2006.

[175] F. R. Rickles, "Mechanisms of cancer-induced thrombosis in cancer," Pathophysiology of Haemostasis and Thrombosis, vol. 35, no. 1-2, pp. 103-110, 2006.

[176] M. A. Kurer, "Protein and mRNA expression of tissue factor pathway inhibitor-1 (TFPI-1) in breast, pancreatic and colorectal cancer cells," Molecular Biology Reports, vol. 34, no. 4, pp. 221-224, 2007.

[177] M. E. Tesselaar, F. P. Romijn, I. K. Van Der Linden, F. A. Prins, R. M. Bertina, and S. Osanto, "Microparticleassociated tissue factor activity: a link between cancer and thrombosis?" Journal of Thrombosis and Haemostasis, vol. 5, no. 3, pp. 520-527, 2007.

[178] D. Garnier, C. Milsom, N. Magnus et al., "Role of the tissue factor pathway in the biology of tumor initiating cells," Thrombosis Research, vol. 125, pp. S44-S50, 2010.

[179] H. H. Versteeg, F. Schaffner, M. Kerver et al., "Inhibition of tissue factor signaling suppresses tumor growth," Blood, vol. 111, no. 1, pp. 190-199, 2008.

[180] J. Rak, C. Milsom, L. May, P. Klement, and J. Yu, “Tissue factor in cancer and angiogenesis: the molecular link between genetic tumor progression, tumor neovascularization, and cancer coagulopathy," Seminars in Thrombosis and Hemostasis, vol. 32, no. 1, pp. 54-70, 2006.

[181] F. Schaffner, H. H. Versteeg, A. Schillert et al., "Cooperation of tissue factor cytoplasmic domain and PAR2 signaling in breast cancer development," Blood, vol. 116, no. 26, pp. 6106-6113, 2010.

[182] A. R. Radjabi, K. Sawada, S. Jagadeeswaran et al., "Thrombin induces tumor invasion through the induction and association of matrix metalloproteinase- 9 and $\beta 1$-integrin on the cell surface," Journal of Biological Chemistry, vol. 283, no. 5, pp. 2822-2834, 2008.

[183] Y. Rong, D. E. Post, R. O. Pieper, D. L. Durden, E. G. Van Meir, and D. J. Brat, "PTEN and hypoxia regulate tissue factor expression and plasma coagulation by glioblastoma," Cancer Research, vol. 65, no. 4, pp. 1406-1413, 2005.

[184] D. F. Altomare, M. T. Rotelli, A. Pentimone et al., "Tissue factor and vascular endothelial growth factor expression in colorectal cancer: relation with cancer recurrence," Colorectal Disease, vol. 9, no. 2, pp. 133-138, 2007.

[185] K. Abe, M. Shoji, J. Chen et al., "Regulation of vascular endothelial growth factor production and angiogenesis by the cytoplasmic tail of tissue factor," Proceedings of the National Academy of Sciences of the United States of America, vol. 96, no. 15, pp. 8663-8668, 1999.

[186] C. Li, M. E. Collier, G. A. Frentzou, J. Greenman, and C. Ettelaie, "Investigation of the mechanisms of tissue factormediated evasion of tumour cells from cellular cytotoxicity," Cancer Immunology, Immunotherapy, vol. 57, no. 9, pp. 1347-1355, 2008.

[187] W. Ruf, "Molecular regulation of blood clotting in tumor biology," Haemostasis, vol. 31, pp. 5-7, 2001.

[188] J. Fang, L. Gu, N. Zhu, H. Tang, C. S. Alvarado, and M. Zhou, "Tissue factor/FVIIa activates Bcl-2 and prevents doxorubicin-induced apoptosis in neuroblastoma cells," BMC Cancer, vol. 8, article no. 69, 2008.

[189] H. H. Versteeg, C. A. Spek, D. J. Richel, and M. P. Peppelenbosch, "Coagulation factors VIIa and Xa inhibit apoptosis and anoikis," Oncogene, vol. 23, no. 2, pp. 410-417, 2004.

[190] X. Jiang, Y. L. Guo, and M. E. Bromberg, "Formation of tissue factor-factor VIIa-factor Xa complex prevents apoptosis in 
human breast cancer cells," Journal of Thrombosis and Haemostasis, vol. 96, no. 2, pp. 196-201, 2006.

[191] X. Jiang, S. Zhu, T. S. Panetti, and M. E. Bromberg, "Formation of tissue factor-factor VIIa-factor Xa complex induces activation of the mTOR pathway which regulates migration of human breast cancer cells," Journal of Thrombosis and Haemostasis, vol. 100, no. 1, pp. 127-133, 2008.

[192] M. L. Nierodzik and S. Karpatkin, "Thrombin induces tumor growth, metastasis, and angiogenesis: evidence for a thrombin-regulated dormant tumor phenotype," Cancer Cell, vol. 10, no. 5, pp. 355-362, 2006.

[193] S. Dützmann, F. Gessler, P. N. Harter et al., "The promigratory and pro-invasive role of the procoagulant tissue factor in malignant gliomas," Cell Adhesion and Migration, vol. 4, no. 4, pp. 515-522, 2010.

[194] D. Green and S. Karpatkin, "Role of thrombin as a tumor growth factor," Cell Cycle, vol. 9, no. 4, pp. 656-661, 2010.

[195] L. Hu, S. Ibrahim, C. Liu, J. Skaar, M. Pagano, and S. Karpatkin, "Thrombin induces tumor cell cycle activation and spontaneous growth by down-regulation of p27kip1, in association with the up-regulation of skp2 and mir-222," Cancer Research, vol. 69, no. 8, pp. 3374-3381, 2009.

[196] L. Hu, J. M. Roth, P. Brooks, J. Luty, and S. Karpatkin, "Thrombin up-regulates cathepsin D which enhances angiogenesis, growth, and metastasis," Cancer Research, vol. 68, no. 12, pp. 4666-4673, 2008.

[197] W. Ruf and B. M. Mueller, "Thrombin generation and the pathogenesis of cancer," Seminars in Thrombosis and Hemostasis, vol. 32, supplement 1, pp. 61-68, 2006.

[198] F. Samad, M. Pandey, and D. J. Loskutoff, "Tissue factor gene expression in the adipose tissues of obese mice," Proceedings of the National Academy of Sciences of the United States of America, vol. 95, no. 13, pp. 7591-7596, 1998.

[199] F. Samad, M. Pandey, and D. J. Loskutoff, "Regulation of tissue factor gene expression in obesity," Blood, vol. 98, no. 12, pp. 3353-3358, 2001.

[200] K. Popko, E. Gorska, A. Stelmaszczyk-Emmel et al., "Proinflammatory cytokines Il- 6 and TNF- $\alpha$ and the development of inflammation in obese subjects," European journal of medical research, vol. 15, supplement 2, pp. 120-122, 2010.

[201] C. S. Tam, S. P. Garnett, C. T. Cowell et al., "IL-6, IL-8 and IL-10 levels in healthy weight and overweight children," Hormone Research in Paediatrics, vol. 73, no. 2, pp. 128-134, 2010.

[202] T. Tzanavari, P. Giannogonas, and K. P. Karalis, "TNF- $\alpha$ and obesity," Current Directions in Autoimmunity, vol. 11, pp. 145-156, 2010.

[203] M. E. Carr, "Diabetes mellitus: a hypercoagulable state," Journal of Diabetes and its Complications, vol. 15, no. 1, pp. 44-54, 2001.

[204] M. Massi-Benedetti and M. O. Federici, "Cariovascular risk factors in type 2 diabetes: the role of hyperglycaemia," Experimental and Clinical Endocrinology \& Diabetes, vol. 107, pp. S120-S123, 1999.

[205] K. Ichikawa, M. Yoshinari, M. Iwase et al., "Advanced glycosylation end products induced tissue factor expression in human monocyte-like U937 cells and increased tissue factor expression in monocytes from diabetic patients," Atherosclerosis, vol. 136, no. 2, pp. 281-287, 1998.

[206] C. Ettelaie, S. Su, C. Li, and M. E. Collier, "Tissue factorcontaining microparticles released from mesangial cells in response to high glucose and AGE induce tube formation in microvascular cells," Microvascular Research, vol. 76, no. 3, pp. 152-160, 2008.
[207] A. J. Gerrits, C. A. Koekman, T. W. van Haeften, and J. W. Akkerman, "Platelet tissue factor synthesis in type 2 diabetic patients is resistant to inhibition by insulin," Diabetes, vol. 59, no. 6, pp. 1487-1495, 2010.

[208] J. Calles-Escandon, E. Garcia-Rubi, S. Mirza, and A. Mortensen, "Type 2 diabetes: one disease, multiple cardiovascular risk factors," Coronary Artery Disease, vol. 10, no. 1, pp. 23-30, 1999.

[209] Action to Control Cardiovascular Risk in Diabetes Study Group, H. C. Gerstein, M. E. Miller et al., "Effects of intensive glucose lowering in type 2 diabetes," The New England Journal of Medicine, vol. 358, no. 24, pp. 2545-2559, 2008.

[210] Advance Collaborative Group, A. Patel, S. MacMahon et al., "Intensive blood glucose control and vascular outcomes in patients with type 2 diabetes," The New England Journal of Medicine, vol. 358, no. 24, pp. 2560-2572, 2008.

[211] W. Duckworth, C. Abraira, T. Moritz et al., "Glucose control and vascular complications in veterans with type 2 diabetes," The New England Journal of Medicine, vol. 360, no. 2, pp. 129-139, 2009.

[212] S. E. Nissen and K. Wolski, "Effect of rosiglitazone on the risk of myocardial infarction and death from cardiovascular causes," The New England Journal of Medicine, vol. 356, no. 24, pp. 2457-2471, 2007.

[213] C. Garcia, B. Feve, P. Ferré et al., "Diabetes and inflammation: fundamental aspects and clinical implications," Diabetes \& Metabolism, vol. 36, no. 5, pp. 327-338, 2010.

[214] J. K. Kim, "Inflammation and insulin resistance: an old story with new ideas," Diabetes and Metabolism Journal, vol. 34, pp. 137-145, 2010.

[215] Z. Gao, A. Zuberi, M. J. Quon, Z. Dong, and J. Ye, “Aspirin inhibits serine phosphorylation of insulin receptor substrate 1 in tumor necrosis factor-treated cells through targeting multiple serine kinases," Journal of Biological Chemistry, vol. 278, no. 27, pp. 24944-24950, 2003.

[216] A. Isada, S. Konno, N. Hizawa et al., "A functional polymorphism $(-603 \mathrm{~A} \rightarrow \mathrm{G})$ in the tissue factor gene promoter is associated with adult-onset asthma," Journal of Human Genetics, vol. 55, no. 3, pp. 167-174, 2010.

[217] R. Ross, "Atherosclerosis - an inflammatory disease," The New England Journal of Medicine, vol. 340, no. 2, pp. 115-126, 1999.

[218] A. C. van der Wal, X. Li, and O. J. de Boer, "Tissue factor expression in the morphologic spectrum of vulnerable atherosclerotic plaques," Seminars in Thrombosis and Hemostasis, vol. 32, no. 1, pp. 40-47, 2006.

[219] N. Mackman, "Role of tissue factor in hemostasis, thrombosis, and vascular development," Arteriosclerosis, Thrombosis, and Vascular Biology, vol. 24, no. 6, pp. 1015-1022, 2004.

[220] A. Celi, S. Cianchetti, G. Dell'omo, and R. Pedrinelli, "Angiotensin II, tissue factor and the thrombotic paradox of hypertension," Expert Review of Cardiovascular Therapy, vol. 8, no. 12, pp. 1723-1729, 2010.

[221] G. Alkistis Frentzou, M. E. Collier, A. M. Seymour, and C. Ettelaie, "Differential induction of cellular proliferation, hypertrophy and apoptosis in H9c2 cardiomyocytes by exogenous tissue factor," Molecular and Cellular Biochemistry, vol. 345, no. 1-2, pp. 119-130, 2010.

[222] I. Ott, "Tissue factor in acute coronary syndromes," Seminars in Vascular Medicine, vol. 3, no. 2, pp. 185-192, 2003.

[223] B. Jude, C. Zawadzki, S. Susen, and D. Corseaux, "Relevance of tissue factor in cardiovascular disease," Archives des Maladies du Coeur et des Caisseaux, vol. 98, no. 6, pp. 667-671, 2005. 
[224] B. Freestone, A. Y. Chong, H. S. Lim, A. Blann, and G. Y. H. Lip, "Angiogenic factors in a trial fibrillation: a possible role in thrombogenesis?" Annals of Medicine, vol. 37, no. 5, pp. 365-372, 2005.

[225] J. Steffel, A. Akhmedov, H. Greutert, T. F. Lüscher, and F. C. Tanner, "Histamine induces tissue factor expression: implications for acute coronary syndromes," Circulation, vol. 112, no. 3, pp. 341-349, 2005.

[226] D. R. Davis and J. H. Erlich, "Cardiac tissue factor: roles in physiology and fibrosis," Clinical and Experimental Pharmacology and Physiology, vol. 35, no. 3, pp. 342-348, 2008.

[227] R. Pawlinski, A. Fernandes, B. Kehrle et al., "Tissue factor deficiency causes cardiac fibrosis and left ventricular dysfunction," Proceedings of the National Academy of Sciences of the United States of America, vol. 99, no. 24, pp. 15333-15338, 2002.

[228] H. Zhou, Y. Yan, G. Xu et al., "Toll-like receptor (TLR)-4 mediates anti- $\beta_{2}$ GPI $/ \beta_{2}$ GPI-induced tissue factor expression in THP-1 cells," Clinical and Experimental Immunology, vol. 163, no. 2, pp. 189-198, 2011.

[229] I. Cavazzana, N. Manuela, C. Irene et al., "Complement activation in anti-phospholipid syndrome: a clue for an inflammatory process?" Journal of Autoimmunity, vol. 28, no. 2-3, pp. 160-164, 2007.

[230] J. Swadzba, T. Iwaniec, and J. Musial, "Increased level of tumor necrosis factor- $\alpha$ in patients with antiphospholipid syndrome: marker not only of inflammation but also of the prothrombotic state," Rheumatology International, vol. 31, no. 3, pp. 307-313, 2009.

[231] D. Tanne, A. Katzav, O. Beilin et al., "Interaction of inflammation, thrombosis, aspirin and enoxaparin in CNS experimental antiphospholipid syndrome," Neurobiology of Disease, vol. 30, no. 1, pp. 56-64, 2008.

[232] J. Berman, G. Girardi, and J. E. Salmon, "TNF- $\alpha$ is a critical effector and a target for therapy in antiphospholipid antibody-induced pregnancy loss," Journal of Immunology, vol. 174, no. 1, pp. 485-490, 2005.

[233] P. R. Ames, I. Antinolfi, A. Ciampa et al., "Primary antiphospholipid syndrome: a low-grade auto-inflammatory disease?" Rheumatology, vol. 47, no. 12, pp. 1832-1837, 2008.

[234] G. Girardi, "Role of tissue factor in the maternal immunological attack of the embryo in the antiphospholipid syndrome," Clinical Reviews in Allergy and Immunology, vol. 39, no. 3, pp. 160-165, 2010.

[235] P. Redecha, C. W. Franzke, W. Ruf, N. Mackman, and G. Girardi, "Neutrophil activation by the tissue factor/Factor VIIa/PAR2 axis mediates fetal death in a mouse model of antiphospholipid syndrome," Journal of Clinical Investigation, vol. 118, no. 10, pp. 3453-3461, 2008.

[236] P. Redecha, R. Tilley, M. Tencati et al., "Tissue factor: a link between $\mathrm{C}_{5 a}$ and neutrophil activation in antiphospholipid antibody-induced fetal injury," Blood, vol. 110, no. 7, pp. 2423-2431, 2007.

[237] G. Girardi, "Pravastatin prevents miscarriages in antiphospholipid antibody-treated mice," Journal of Reproductive Immunology, vol. 82, no. 2, pp. 126-131, 2009.

[238] P. Redecha, N. van Rooijen, D. Torry, and G. Girardi, "Pravastatin prevents miscarriages in mice: role of tissue factor in placental and fetal injury," Blood, vol. 113, no. 17, pp. 4101-4109, 2009.

[239] J. Chen, M. Kasper, T. Heck et al., "Tissue factor as a link between wounding and tissue repair," Diabetes, vol. 54, no. 7, pp. 2143-2154, 2005.
[240] Z. Xu, H. Xu, V. A. Ploplis, and F. J. Castellino, "Factor VII deficiency impairs cutaneous wound healing in mice," Molecular Medicine, vol. 16, no. 5-6, pp. 167-176, 2010.

[241] L. Holmdahl and M. L. Ivarsson, "The role of cytokines, coagulation, and fibrinolysis in peritoneal tissue repair," European Journal of Surgery, vol. 165, no. 11, pp. 1012-1019, 1999.

[242] S. Albrecht, M. Kotzsch, C. Haller et al., "Immunological and functional analyses of the extracellular domain of human tissue factor," Journal of Biological, vol. 379, no. 2, pp. 157-165, 1998.

[243] G. C. Parry and N. Mackman, "Mouse embryogenesis requires the tissue factor extracellular domain but not the cytoplasmic domain (TF/FVIIa-dependent extracellular protease activity is required for embryogenesis," The Journal of Clinical Investigation, vol. 105, no. 11, pp. 1547-1554, 2000.

[244] E. Melis, L. Moons, M. De Mol et al., "Targeted deletion of the cytosolic domain of tissue factor in mice does not affect development," Biochemical and Biophysical Research Communications, vol. 286, no. 3, pp. 580-586, 2001.

[245] T. Luther, C. Flössel, N. Mackman et al., "Tissue factor expression during human and mouse development," The American Journal of Pathology, vol. 149, no. 1, pp. 101-113, 1996.

[246] B. Pedersen, T. Holscher, Y. Sato, R. Pawlinski, and N. Mackman, "A balance between tissue factor and tissue factor pathway inhibitor is required for embryonic development and hemostasis in adult mice," Blood, vol. 105, no. 7, pp. 2777-2782, 2005.

[247] C. Pouplard, S. Iochmann, B. Renard et al., "Induction of monocyte tissue factor expression by antibodies to heparinplatelet factor 4 complexes developed in heparin-induced thrombocytopenia," Blood, vol. 97, no. 10, pp. 3300-3302, 2001.

[248] K. Ritis, M. Doumas, D. Mastellos et al., "A novel C5a receptor-tissue factor cross-talk in neutrophils links innate immunity to coagulation pathways," Journal of Immunology, vol. 177, no. 7, pp. 4794-4802, 2006.

[249] A. W. Rijneveld, S. Weijer, P. Bresser et al., "Local activation of the tissue factor-factor VIIa pathway in patients with pneumonia and the effect of inhibition of this pathway in murine pneumococcal pneumonia," Critical Care Medicine, vol. 34, no. 6, pp. 1725-1730, 2006.

[250] M. Colucci, M. R. Rossiello, A. Pentimone et al., "Changes in coagulation-fibrinolysis balance in blood mononuclear cells and in gastric mucosa from patients with Helicobacter pylori infection," Thrombosis Research, vol. 116, no. 6, pp. 471-477, 2005.

[251] N. T. Funderburg, E. Mayne, S. F. Sieg et al., "Increased tissue factor expression on circulating monocytes in chronic HIV infection: relationship to in vivo coagulation and immune activation," Blood, vol. 115, no. 2, pp. 161-167, 2010.

[252] I. M. Francischetti, K. B. Seydel, R. Q. Monteiro et al., "Plasmodium falciparum-infected erythrocytes induce tissue factor expression in endothelial cells and support the assembly of multimolecular coagulation complexes," Journal of Thrombosis and Haemostasis, vol. 5, no. 1, pp. 155-165, 2007.

[253] B. S. Donahue, D. Gailani, and A. E. Mast, "Disposition of tissue factor pathway inhibitor during cardiopulmonary bypass," Journal of Thrombosis and Haemostasis, vol. 4, no. 5, pp. 1011-1016, 2006.

[254] L. Moberg, "The role of the innate immunity in islet transplantation," Upsala Journal of Medical Sciences, vol. 110, no. 1, pp. 17-55, 2005. 
[255] A. Bukovsky, C. A. Labarrere, B. Haag, C. Carter, and W. P. Faulk, "Tissue factor in normal and transplanted human kidneys," Transplantation, vol. 54, no. 4, pp. 644-650, 1992.

[256] M. Usui, N. Kuriyama, M. Kisawada et al., "Tissue factor expression demonstrates severe sinusoidal endothelial cell damage during rejection after living-donor liver transplantation," Journal of Hepato-Biliary-Pancreatic Surgery, vol. 16, no. 4, pp. 513-520, 2009.

[257] F. Li, C.-H. Wang, J.-G. Wang et al., "Elevated tissue factor expression contributes to exacerbated diabetic nephropathy in mice lacking eNOS fed a high fat diet," Journal of Thrombosis and Haemostasis, vol. 8, no. 10, pp. 2122-2132, 2010.

[258] K. E. Brummel-Ziedins, C. Y. Vossen, S. Butenas, K. G. Mann, and F. R. Rosendaal, "Thrombin generation profiles in deep venous thrombosis," Journal of Thrombosis and Haemostasis, vol. 3, no. 11, pp. 2497-2505, 2005.

[259] J. Bouligand, O. Cabaret, M. Canonico et al., "Effect of NFE2L2 genetic polymorphism on the association between oral estrogen therapy and the risk of venous thromboembolism in postmenopausal women," Clinical Pharmacology \& Therapeutics, vol. 89, no. 1, pp. 60-64, 2011.

[260] A. Panasiuk, J. Zak, B. Panasiuk, and D. Prokopowicz, "Increase in expression of monocytic tissue factor (CD142) with monocytes and blood platelet activation in liver cirrhosis," Blood Coagulation and Fibrinolysis, vol. 18, no. 8, pp. 739-744, 2007.

[261] N. Busso, C. Morard, R. Salvi, V. Péclat, and A. So, "Role of the tissue factor pathway in synovial inflammation," Arthritis \& Rheumatism, vol. 48, no. 3, pp. 651-659, 2003.

[262] A. Solovey, R. Kollander, A. Shet et al., "Endothelial cell expression of tissue factor in sickle mice is augmented by hypoxia/reoxygenation and inhibited by lovastatin," Blood, vol. 104, no. 3, pp. 840-846, 2004.

[263] J. P. Luyendyk, K. C. Flanagan, C. D. Williams et al., "Tissue factor contributes to neutrophil CD11b expression in $\alpha$-naphthylisothiocyanate-treated mice," Toxicology and Applied Pharmacology, vol. 250, no. 3, pp. 256-262, 2011.

[264] A. Dorfleutner, E. Hintermann, T. Tarui, Y. Takada, and W. Ruf, "Cross-talk of integrin $\alpha 3 \beta 1$ and tissue factor in cell migration," Molecular Biology of the Cell, vol. 15, no. 10, pp. 4416-4425, 2004.

[265] A. Siegbahn, M. Johnell, B. B. Sorensen, L. C. Petersen, and C.-H. Heldin, "Regulation of chemotaxis by the cytoplasmic domain of tissue factor," Journal of Thrombosis and Haemostasis, vol. 93, no. 1, pp. 27-34, 2005.

[266] J. Apostolopoulos, L. Moussa, and P. G. Tipping, "The cytoplasmic domain of tissue factor restricts physiological albuminuria and pathological proteinuria associated with glomerulonephritis in mice," Nephron Experimental Nephrology, vol. 116, no. 4, pp. e72-e83, 2010.

[267] M. E. Bromberg, W. H. Konigsberg, J. F. Madison, A. Pawashe, and A. Garen, "Tissue factor promotes melanoma metastasis by a pathway independent of blood coagulation," Proceedings of the National Academy of Sciences of the United States of America, vol. 92, no. 18, pp. 8205-8209, 1995.

[268] N. Agmon-Levin, M. Blank, G. Zandman-Goddard et al., "Vitamin D: an instrumental factor in the anti-phospholipid syndrome by inhibition of tissue factor expression," Annals of the Rheumatic Diseases, vol. 70, no. 1, pp. 145-150, 2011.

[269] M. R. Rossiello, S. Momi, R. Caracchini et al., "A novel nitric oxide-releasing statin derivative exerts an antiplatelet/antithrombotic activity and inhibits tissue factor expression," Journal of Thrombosis and Haemostasis, vol. 3, no. 11, pp. 2554-2562, 2005.
[270] M. Matsuyama, K. Akioka, M. Okamoto et al., "Control of renal ischemic reperfusion injury by antisense oligodeoxynuceotide of tissue factor," Transplantation Proceedings, vol. 35, pp. 103-104, 2003.

[271] A. J. Chu, T. H. Chou, and B. D. M. Chen, "Prevention of colorectal cancer using COX-2 inhibitors: basic science and clinical applications," Frontiers in Bioscience, vol. 9, pp. 2697-2713, 2004.

[272] X. Wang, M. Wang, M. Amarzguioui, F. Liu, Ø. Fodstad, and H. Prydz, "Downregulation of tissue factor by RNA interference in human melanoma LOX-L cells reduces pulmonary metastasis in nude mice," International Journal of Cancer, vol. 112, no. 6, pp. 994-1002, 2004.

[273] B. Freeman, B. A. Zehnbauer, and T. G. Buchman, "A meta-analysis of controlled trials of anticoagulant therapies in patients with sepsis," Shock, vol. 20, no. 1, pp. 5-9, 2003.

[274] D. L. Miller, K. Welty-Wolf, M. S. Carraway et al., "Extrinsic coagulation blockade attenuates lung injury and proinflammatory cytokine release after intratracheal lipopolysaccharide," American Journal of Respiratory Cell and Molecular Biology, vol. 26, no. 6, pp. 650-658, 2002.

[275] F. B. Taylor, A. C. Chang, G. Peer, A. Li, M. Ezban, and U. Hedner, "Active site inhibited factor VIIa (DEGR VIIa) attenuates the coagulant and interleukin- 6 and -8 , but not tumor necrosis factor, responses of the baboon to $\mathrm{LD}_{100}$ Escherichia coli," Blood, vol. 91, no. 5, pp. 1609-1615, 1998.

[276] C. S. Arnold, C. Parker, R. Upshaw et al., "The antithrombotic and anti-inflammatory effects of BCX3607, a small molecule tissue factor/factor VIIa inhibitor," Thrombosis Research, vol. 117, no. 3, pp. 343-349, 2006.

[277] Y. Banerjee, J. Mizuguchi, S. Iwanaga, and R. M. Kini, "Hemextin AB complex-a snake venom anticoagulant protein complex that inhibits factor VIIa activity," Pathophysiology of Haemostasis and Thrombosis, vol. 34, no. 4-5, pp. 184-187, 2006.

[278] S. T. Loubele, C. A. Spek, P. Leenders et al., "Active site inhibited factor VIIa attenuates myocardial ischemia/ reperfusion injury in mice," Journal of Thrombosis and Haemostasis, vol. 7, no. 2, pp. 290-298, 2009.

[279] P. C. Wong, J. M. Luettgen, A. R. Rendina et al., "BMS593214, an active site-directed factor VIIa inhibitor: enzyme kinetics, antithrombotic and antihaemostatic studies," Journal of Thrombosis and Haemostasis, vol. 104, no. 2, pp. 261-269, 2010.

[280] F. Ghrib, P. Léger, M. Ezban, A. J. Kristensen Cambus, and B. Boneu, "Anti-thrombotic and haemorrhagic effects of active site-inhibited factor VIIa in rats," British Journal of Haematology, vol. 112, no. 2, pp. 506-512, 2001.

[281] E. I. Lev, J. D. Marmur, M. Zdravkovic et al., "Antithrombotic effect of tissue factor inhibition by inactivated factor VIIa: an ex vivo human study," Arteriosclerosis, Thrombosis, and Vascular Biology, vol. 22, no. 6, pp. 1036-1041, 2002.

[282] U. Ørvim, R. M. Barstad, L. Oørning et al., "Antithrombotic efficacy of inactivated active site recombinant factor VIIa is shear dependent in human blood," Arteriosclerosis, Thrombosis, and Vascular Biology, vol. 17, no. 11, pp. 3049-3056, 1997.

[283] D. Kirchhofer, T. B. Tschopp, and H. R. Baumgartner, "Active site-blocked factors VIIa and IXa differentially inhibit fibrin formation in a human ex vivo thrombosis model," Arteriosclerosis, Thrombosis, and Vascular Biology, vol. 15, no. 8, pp. 1098-1106, 1995.

[284] J. Himber, C. J. Refino, L. Burcklen, S. Roux, and D. Kirchhofer, "Inhibition of arterial thrombosis by a soluble tissue factor mutant and active site-blocked factors IXa and 
Xa in the guinea pig," Journal of Thrombosis and Haemostasis, vol. 85, no. 3, pp. 475-481, 2001.

[285] L. Örning, P. M. Fischer, C.-K. Hu et al., "A cyclic pentapeptide derived from the second EGF-like domain of factor VII is an inhibitor of tissue factor dependent coagulation and thrombus formation," Journal of Thrombosis and Haemostasis, vol. 87, no. 1, pp. 13-21, 2002.

[286] J. A. Szalony, O. D. Suleymanov, A. K. Salyers et al., "Administration of a small molecule tissue factor/factor VIIa inhibitor in a non-human primate thrombosis model of venous thrombosis: effects on thrombus formation and bleeding time," Thrombosis Research, vol. 112, no. 3, pp. 167-174, 2003.

[287] J. Zhao, G. Aguilar, S. Palencia, E. Newton, and A. Abo, "RNAPc2 Inhibits colorectal cancer in mice through tissue factor," Clinical Cancer Research, vol. 15, no. 1, pp. 208-216, 2009.

[288] T. A. Hembrough, G. M. Swartz, A. Papathanassiu et al., "Tissue factor/factor VIIa inhibitors block angiogenesis and tumor growth through a nonhemostatic mechanism," Cancer Research, vol. 63, no. 11, pp. 2997-3000, 2003.

[289] P. Zerbib, A. Grimonprez, D. Corseaux et al., "Inhibition of tissue factor-factor VIIa proteolytic activity blunts hepatic metastasis in colorectal cancer," Journal of Surgical Research, vol. 153, no. 2, pp. 239-245, 2009.

[290] E. Lindmark and A. Siegbahn, "Tissue factor regulation and cytokine expression in monocyte-endothelial cell co-cultures: effects of a statin, an ACE-inhibitor and a low-molecular-weight heparin," Thrombosis Research, vol. 108, no. 1, pp. 77-84, 2002.

[291] K. Akahane, K. Okamoto, M. Kikuchi et al., "Inhibition of factor Xa suppresses the expression of tissue factor in human monocytes and lipopolysaccharide-induced endotoxemia in rats," Surgery, vol. 130, no. 5, pp. 809-818, 2001.

[292] C. Viskov, M. Just, V. Laux, P. Mourier, and M. Lorenz, "Description of the chemical and pharmacological characteristics of a new hemisynthetic ultra-low-molecularweight heparin, AVE5026," Journal of Thrombosis and Haemostasis, vol. 7, no. 7, pp. 1143-1151, 2009.

[293] G. Lopopolo, F. Fiorella, M. de Candia et al., "Biarylmethoxy isonipecotanilides as potent and selective inhibitors of blood coagulation factor Xa," European Journal of Pharmaceutical Sciences, vol. 42, no. 3, pp. 180-191, 2011.

[294] M. Nijkeuter and M. V. Huisman, "Pentasaccharides in the prophylaxis and treatment of venous thromboembolism: a systematic review," Current Opinion in Pulmonary Medicine, vol. 10, no. 5, pp. 338-344, 2004.

[295] D. Bergqvist, "Enoxaparin: a pharmacoeconomic review of its use in the prevention and treatment of venous thromboembolism and in acute coronary syndromes," PharmacoEconomics, vol. 20, no. 4, pp. 225-243, 2002.

[296] T. M. Chapman and K. L. Goa, "Bemiparin: a review of its use in the prevention of venous thromboembolism and treatment of deep vein thrombosis," Drugs, vol. 63, no. 21, pp. 2357-2377, 2003.

[297] K. Wellington, K. McClellan, and B. Jarvis, "Reviparin: a review of its efficacy in the prevention and treatment of venous thromboembolism," Drugs, vol. 61, no. 8, pp. 1185-1209, 2001.

[298] A. Diquelou, D. Dupouy, R. Cariou, K. S. Sakariassen, B. Boneu, and Y. Cadroy, "A comparative study of the anticoagulant and anti-thrombotic effects of unfractionated heparin and a low molecular weight heparin (Fraxiparine) in an experimental model of human venous thrombosis,"
Journal of Thrombosis and Haemostasis, vol. 74, no. 5, pp. 1286-1292, 1995.

[299] S. M. Cheer, C. J. Dunn, and R. Foster, "Tinzaparin sodium: a review of its pharmacology and clinical use in the prophylaxis and treatment of thromboembolic disease," Drugs, vol. 64, no. 13, pp. 1479-1502, 2004.

[300] G. F. Pineo and R. D. Hull, "Dalteparin sodium," Expert Opinion on Pharmacotherapy, vol. 2, no. 8, pp. 1325-1337, 2001.

[301] C. Bal dit Sollier, C. Kang, N. Berge et al., "Activity of a synthetic hexadecasaccharide(SanOrg123781A) in a pig model of arterial thrombosis," Journal of Thrombosis and Haemostasis, vol. 2, no. 6, pp. 925-930, 2004.

[302] M. Ragosta, L. W. Gimple, S. D. Gertz et al., "Specific factor $\mathrm{Xa}$ inhibition reduces restenosis after balloon angioplasty of atherosclerotic femoral arteries in rabbits," Circulation, vol. 89, no. 3, pp. 1262-1271, 1994.

[303] U. Ørvim, R. M. Barstad, G. P. Vlasuk, and K. S. Sakariassen, "Effect of selective factor $\mathrm{Xa}$ inhibition on arterial thrombus formation triggered by tissue factor/factor VIIa or collagen in an ex vivo model of shear-dependent human thrombogenesis," Arteriosclerosis, Thrombosis, and Vascular Biology, vol. 15, no. 12, pp. 2188-2194, 1995.

[304] B. Kaiser, W. Jeske, J. M. Walenga, and J. Fareed, "Inactivation of factor Xa by the synthetic inhibitor DX-9065a causes strong anticoagulant and antiplatelet actions in human blood," Blood Coagulation and Fibrinolysis, vol. 10, no. 8, pp. 495-501, 1999.

[305] T. Iba, A. Kidokoro, M. Fukunaga et al., "Factor Xa-inhibitor (DX-9065a) modulates the leukocyte-endothelial cell interaction in endotoxemic rat," Shock, vol. 17, no. 2, pp. 159-162, 2002.

[306] K. Tanabe, Y. Terada, T. Shibutani, S. Kunitada, and T. Kondo, "A specific inhibitor of factor Xa, DX-9065a, exerts effective protection against experimental tumor-induced disseminated intravascular coagulation in rats," Thrombosis Research, vol. 96, no. 2, pp. 135-143, 1999.

[307] M. Kawamura, N. Konishi, K. Hiroe et al., "Antithrombotic and anticoagulant profiles of TAK-442, a novel factor Xa inhibitor, in a rabbit model of venous thrombosis," Journal of Cardiovascular Pharmacology, vol. 56, no. 2, pp. 156-161, 2010.

[308] T. Yokoyama, A. B. Kelly, U. M. Marzec, S. R. Hanson, S. Kunitada, and L. A. Harker, "Antithrombotic effects of orally active synthetic antagonist of activated factor $\mathrm{X}$ in nonhuman primates," Circulation, vol. 92, no. 3, pp. 485-491, 1995.

[309] M. U. Zafar, M. E. Farkouh, J. Osende et al., "Potent arterial antithrombotic effect of direct factor-Xa inhibition with ZK807834 administered to coronary artery disease patients," Journal of Thrombosis and Haemostasis, vol. 97, no. 3, pp. 487-492, 2007.

[310] D. R. Abendschein, P. K. Baum, D. R. Light, and J. Morser, "Effect of vascular injury on inhibition of venous thrombosis with ZK-807834, a direct inhibitor of factor Xa," Journal of Thrombosis and Haemostasis, vol. 1, no. 9, pp. 1955-1958, 2003.

[311] T. B. McClanahan, G. W. Hicks, A. L. Morrison et al., "The antithrombotic effects of CI-1031 (ZK-807834) and enoxaparin in a canine electrolytic injury model of arterial and venous thrombosis," European Journal of Pharmacology, vol. 432, no. 2-3, pp. 187-194, 2001.

[312] P. C. Wong, M. L. Quan, E. J. Crain, C. A. Watson, R. R. Wexler, and R. M. Knabb, "Nonpeptide factor Xa inhibitors: I. Studies with SF303 and SK549, a new class of potent 
antithrombotics," Journal of Pharmacology and Experimental Therapeutics, vol. 292, no. 1, pp. 351-357, 2000.

[313] K. Sato, Y. Taniuchi, T. Kawasaki et al., "Comparison of the anticoagulant and antithrombotic effects of YM-75466, a novel orally-active factor Xa inhibitor, and warfarin in mice," Japanese Journal of Pharmacology, vol. 78, no. 2, pp. 191-197, 1998.

[314] S. S. Rebello, R. G. Bentley, S. R. Morgan et al., "Antithrombotic efficacy of a novel factor Xa inhibitor, FXV673, in a canine model of coronary artery thrombolysis," British Journal of Pharmacology, vol. 133, no. 7, pp. 1190-1198, 2001.

[315] P. C. Wong, E. J. Crain, C. A. Watson et al., "Nonpeptide factor Xa inhibitors III: effects of DPC423, an orally-active pyrazole antithrombotic agent, on arterial thrombosis in rabbits," Journal of Pharmacology and Experimental Therapeutics, vol. 303, no. 3, pp. 993-1000, 2002.

[316] J. R. Pruitt, D. J. Pinto, M. J. Estrella et al., "Isoxazolines and isoxazoles as factor Xa inhibitors," Bioorganic and Medicinal Chemistry Letters, vol. 10, no. 8, pp. 685-689, 2000.

[317] J. S. Bostwick, R. Bentley, S. Morgan et al., "RPR120844, a novel, specific inhibitor of coagulation factor Xa inhibits venous thrombosis in the rabbit," Journal of Thrombosis and Haemostasis, vol. 81, no. 1, pp. 157-160, 1999.

[318] M. P. Gulseth, J. Michaud, and E. A. Nutescu, "Rivaroxaban: an oral direct inhibitor of factor Xa," American Journal of Health-System Pharmacy, vol. 65, no. 16, pp. 1520-1529, 2008.

[319] M. A. Abboud, S. J. Needle, C. L. Burns-Kurtis et al., "Antithrombotic potential of GW813893: a novel, orally active, active-site directed factor Xa inhibitor," Journal of Cardiovascular Pharmacology, vol. 52, no. 1, pp. 66-71, 2008.

[320] P. C. Wong and X. Jiang, "Apixaban, a direct factor Xa inhibitor, inhibits tissue-factor induced human platelet aggregation in vitro: comparison with direct inhibitors of factor VIIa, XIa and thrombin," Journal of Thrombosis and Haemostasis, vol. 104, no. 2, pp. 302-310, 2010.

[321] T. Furugohri, K. Isobe, Y. Honda et al., "DU-176b, a potent and orally active factor Xa inhibitor: in vitro and in vivo pharmacological profiles. (new anticoagulant for the prophylaxis and treatment of thromboembolic diseases," Journal of Thrombosis and Haemostasis, vol. 6, pp. 1542-1549, 2008.

[322] B. I. Eriksson, L. Borris, O. E. Dahl et al., "Oral, direct factor Xa inhibition with BAY 59-7939 for the prevention of venous thromboembolism after total hip replacement," Journal of Thrombosis and Haemostasis, vol. 4, no. 1, pp. 121-128, 2006.

[323] I. J. Banke, M. J. Arlt, M. M. Mueller et al., "Effective inhibition of experimental metastasis and prolongation of survival in mice by a potent factor Xa-specific synthetic serine protease inhibitor with weak anticoagulant activity," Journal of Thrombosis and Haemostasis, vol. 94, no. 5, pp. 1084-1093, 2005.

[324] A. Amirkhosravi, S. A. Mousa, M. Amaya, and J. L. Francis, "Antimetastatic effect of tinzaparin, a low-molecular-weight heparin," Journal of Thrombosis and Haemostasis, vol. 1, no. 9, pp. 1972-1976, 2003.

[325] R. Q. Monteiro, A. R. Rezaie, J. M. Ribeiro, and I. M. Francischetti, "Ixolaris: a Factor Xa heparin-binding exosite inhibitor," Biochemical Journal, vol. 387, no. 3, pp. 871-877, 2005.

[326] M. Nakata, S. Kanekura, and I. Maruyama, "DX9065a, an Xa inhibitor, inhibits prothrombin-induced A549 lung adenocarcinoma cell proliferation," Cancer Letters, vol. 122, no. 1-2, pp. 127-133, 1998.
[327] C. Rossi, S. Hess, R. W. Eckl et al., "Effect of MCM09, an active site-directed inhibitor of factor Xa, on B16-BL6 lung colonies in mice," Journal of Thrombosis and Haemostasis, vol. 4, no. 3, pp. 608-613, 2006.

[328] D. J. Tyrrell, A. P. Horne, K. R. Holme, J. M. H. Preuss, and C. P. Page, "Heparin in inflammation: potential therapectic applications beyond anticoagulation," in Advance in Pharmacology, vol. 46, pp. 151-208, Academic Press, San Diego, Calif, USA, 1999.

[329] G. S. Aldea, L. O. Soltow, W. L. Chandler et al., "Limitation of thrombin generation, platelet activation, and inflammation by elimination of cardiotomy suction in patients undergoing coronary artery bypass grafting treated with heparin-bonded circuits," Journal of Thoracic and Cardiovascular Surgery, vol. 123, no. 4, pp. 742-755, 2002.

[330] A. Koster, T. Fischer, M. Praus et al., "Hemostatic activation and inflammatory response during cardiopulmonary bypass: impact of heparin management," Anesthesiology, vol. 97, no. 4, pp. 837-841, 2002.

[331] G. Girardi, "Heparin treatment in pregnancy loss: potential therapeutic benefits beyond anticoagulation," Journal of Reproductive Immunology, vol. 66, no. 1, pp. 45-51, 2005.

[332] S. Nylander and C. Mattsson, "Thrombin-induced platelet activation and its inhibition by anticoagulants with different modes of action," Blood Coagulation and Fibrinolysis, vol. 14, no. 2, pp. 159-167, 2003.

[333] M. Caunt, Y. Q. Huang, P. C. Brooks, and S. Karpatkin, "Thrombin induces neoangiogenesis in the chick chorioallantoic membrane," Journal of Thrombosis and Haemostasis, vol. 1, no. 10, pp. 2097-2102, 2003.

[334] T. Arisato, K. P. Sarker, K. Kawahara et al., "The agonist of the protease-activated receptor-1 (PAR1) but not PAR3 mimics thrombin-induced vascular endothelial growth factor release in human vascular smooth muscle cells," Cellular and Molecular Life Sciences, vol. 60, no. 8, pp. 1716-1724, 2003.

[335] P. Jilma-Stohlawetz, C. C. Folman, A. E. von dem Borne et al., "Effects of anticoagulation on thrombopoietin release during endotoxemia," Journal of Laboratory and Clinical Medicine, vol. 137, no. 1, pp. 64-69, 2001.

[336] K. G. Fischer, "The role of recombinant hirudins in the management of thrombotic disorders," BioDrugs, vol. 18, no. 4, pp. 235-268, 2004.

[337] W. E. Dager, T. G. Vondracek, B. A. McIntosh, and E. A. Nutescu, "Ximelagatran: an oral direct thrombin inhibitor," Annals of Pharmacotherapy, vol. 38, no. 11, pp. 1881-1897, 2004.

[338] J. Fareed and W. P. Jeske, "Small-molecule direct antithrombins: argatroban," Best Practice \& Research: Clinical Haematology, vol. 17, no. 1, pp. 127-138, 2004.

[339] G. Vogel, M. D. G. Meuleman, T. G. Van Dinther, R. Buijsman, A. W. Princen, and M. J. Smit, "Antithrombotic properties of a direct thrombin inhibitor with a prolonged half-life and AT-mediated factor Xa inhibitory activity," Journal of Thrombosis and Haemostasis, vol. 1, no. 9, pp. 1945-1954, 2003.

[340] M. T. Nieman, F. Burke, M. Warnock et al., "Thrombostatin FM-19 compounds: direct thrombin inhibitors-mechanism of action in vitro and in vivo," Journal of Thrombosis and Haemostasis, vol. 6, no. 5, pp. 837-845, 2008.

[341] M. T. Nieman, G. A. LaRusch, C. Fang, Y. Zhou, and A. H. Schmaier, "Oral thrombostatin FM19 inhibits prostate cancer," Journal of Thrombosis and Haemostasis, vol. 104, no. 5, pp. 1044-1048, 2010. 
[342] K. Asanuma, H. Wakabayashi, T. Hayashi et al., "Thrombin inhibitor, argatroban, prevents tumor cell migration and bone metastasis," Oncology, vol. 67, no. 2, pp. 166-173, 2004.

[343] M. Ohkoshi and Y. Sasaki, "Antimetastatic activity of a synthetic serine protease inhibitor, FOY-305 (Foypan)," In Vivo, vol. 19, no. 1, pp. 133-136, 2005.

[344] K. DeFeo, C. Hayes, M. Chernick, J. V. Ryn, and S. K. Gilmour, "Use of dabigatran etexilate to reduce breast cancer progression," Cancer Biology and Therapy, vol. 10, no. 10, pp. 1001-1008, 2010.

[345] A. A. Creasey, A. C. Chang, L. Fiegen, T. C. Wun, F. B. Taylor, and L. B. Hinshaw, "Tissue factor pathway inhibitor reduces mortality from E. Coli septic shock," The Journal of Clinical Investigation, vol. 91, pp. 2850-2860, 1993.

[346] K. Johnson, L. Aarden, Y. Choi, E. De Groot, and A. Creasey, "The proinflammatory cytokine response to coagulation and endotoxin in whole blood," Blood, vol. 87, no. 12, pp. 5051-5060, 1996.

[347] D. Chen, K. Riesbeck, J. H. McVey et al., "Human thrombin and FXa mediate porcine endothelial cell activation; modulation by expression of TFPI-CD4 and hirudin-CD4 fusion proteins," Xenotransplantation, vol. 8, no. 4, pp. 258-265, 2001.

[348] C. T. Park, A. A. Creasey, and S. D. Wright, "Tissue factor pathway inhibitor blocks cellular effects of endotoxin by binding to endotoxin and interfering with transfer to CD14," Blood, vol. 89, no. 12, pp. 4268-4274, 1997.

[349] C. W. Kopp, T. Hölzenbein, S. Steiner et al., "Inhibition of restenosis by tissue factor pathway inhibitor: in vivo and in vitro evidence for suppressed monocyte chemoattraction and reduced gelatinolytic activity," Blood, vol. 103, no. 5, pp. 1653-1661, 2004.

[350] P. F. Laterre, "Beyond antibiotics in severe communityacquired pneumonia: the role and rationale for tissue factor pathway inhibition," Critical Care, vol. 12, no. 6, article no. S4, 2008.

[351] N. Kijiyama, H. Ueno, I. Sugimoto et al., "Intratracheal gene transfer of tissue factor pathway inhibitor attenuates pulmonary fibrosis," Biochemical and Biophysical Research Communications, vol. 339, no. 4, pp. 1113-1119, 2006.

[352] L. J. Toltl, L. L. Swystun, L. Pepler, and P. C. Liaw, "Protective effects of activated protein C in sepsis," Journal of Thrombosis and Haemostasis, vol. 100, no. 4, pp. 582-592, 2008.

[353] P. P. Sarangi, H. W. Lee, and M. Kim, "Activated protein C action in inflammation," British Journal of Haematology, vol. 148, no. 6, pp. 817-833, 2010.

[354] B. White, M. Schmidt, C. Murrph et al., "Activated protein $\mathrm{C}$ inhibits lipopolysaccharide-induced nuclear translocation of nuclear factor $\kappa \mathrm{B}(\mathrm{NF}-\kappa \mathrm{B})$ and tumor necrosis factor $\alpha$ $(\mathrm{TNF}-\kappa)$ production in the THP-1 moncytic cell line," British Journal of Haematology, vol. 110, no. 1, pp. 130-134, 2000.

[355] M. Nimah and R. J. Brilli, "Coagulation dysfunction in sepsis and multiple organ system failure," Critical Care Clinics, vol. 19, no. 3, pp. 441-458, 2003.

[356] D. E. Joyce and B. W. Grinnell, "Recombinant human activated protein $\mathrm{C}$ attunates the inflammatory response in endothelium and monocytes by modulating nuclear factor«B," Critical Care Medicine, vol. 30, pp. S288-S293, 2002.

[357] A. Mansell, A. Reinicke, D. M. Worrall, and L. A. O'Neill, "The serine protease inhibitor antithrombin III inhibits LPS-mediated NF- $\kappa$ B activation by TLR-4," FEBS Letters, vol. 508, no. 3, pp. 313-317, 2001.

[358] H. Isobe, K. Okajima, M. Uchiba, N. Harada, and H. Okabe, "Antithrombin prevents endotoxin-induced hyptension by inhibiting the induction of nitric oxide synthesis in rats," Blood, vol. 99, pp. 1638-1645, 2002.

[359] M. C. Minnema, A. C. K. Chang, P. M. Jansen et al., "Recombinant human antithrombin III improves survival and attenuates inflammatory responses in baboons lethally challenged with E. Coli," Blood, vol. 95, pp. 1117-1123, 2000.

[360] B. L. Warren, A. Eid, P. Singer et al., "Caring for the critically ill patients. High-dose antithrombin III in severe sepsis: a randomized controlled trial," Journal of the American Medical Association, vol. 286, pp. 1869-1878, 2001.

[361] A. K. Lindahl, P. M. Sandset, M. Thune-Wiiger, O. Nordfang, and K. S. Sakariassen, "Tissue factor pathway inhibitor prevents thrombus formation on procoagulant subendothelial matrix," Blood Coagulation and Fibrinolysis, vol. 5, no. 5, pp. 755-760, 1994.

[362] J. Holst, B. Lindblad, D. Bergqvist et al., "Antithrombotic effect of recombinant truncated tissue factor pathway inhibitor (TFPI1-161) in experimental venous thrombosis: a comparison with low molecular weight heparin," Journal of Thrombosis and Haemostasis, vol. 71, no. 2, pp. 214-219, 1994.

[363] D. R. Sheppard, "Activated protein C resistance: the most common risk factor for venous thromboembolism," Journal of the American Board of Family Practice, vol. 13, no. 2, pp. 111-115, 2000.

[364] M. Bhattacharyya, M. Kannan, V. P. Chaudhry, and R. Saxena, "Venous thrombosis: prevalence of prothrombotic defects in north Indian population," Indian Journal of Pathology and Microbiology, vol. 46, no. 4, pp. 621-624, 2003.

[365] F. España, A. Vayá, Y. Mira et al., "Low level of circulating activated protein $\mathrm{C}$ is a risk factor for venous thromboembolism," Journal of Thrombosis and Haemostasis, vol. 86, no. 6, pp. 1368-1373, 2001.

[366] T. Urano, F. J. Castellino, H. Ihara et al., "Activated protein $\mathrm{C}$ attenuates coagulation-associated over-expression of fibrinolytic activity by suppressing the thrombindependent inactivation of PAI-1," Journal of Thrombosis and Haemostasis, vol. 1, no. 12, pp. 2615-2620, 2003.

[367] L. Bajzar, M. E. Nesheim, and P. B. Tracy, "The profibrinolytic effect of activated protein $\mathrm{C}$ in clots formed from plasma is TAFI-dependent," Blood, vol. 88, no. 6, pp. 2093-2100, 1996.

[368] C. V. Jackson, B. D. Bailey, and T. J. Shetler, "Pharmacological profile of recombinant, human activated protein $\mathrm{C}$ (LY203638) in a canine model of coronary artery thrombosis," Journal of Pharmacology and Experimental Therapeutics, vol. 295, no. 3, pp. 967-971, 2000.

[369] Y. Aoki, Y. Fukumoto, K. Inoue, Y. Katsuura, K. Komoriya, and S. Miyamoto, "Effect of activated human protein C on experimental venous thrombosis induced by stasis with operative invasion in mice," Arzneimittel-Forschung, vol. 50, no. 8, pp. 695-699, 2000.

[370] K. D. Kurz, T. Smith, A. Wilson, B. Gerlitz, M. A. Richardson, and B. W. Grinnell, "Antithrombotic efficacy in the guinea pig of a derivative of human protein $\mathrm{C}$ with enhanced activation by thrombin," Blood, vol. 89, no. 2, pp. 534-540, 1997.

[371] H. Araki, K. Nishi, N. Ishihara, and K. Okajima, "Inhibitory effects of activated protein $\mathrm{C}$ and heparin on thrombotic arterial occlusion in rat mesenteric arteries," Thrombosis Research, vol. 62, no. 3, pp. 209-216, 1991.

[372] A. Gruber, S. R. Hanson, A. B. Kelly et al., "Inhibition of thrombus formation by activated recombinant protein $\mathrm{C}$ in a primate model of arterial thrombosis," Circulation, vol. 82, no. 2, pp. 578-585, 1990. 
[373] K. Malm, B. Dahlbäck, and B. Arnljots, "Prevention of thrombosis following deep arterial injury in rats by bovine activated protein $\mathrm{C}$ requiring co-administration of bovine protein S," Journal of Thrombosis and Haemostasis, vol. 90, no. 2, pp. 227-234, 2003.

[374] B. Arnljots, D. Bergqvist, and B. Dahlback, "Inhibition of microarterial thrombosis by activated protein $\mathrm{C}$ in a rabbit model," Journal of Thrombosis and Haemostasis, vol. 72, no. 3, pp. 415-420, 1994.

[375] R. S. Foo, A. H. Gershlick, K. Hogrefe et al., "Inhibition of platelet thrombosis using an activated protein C-loaded stent: In vitro and in vivo results," Journal of Thrombosis and Haemostasis, vol. 83, no. 3, pp. 496-502, 2000.

[376] L. Ostrovsky, R. C. Woodman, D. Payne, D. Teoh, and P. Kubes, "Antithrombin III prevents and rapidly reverses leukocyte recruitment in ischemia/reperfusion," Circulation, vol. 96, no. 7, pp. 2302-2310, 1997.

[377] Y.-F. Lin, N. Zhang, H.-S. Guo et al., "Recombinant tissue factor pathway inhibitor induces apoptosis in cultured rat mesangial cells via its Kunitz-3 domain and C-terminal through inhibiting PI3-kinase/Akt pathway," Apoptosis, vol. 12, no. 12, pp. 2163-2173, 2007.

[378] E. Sierko, M. Z. Wojtukiewicz, and W. Kisiel, "The role of tissue factor pathway inhibitor-2 in cancer biology," Seminars in Thrombosis and Hemostasis, vol. 33, no. 7, pp. 653-659, 2007.

[379] M. Kurata, K. Okajima, T. Kawamoto, M. Uchiba, and N. Ohkohchi, "Antithrombin reduces reperfusion-induced hepatic metastasis of colon cancer cells," World Journal of Gastroenterology, vol. 12, no. 1, pp. 60-65, 2006.

[380] M. S. O’Reilly, “Antiangiogenic antithrombin," Seminars in Thrombosis and Hemostasis, vol. 33, no. 7, pp. 660-666, 2007.

[381] G. L. van Sluis, H. R. Büller, and C. A. Spek, "The role of activated protein $\mathrm{C}$ in cancer progression," Thrombosis research, vol. 125, supplement 2, pp. S138-142, 2010.

[382] M. Bezuhly, R. Cullen, C. T. Esmon et al., "Role of activated protein $\mathrm{C}$ and its receptor in inhibition of tumor metastasis," Blood, vol. 113, no. 14, pp. 3371-3374, 2009.

[383] C. K. Derian, B. P. Damiano, M. F. Addo et al., "Blockade of the thrombin receptor protease-activated receptor-1 with a small-molecule antagonist prevents thrombus formation and vascular occlusion in nonhuman primates," Journal of Pharmacology and Experimental Therapeutics, vol. 304, no. 2, pp. 855-861, 2003.

[384] C.-C. Wu and C.-M. Teng, "Comparison of the effects of PAR1 antagonists, PAR4 antagonists, and their combinations on thrombin-induced human platelet activation," European Journal of Pharmacology, vol. 546, no. 1-3, pp. 142-147, 2006.

[385] H.-S. Ahn, C. Foster, G. Boykow, A. Stamford, M. Manna, and M. Graziano, "Inhibition of cellular action of thrombin by N3-cyclopropyl-7-[4-(1- methylethyl)phenyl]methyl7H-pyrrolo[3,2-f] quinazoline-1,3-diamine (SCH 79797), a nonpeptide thrombin receptor antagonist," Biochemical Pharmacology, vol. 60, no. 10, pp. 1425-1434, 2000.

[386] L. Ma, R. Perini, W. McKnight et al., "Proteinase-activated receptors 1 and 4 counter-regulate endostatin and VEGF release from human platelets," Proceedings of the National Academy of Sciences of the United States of America, vol. 102, no. 1, pp. 216-220, 2005.

[387] J. L. Strande, A. Hsu, J. Su, X. Fu, G. J. Gross, and J. E. Baker, "SCH 79797, a selective PAR1 antagonist, limits myocardial ischemia/reperfusion injury in rat hearts," Basic Research in Cardiology, vol. 102, no. 4, pp. 350-358, 2007.
[388] N. Kamio, H. Hashizume, S. Nakao, K. Matsushima, and H. Sugiya, "Plasmin is involved in inflammation via proteaseactivated receptor-1 activation in human dental pulp," Biochemical Pharmacology, vol. 75, no. 10, pp. 1974-1980, 2008.

[389] S. Chackalamannil, Y. Wang, W. J. Greenlee et al., "Discovery of a novel, orally active himbacine-based thrombin receptor antagonist (SCH 530348) with potent antiplatelet activity," Journal of Medicinal Chemistry, vol. 51, no. 11, pp. 30613064, 2008.

[390] R. Colognato, J. R. Slupsky, M. Jendrach, L. Burysek, T. Syrovets, and T. Simmet, "Differential expression and regulation of protease-activated receptors in human peripheral monocytes and monocyte-derived antigenpresenting cells," Blood, vol. 102, no. 7, pp. 2645-2652, 2003.

[391] J. T. Elliott, W. J. Hoekstra, B. E. Maryanoff, and G. D. Prestwich, "Photoactivatable peptides based on BMS197525: a potent antagonist of the human thrombin receptor (PAR-1)," Bioorganic and Medicinal Chemistry Letters, vol. 9, no. 2, pp. 279-284, 1999.

[392] M. S. Bernatowicz, C. E. Klimas, K. S. Hartl, M. Peluso, N. J. Allegretto, and S. M. Seiler, "Development of potent thrombin receptor antagonist peptides," Journal of Medicinal Chemistry, vol. 39, no. 25, pp. 4879-4887, 1996.

[393] Y. Kato, Y. Kita, Y. Hirasawa-Taniyama et al., "Inhibition of arterial thrombosis by a protease-activated receptor 1 antagonist, FR171113, in the guinea pig," European Journal of Pharmacology, vol. 473, no. 2-3, pp. 163-169, 2003.

[394] M. T. Nieman, M. Warnock, A. A. Hasan et al., "The preparation and characterization of novel peptide antagonists to thrombin and factor VIIa and activation of protease-activated receptor 1," Journal of Pharmacology and Experimental Therapeutics, vol. 311, no. 2, pp. 492-501, 2004.

[395] N. Cenac, C. N. Andrews, M. Holzhausen et al., "Role for protease activity in visceral pain in irritable bowel syndrome," Journal of Clinical Investigation, vol. 117, no. 3, pp. 636-647, 2007.

[396] S. H. Slofstra, M. F. Bijlsma, A. P. Groot et al., "Proteaseactivated receptor- 4 inhibition protects from multiorgan failure in a murine model of systemic inflammation," Blood, vol. 110, no. 9, pp. 3176-3182, 2007.

[397] C.-C. Wu, T.-L. Hwang, C.-H. Liao et al., "Selective inhibition of protease-activated receptor 4-dependent platelet activation by $\mathrm{YD}_{-3}$," Journal of Thrombosis and Haemostasis, vol. 87, no. 6, pp. 1026-1033, 2002.

[398] J. L. Strande, A. Hsu, J. Su, X. Fu, G. J. Gross, and J. E. Baker, "Inhibiting protease-activated receptor 4 limits myocardial ischemia/reperfusion injury in rat hearts by unmasking adenosine signaling," Journal of Pharmacology and Experimental Therapeutics, vol. 324, no. 3, pp. 1045-1054, 2008.

[399] A. J. Leger, S. L. Jacques, J. Badar et al., "Blocking the protease-activated receptor $1-4$ heterodimer in plateletmediated thrombosis," Circulation, vol. 113, no. 9, pp. 1244-1254, 2006.

[400] R. Colognato, J. R. Slupsky, M. Jendrach, L. Burysek, T. Syrovets, and T. Simmet, "Differential expression and regulation of protease-activated receptors in human peripheral monocytes and monocyte-derived antigenpresenting cells," Blood, vol. 102, no. 7, pp. 2645-2652, 2003.

[401] N. Roche, R. G. Stirling, S. Lim, B. G. Oliver, and K. F. Chung, "Regulation of protease-activated receptor-I in mononuclear cells by neutrophil proteases," Respiratory Medicine, vol. 97, no. 3, pp. 228-233, 2003.

[402] S. Dulon, C. Candé, N. W. Bunnett, M. D. Hollenberg, M. Chignard, and D. Pidard, "Proteinase-activated receptor-2 
and human lung epithelial cells: disarming by neutrophil serine proteinases," American Journal of Respiratory Cell and Molecular Biology, vol. 28, no. 3, pp. 339-346, 2003.

[403] G. S. Cottrell, S. Amadesi, F. Schmidlin, and N. Bunnett, "Protease-activated receptor 2: activation, signalling and function," Biochemical Society Transactions, vol. 31, no. 6, pp. 1191-1197, 2003.

[404] M. Tang, G. Wang, P. Lu et al., "Regulator of G-protein signaling-2 mediates vascular smooth muscle relaxation and blood pressure," Nature Medicine, vol. 9, no. 12, pp. 1506-1512, 2003.

[405] A. Silini, C. Ghilardi, C. Ardinghi et al., "Protease-activated receptor-1 (PAR-1) promotes the motility of human melanomas and is associated to their metastatic phenotype," Clinical and Experimental Metastasis, vol. 27, no. 1, pp. 43-53, 2010.

[406] L. Ma, R. Perini, W. McKnight et al., "Proteinase-activated receptors 1 and 4 counter-regulate endostatin and VEGF release from human platelets," Proceedings of the National Academy of Sciences of the United States of America, vol. 102, no. 1, pp. 216-220, 2005.

[407] L.-H. Chang, C.-H. Chen, D.-Y. Huang, H.-C. Pai, S.-L. Pan, and C.-M. Teng, "Thrombin induces expression of twist and cell motility via the hypoxia-inducible factor- $1 \alpha$ translational pathway in colorectal cancer cells," Journal of Cellular Physiology, vol. 226, no. 4, pp. 1060-1068, 2011.

[408] A. B. Pawashe, P. Golino, G. Ambrosio et al., "A monoclonal antibody against rabbit tissue factor inhibits thrombus formation in stenotic injured rabbit carotid arteries," Circulation Research, vol. 74, no. 1, pp. 56-63, 1994.

[409] J. Himber, C. Wohlgensinger, S. Roux et al., "Inhibition of tissue factor limits the growth of venous thrombus in the rabbit," Journal of Thrombosis and Haemostasis, vol. 1, pp. 889-895, 2003.

[410] C. C. Milsom, J. L. Yu, N. Mackman et al., "Tissue factor regulation by epidermal growth factor receptor and epithelial-to-mesenchymal transitions: effect on tumor initiation and angiogenesis," Cancer Research, vol. 68, no. 24, pp. 10068-10076, 2008.

[411] D. M. Berman, O. Cabrera, N. M. Kenyon et al., "Interference with tissue factor prolongs intrahepatic islet allograft survival in a nonhuman primate marginal mass model," Transplantation, vol. 84, no. 3, pp. 308-315, 2007.

[412] F. W. Eichbaum, O. Slemer, and S. B. Zyngier, "Antiinflammatory effect of warfarin and vitamin K1," NaunynSchmiedeberg's Archives of Pharmacology, vol. 307, no. 2, pp. 185-190, 1979.

[413] P. S. Maclean, R. C. Tait, A. Rumley, A. D. McMahon, and G. D. Lowe, "Anticoagulation with warfarin downregulates inflammation," Journal of Thrombosis and Haemostasis, vol. 1, no. 8, pp. 1838-1839, 2003.

[414] V. Pengo, G. Denas, S. P. Jose, and M. F. Pengo, "Cancer prevention and vitamin K antagonists: an overview," Thrombosis Research, vol. 125, pp. S103-S105, 2010.

[415] S. Del Turco, G. Basta, G. Lazzerini et al., "Parallel decrease of tissue factor surface exposure and increase of tissue factor microparticle release by the n-3 fatty acid docosahexaenoate in endothelial cells," Journal of Thrombosis and Haemostasis, vol. 98, no. 1, pp. 210-219, 2007.

[416] A. J. Chu, "Blood coagulation fuels inflammation implementing a blood coagulation-inflammation-thrombosis Circuit," in Handbook of Hematology Research, R. Tondre and C. Lebegue, Eds., Chapter 2, pp. 33-86, Nova Science, 2010.
[417] C. Jin and R. A. Flavell, "Molecular mechanism of NLRP3 inflammasome activation," Journal of Clinical Immunology, vol. 30, no. 5, pp. 628-631, 2010.

[418] D. J. Taxman, M. T. Huang, and J. P. Ting, "Inflammasome inhibition as a pathogenic stealth mechanism," Cell Host \& Microbe, vol. 8, no. 1, pp. 7-11, 2010.

[419] T. D. Kanneganti, "Central roles of NLRs and inflammasomes in viral infection," Nature Reviews Immunology, vol. 10, no. 10, pp. 688-698, 2010.

[420] S. Joly and F. S. Sutterwala, "Fungal pathogen recognition by the NLRP3 inflammasome," Virulence, vol. 1, no. 4, pp. 276-280, 2010.

[421] I. K. Pang and A. Iwasaki, "Inflammasomes as mediators of immunity against influenza virus," Trends in Immunology, vol. 32, no. 1, pp. 34-41, 2011.

[422] L. Franchi, R. Muñoz-Planillo, T. Reimer, T. Eigenbrod, and G. Núñez, "Inflammasomes as microbial sensors," European Journal of Immunology, vol. 40, no. 3, pp. 611-615, 2010.

[423] P. Duewell, H. Kono, K. J. Rayner et al., "NLRP3 inflammasomes are required for atherogenesis and activated by cholesterol crystals," Nature, vol. 464, no. 7293, pp. 1357-1361, 2010.

[424] F. Martinon, "Mechanisms of uric acid crystal-mediated autoinflammation," Immunological Reviews, vol. 233, no. 1, pp. 218-232, 2010.

[425] C. Dostert, V. Pétrilli, R. Van Bruggen, C. Steele, B. T. Mossman, and J. Tschopp, "Innate immune activation through Nalp3 inflammasome sensing of asbestos and silica," Science, vol. 320, no. 5876, pp. 674-677, 2008.

[426] B. K. Davis, H. Wen, and J. P. Ting, "The Inflammasome NLRs in immunity, inflammation, and associated diseases," Annual Review of Immunology, vol. 29, pp. 707-735, 2011.

[427] A. J. Chu, "Biochemical strategies to anticoagulation: a comparative overview," Current Vascular Pharmacology, vol. 2, no. 3, pp. 199-228, 2004. 


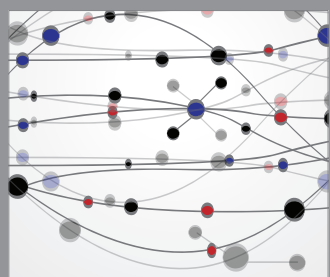

The Scientific World Journal
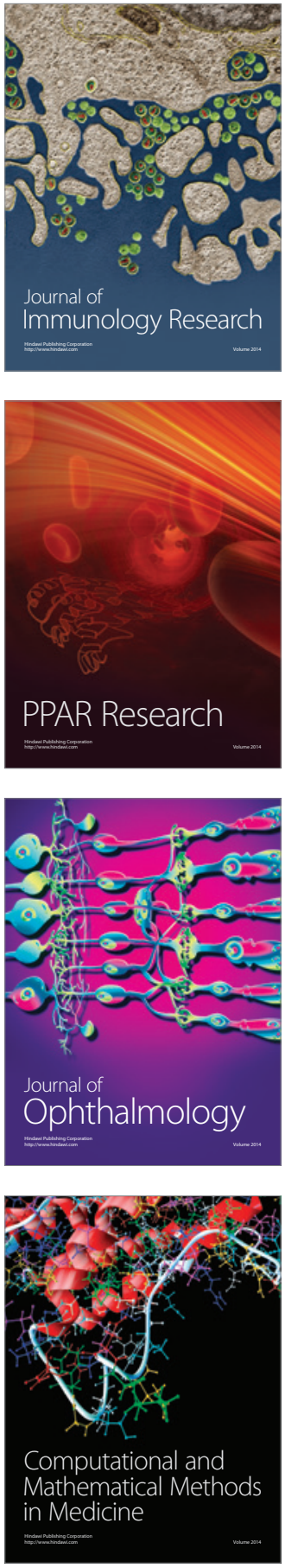

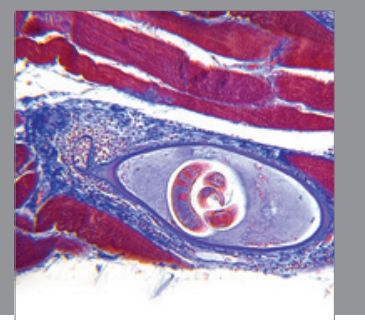

Gastroenterology

Research and Practice
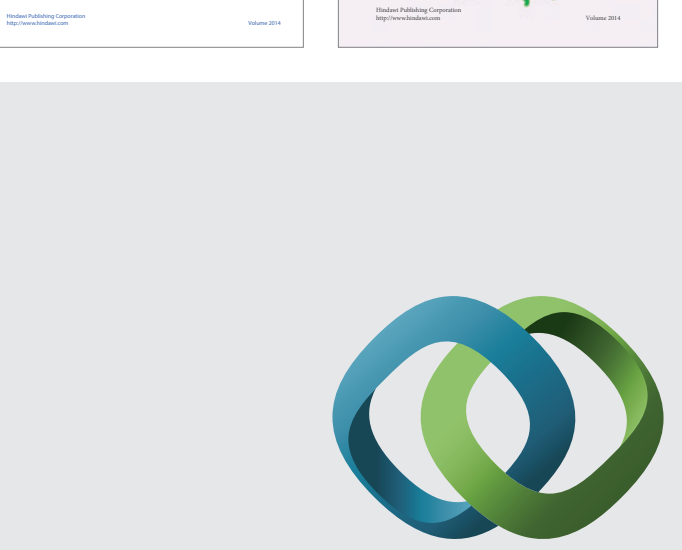

\section{Hindawi}

Submit your manuscripts at

http://www.hindawi.com
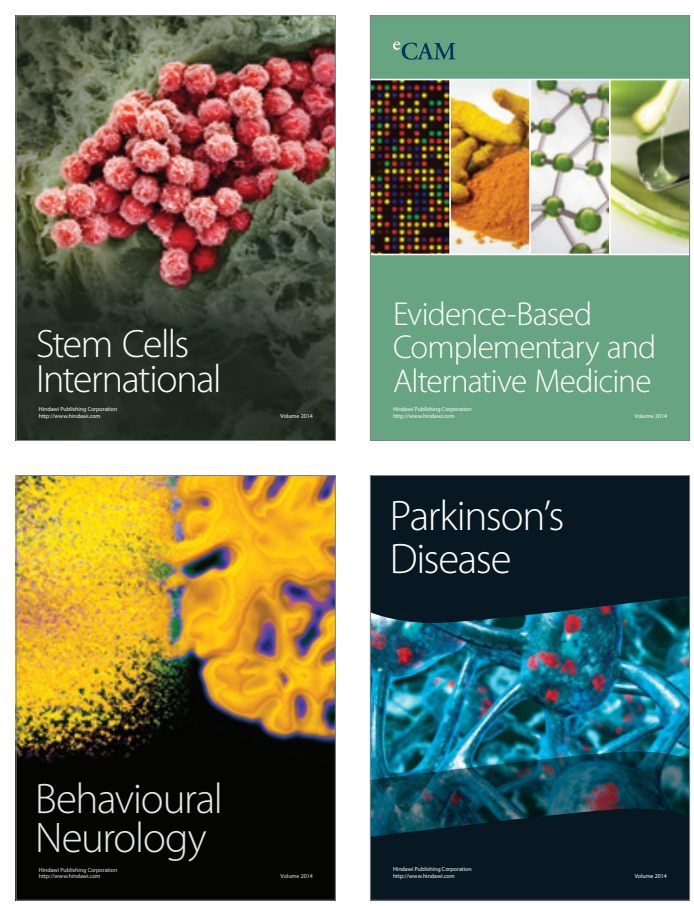

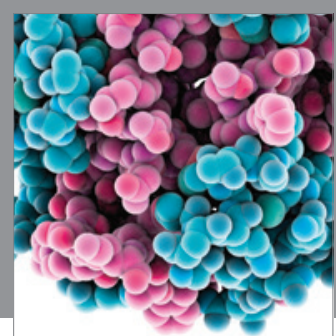

Journal of
Diabetes Research

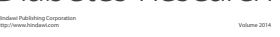

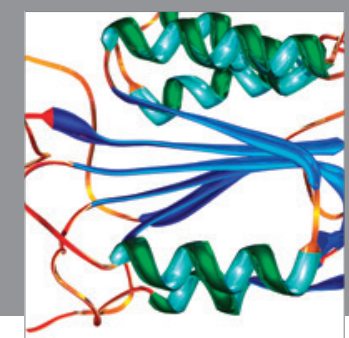

Disease Markers
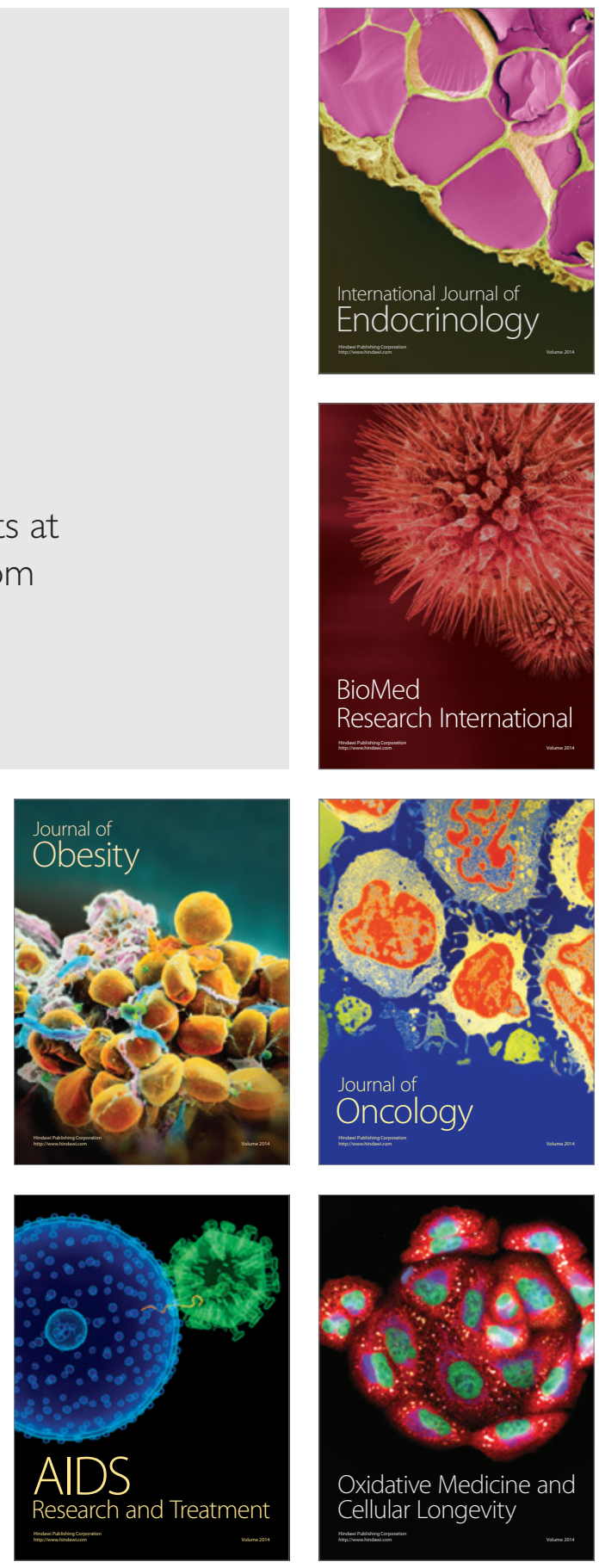